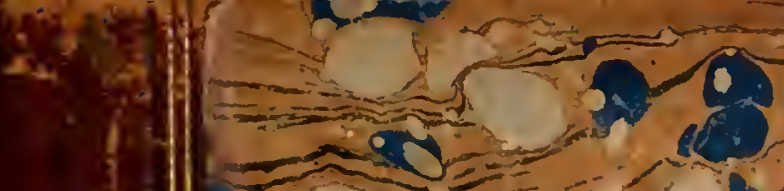

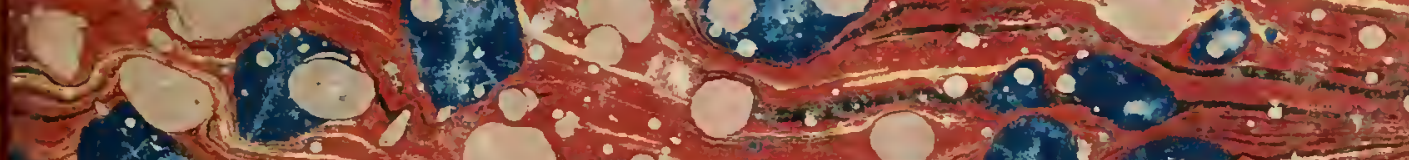

1.. $-2.00,20,6=$

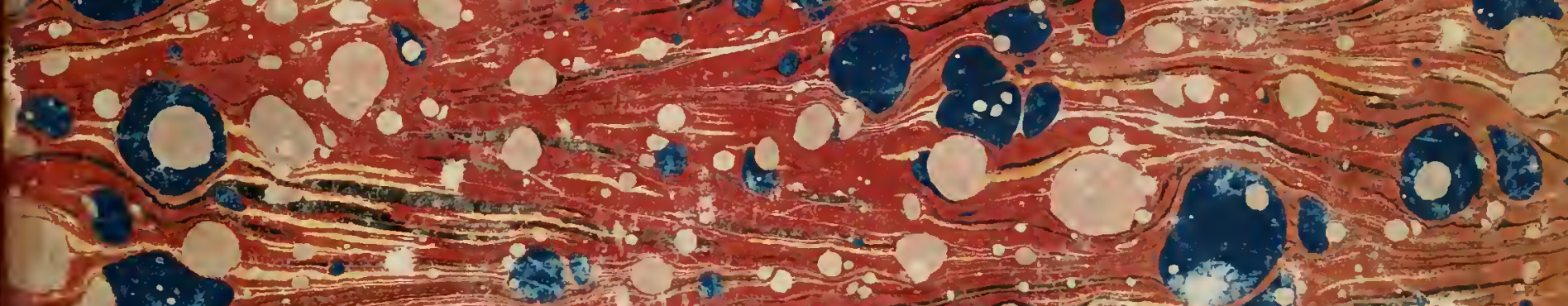

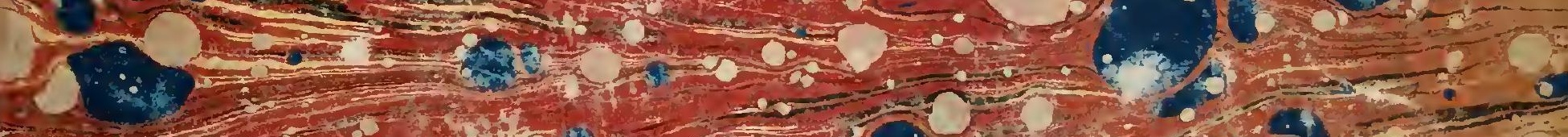

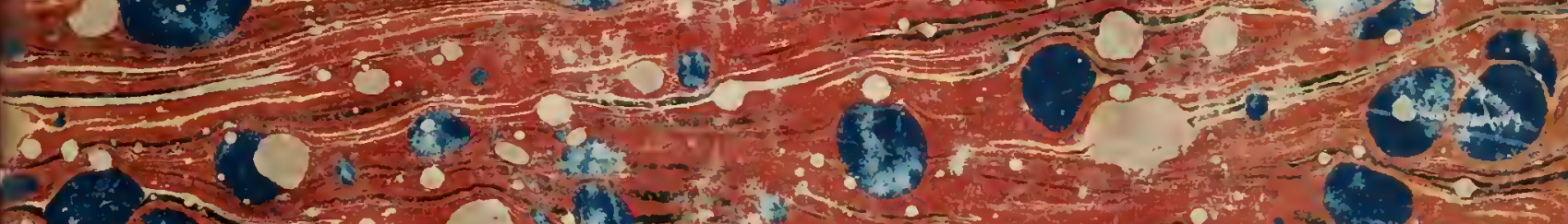

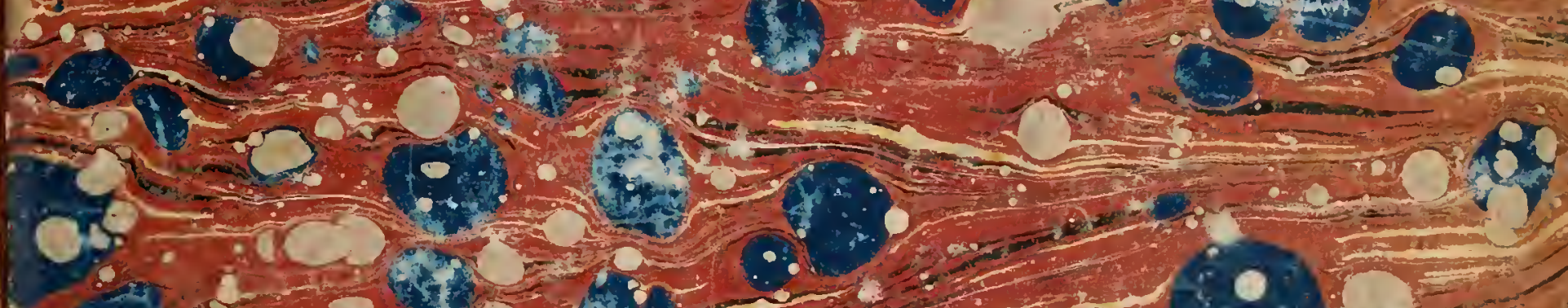

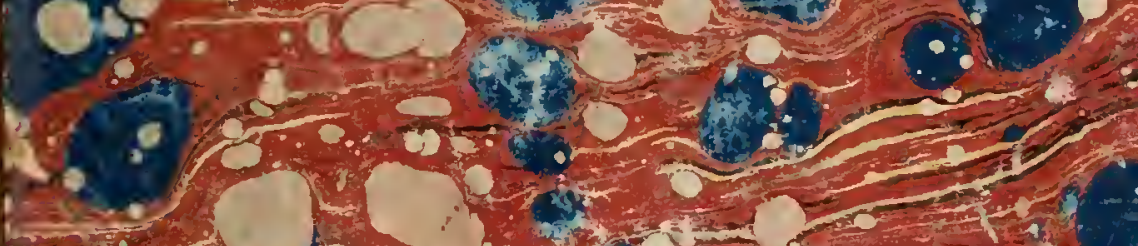

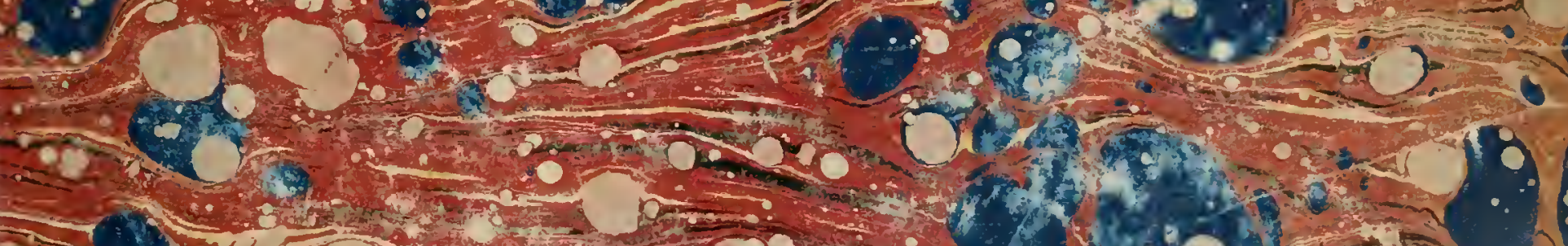
ond 1500 a 80.0 1. 9303 


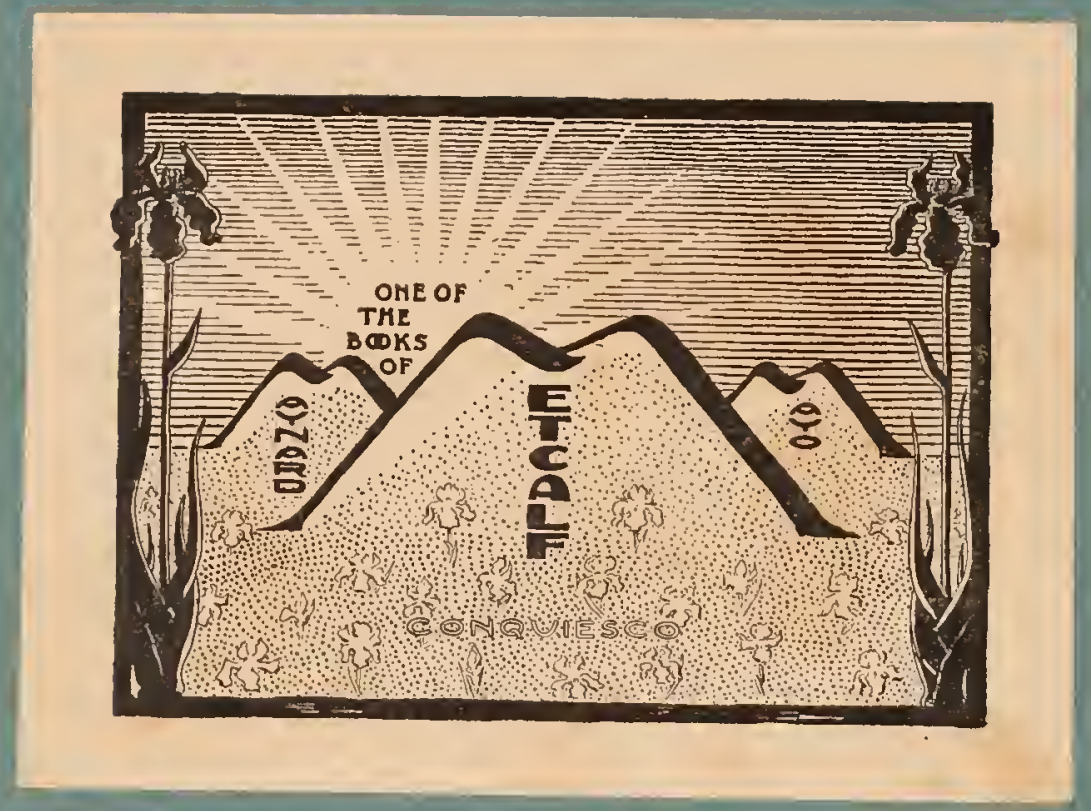





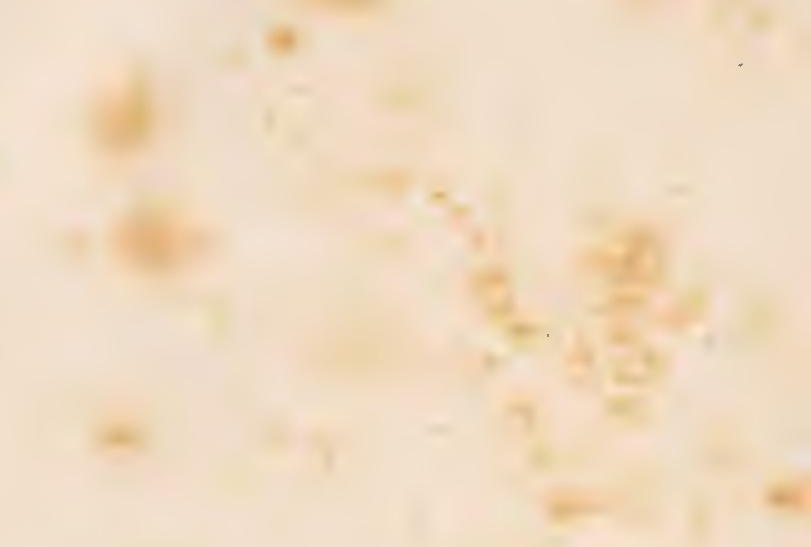

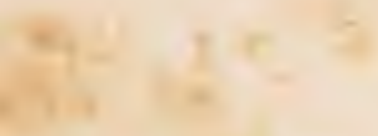

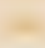

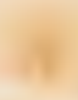
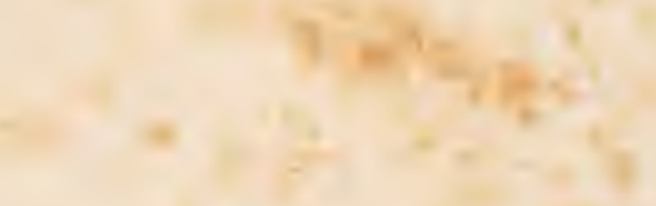

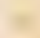

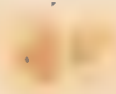




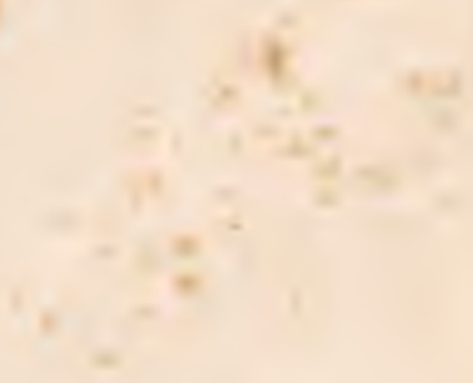

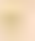

a

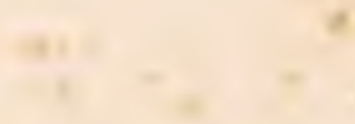

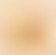

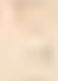

.

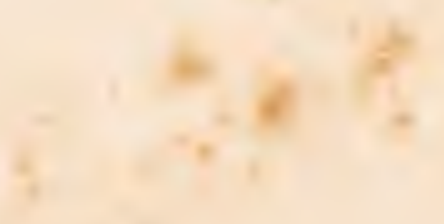

.

3

$+$

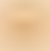

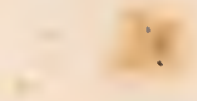

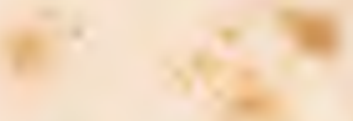

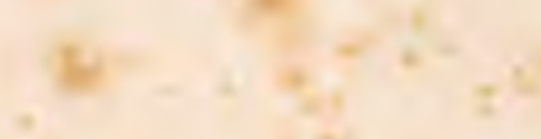

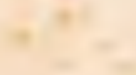

$+$

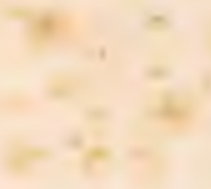

.

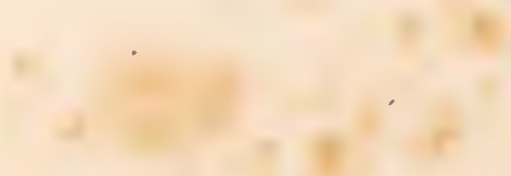

. 






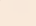







\title{
Zubyliologilde studien
}

von

\section{I) Gustav Woldemar locke.}

\section{A. Wirbellose Thiere.}

\section{Erstes Heft.}

\author{
Mit drei Tafela Abbildungen.
}

I. Wolygatrifde Jufulorien.

$$
\text { Breme n, }
$$

Druek und lerlag ron l. Sch iine in a n $n$. 


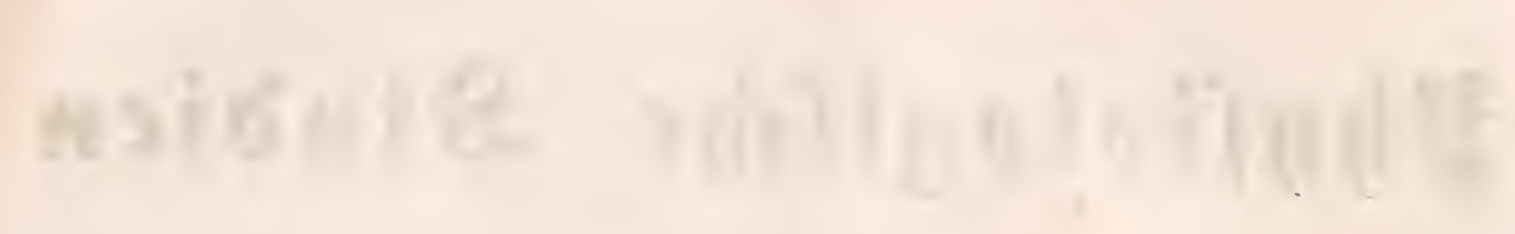

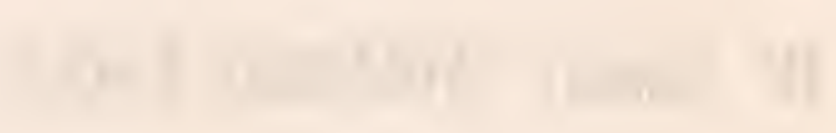

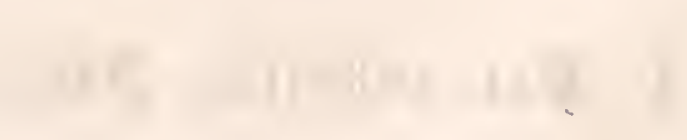



, 


\section{I n l a l $\mathbf{t}$.}

Einleitung . . . . . . . . . . . . . . . . . . . . . . . . . . . Seite 1

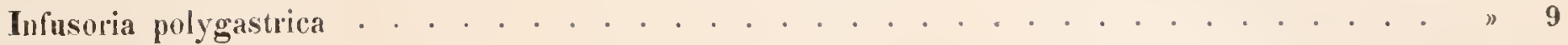

1. Anentera (Darmtose) . . . . . . . . . . . . . . . . . . . . . . . . 13

Erste Familie: Molladina . . . . . . . . . . . . . . . . . 》 14

Monas . . . . . . . . . . . . . . . . . . . . . . . ” 19

Uvella, Polytoma, Microglena . . . . . . . . . . . . . . . » 21

Glenomorum, Phacelononas, Dosococcus . . . . . . . . . . . . . » 26

Chilomonas, Bodo . . . . . . . . . . . . . . . . . . . » 27

Zweite Familie: Cryptomonadina . . . . . . . . . . . . . . o 28

Dritte Familie: Voliocina Gyges . . . . . . . . . . . . . . . . " 29

Pandorina, Gonium elc. . . . . . . . . . . . . . . . . . . " 30

Volvox . . . . . . . . . . . . . . . " 31

Vierte Familie: Vibrionia . . . . . . . . . . . . . . . . . . " 36

Fiinfte Familie: Closterina . . . . . . . . . . . . . . . . " 37

(Euastrum) . . . . . . . . . . . . . . . . . . . . . . n 38

Closterium . . . . . . . . . . . . . . . . . . . . 51

Erklärming der Tafelı . . . . . . . . . . . . . . . . . . . . . . . . . . . . . . . . n 63 




\section{E I}

Die Aufgabe der Physiologie, die Ermittelung aller Gesetze des organischen Lehens, deren vollständige Ergründung uns befähigen würde, jede Erscheinung desselben nach Ursache, Zussammenhang und Bedentung zu würdigen und verstehen, mag noch lange ilırer vollständigen Lösung vergeblich harren, obgleich nach dem Ausspruche eines geachteten Lehrers bei der Bekanntschaft mit allen Thatsachen jene Gesetze sich ganz von sellst ergeben. Ohne Zweifel ist unsere Kenntniss der Thatsachen selır lïckenhaft und das nächste Bedürfniss, liese Lücken ausfüllen zu lelfen, wird von jedem Schriftsteller in diesem Gebiete als Hauptaufgabe festgehalten werden müssen; in jetziger Zeit genügt jedoch das Sammeln vereinzelter Beolachtungen selbst in fernen Erdtheilen kaum zu einer Berechtigung als Schriftsteller in Fache der Plysiologie hervorzutreten, und ist das Vergleichen des schon gesammelten Reichthums und die Ableitmng jener sich von sellsst ergebenden Gesetze, damit letztere das ungeheure Material in übersichtliche Reihen zu ordnen gestatten, vielleicht für die Fortbildung der Wissenschaft zunächst erspriesslicher, wie die Vermelirung desselben durch neue Entdeckungen von Arten und Geschlechtern beider organischen Reiche. Das vereinte Streben so vieler in verschiedenen Ländern thätiger Forscher hat in den letzten Decennien für diesen Zwweck zwar Grosses geleistet, die Kenntnisse, die Instrumente und Untersuchungsmethoden sind erweitert und verfeinert, und doch genügt das Ergebniss all dieses Aufwandes von Scharfsim, Mülle und Fleiss keineswegs, um auch nur die bescheidensten Ansprüche derjenigen zu befriedigen, welche nach jenen Gesetzen eine practische Anwendung im Leben selbst zu machen veranlasst werden. Manche Schwierigkeiten, deren Einfluss die Erforschung der Thatsachen erschwert oder unmöglich macht, liegen klar zu Tage. Die Mannigfaltigkeit der Naturkörper, ihre ungleichmässige Vertheilung über verschiedene Himmelsstriche, die Häufigkeit einiger gegen die Seltenheit anderer und die dadurch bedingte Unmöglichkeit, dieselben übersehen und überall sich jederzeit in genügender Zahl zur Untersuchung zu verschaffen, verhindern schon den vollständigen Ausbau des Gebäudes der Wissenschaft. Nicht minder findet die Untersuchung selbst bei den zugänglichen Organismen unübersteigliche Hindernisse vor; wie z. B. die geringe Grösse der Organismen oder gleichartiger 'Theilchen derselben, dunkele Färbung oder zu 
grosse Durchsichtigkeit, Verschiedenheit der Entwickelung nach Clima und Jalıreszeit, leiclite Zersetzbarkeit oder zu langsame Entwickelung, änsserliche Gleichartigkeit in Form, Grösse und Farbe bei Organen oder Entwickelungszuständen von ganz verschiedener physiologischer Bedentung, und vieles Aehnliche. Die Naturforscher dürfen aus diesem Grunde nicht daranf ausgehen, durch Untersuchung des nöthigen Materiales die bestimmte Antwort auf gewisse, beim Entwickelungsgange der Wissenschaft durch diese oder jene Pliase in den Vordergrand geriickte Fragen mit Sicherheit finden zu wollen, sondern müssen sich mit dem Versuche begnügen, je nach dem günstigen Zusammentrefen zulälliger Ůmstände der Natur etwas melır oder weniger von jener Antwort abzulanschen; aher auch darauf gefasst sein, selbst bei mit Geschick und Ausdauer wiederholten Versuchen nelien Anwendung aller zeitgemässen Huilfsmittel in dieser Beziehung fast ganz leer auszugehen.

Im eigenen Interesse muss daher jeder Naturforscher, als Fremnd der WVissenschaft, das einzige Miittel, welches hei dieser Lage der Dinge wirkliche Hiilfe verspricht, zo fördern suchen, und dazu kam nur die Vermehrung der Untersuchungen his zu einem allgemein erreichbaren Grade von Genauigkeit von Nutzen sein, welche zugleich notlıwendig eine Vermehrung der Zahl der Beobachter voraussetzt. In früheren Zeiten experimentirte jeder Naturforscher nach eigenem Ermessen bis zu einem gewissen Punkte, und es wurde oft dasselbe Problem auf selır verschiedenem IVege gleichlantend gelöst; seit jedoch die wissenschaftlichen Resultate ron einiger Bedeutung nicht unelır lıäufig gefunden werden, seitden es sich of herausgestellt, dass Täuschungen und Trugschlïsse bei sorgfältiger und vielseitiger Prüfung zu vermeilen gewesen, befleissigen die Beobachter sich mehr einer bestimmten Untersuchungsmethode, welche, so weit es möglich ist, vor Felıgriffen zu sicherm verspricht. Diese Methode muss zwar einem jeden Gegenstande angepasst werden und erfordert eine Art ron Individualisiren: in selır vielen Punkten jedoch wird eine physiologische Uutersuchnng immer gleichartig bleilien, oder doch nur geringe Abweichungen nöthig machen. Die Kenntiniss aller Möglichkeiten, nach welchen die Untersuchungsmethoden variirt werden kümnen, befähigt daher erst den Beobachter im concreten Falle die rationellste Form derselben anzuwenden; der Beobachter selbst hefindet sich in einem steten Entwickelungsgange, während dessen seine Erfahrung und Kenntnisse, technische Fertigkeit unl Uebung der Simne etc. sich vermehren und verschiedene Versuche und Schlussfolgerungen gestatten; und endlich kann es von grosser Bedeutung sein, ob sich der Iragliche Naturkörper zum ersten Male der Untersuchung darbietet, ob der Beobachter ganz allein steht, oder frühere und gleichzeitige Arbeiten Anderer zu gegenseitiger Belehrung und eine Art von Wetteifer Veranlassung geben.

Nicht wenige Faktoren sind demnach hei der Entscheidung üler die Qualität des Ergebnisses wissenschaftlicher Forschungen in Rechung zu bringen, und es würde eine möglichst genaue Uebersicht derselben für physiologische Untersuchungen als erfreulicher Zuwachs der wissenschaftichen Hülfsmittel anzusehen sein. Leider ist diese Aufgalıe noch durch unendliche Schwierigkeiten umthïrmt, welche erst beim Versuche selbst in deutlicheren Umrissen hervortreten kümnen, damm aber auch den beherztesten Forscher leicht für immer abschrecken müchten. Es lassen sich leicht eine Menge von Anforderungen für sorgfältige Untersuchungen aufzälllen; Niemand wird jedoch als Ergebniss eine 


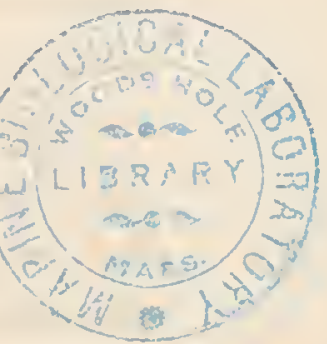


vüllig sichere Beschreibung von Form, Grösse, Farbe etc., cine erschöpfende Nachweisung der chemischen Zusammensetzung etc. ctc. - kurz das Resultat einer als Ideal aufzustellenden Untersuchung verlangen: ebensowenig darf man aber auch in Befolgung der besten Ánleitungen irgend Sicherheit dafür finden wollen, lass man nur Unwichtiges übersehen, nur in Nebendingen getäuscht werden kann. Hier giebt es somit, weder beim Beginn noch am Abschlusse einer Beobachtungsreilıe, sichere Normen, welche für das Ermittelte als Maassstab gelten können; jede einzelne Beobachtung und jeder Forscher für sich treten in eine Bezielıng, die rein individuell bleiben kann, und in welche Niennaud vollkonmen Einsiclıt gewinnen wirl. Nu die immer sich gleiche Natur liefert hier den Maassstab, und erst wenn verschieılene von einander unablıängige Beobachter durch abweichende Untersuchungsmethodeı immer wieder dasselbe Resultat gefunden haben, darf dasselbe als sicheres und danerndes. Eigenthum rler Wissenschaft angesehen werden. - Darun: mehr Untersuchungen! mehr Beobachter!

Wird durch Beides eine gleichnıässigere Bearbeitung aller Abtheilungen der organischen Reiche nothirendiger Weise ins Leben gerufen, so ist nur zu bedauern, lass eine grosse individuelle Verschiedenheit der Beobachter bleiben wird, und nur in einer möglichsten Verfeinerung der Untersuchungsmethode und der Verüffentlichung genaner Vorschriften, wie alle vichtigeren physiologischen Beobachtungen nuit Erfolg anzustellen sind, wird das Ausgleichungsmittel für diesen Uebelstand zu suchen sein. In dieser letzteren Beziehung kam es der Wissenschaft nuitzen, wenn auch solclie Versuche zur allgemeinen Kenntniss gelangen, welche, trot\% mïglichster Eischöpfung aller Huilfsmittel, nicht zu geuügenden Resultate geführt haben, und in dieser Hinsicht wagt der Verfasser überhanpt die Veröffentlichung, Physiologischer Studien": die zahlreiclıen Nebenzwecke, welche bei derselben olme Nachtheil verfolgt werden können, möchten jedoch zusammen genommen vielleicht jenen ersten überwiegen, und bedürfen daher noch einer kurzen Andeutnng.

Bleibt auch die Behauptnng unangefochten, dass nicht nur die Ergebnisse der Untersuchungen, sondern auch solche Versuche mit weniger bekannten Naturkürpern, welche kein genügendes Resultat geliefert lıben, lehrreich sein künnen, so würde doch schwerlich die Veröflentlichung einer Reihe missglückter Streifzüge über die Grenzcn des wissenschaftlichen Gebietes dadurch gerechtfertigt erscheinen. Der Verfasser will daher, an die natiirlichen Abtheilungen der organischen TVesen sich lehnent, das Ergebniss der bisherigen Forschungen mit der Natur vergJeichen, so weit es möglich ist das Bekannte. bestätigen, verbessern und ergänzen, dann aber auch die wichtigsten Fragen, welche noch vergehens ihrer Lösung harren, aufwerfen und die Gründe entwickeln, welche ihre Beantwortung unmüglich machen, die Versuche beschreiben, welche kein Resultat geliefert haben.

So werden die physiologischen Studien zunächst ein Bild des augenblicklichen Standpunktes der Wissenschaft in den bearbeiteten Abtheilnngen geben, durch die Vergleichung nit der Natur eine Kritik der bisherigen Leistungen möglich machen, und dieselben zu verbessern suchen; ferner, da jede wahre Pliysiologie eine vergleichende ist, durch Untersuchung aller zngänglichen verwandten Geschlechter und Arten das Material zu Monographieen üher einzelne Familieu sammelu, deren grïulliche Bearbeitung nicht olıne Einfluss auf die Systematik iberhaupt bleiben kann; sodann durch Zusammen- 
stellung der beobachteten Lebenserscheinungen, der Individualität, Missbildungen, Fortpflanzungs-Arten, Entwickelungsgeschichte und Absterben auf die Lücken in der bisherigen Beobachtung aufmerksam machen und zu deren Ergänzung auffordern; und endlich bei einer Betraclitung des noch Unerklärten oder Räthselhaften die Griinde anzugeben suclien, warım die Forschung hier weiter einzudringen nicht vermag, in der Hoffnnng, dass der bestimmte Ausspruch: „das wissen wir noch nicht und darum ist es nicht zu ergründen," andere Beobachter um so mehr anregen wird, auf die Lösung dieser Fragen hinzuarbeiten. - Dass eine so durchgeführte Arbeit von wesentlichem Nutzen für die Wissenschaft sein müsste und doch obigen Titel rechtfertigen würde, liegt klar an Tage; wie aber die Durchführung gelingen wird ist die schwierigere Frage von allen. - Oft wird es unmöglich bleiben denı Systeme selbst in den grösseren Abtheilungen zu folgen, da alle Organismen über verschiedene Erdtheile und meistens sehr ungleichmässig vertheilt sind, ohne dass Gattung und Art iiberall ilre Repräsentanten finden liessen; die Gegensätze von Land und Meer, von Thal und Berg, von Wald und Ebene, die geologischen Verschiedenheiten etc. entziehen selbst in der gemässigten Zone Vieles der Untersuchung zu einer Jalıreszeit, wo langsamere Entwickelnng, besondere Fortpflanzungsarten und die minder rasche, Zersetzbarkeit der organischen Materie Versuche und Beobachtungen vorzugsweise begünstigen kömnten. Aber auch bei zugänglichen Organismen lässt sich die Untersuchung nicht immer zu einem gewissen Abschlusse bringen, weil das Material oder die Hülfsuittel, welche darauf Anwendung finden, nicht ausreichen. Geringe Dimensionen, Durchsichtigkeit, Zartheit einzelner Theile und äusserst langsame Veränderungen in Grösse, Form und Farbe, ermülen micht selten auch den angestrengtesten Fleiss und die eiserne Ansdauer erfolglos; kleinere Gegenstände lasseı sich in dem Angenblicke, wo sie zu einer vergleichenden Beobachtung dienen sollen, oft gar niclit auftreiben, oder sind zu beweglich, um eine sorgfältige Prüfung zu gestatten, zu zart, um anch den leisesten Druck zu ertragen etc. etc. Genug, da solche Schwierigkeiten sich in allen Klassen des Systemes wiedlerholen, so miissen überall empfindliche Lücken bleiben, für deren Ausfüllung in nächster Zeit durclans keine Sicherheit gehoteı werden kann, und man wird dadurch in die Alternative versetzt, entweder vereinzelte Abhandlungen über diejenigen Organismen zu veröffentlichen, deren Bau sich am weitesten hat verfolgen lassen; oder solche "Studien" wie hier beabsichtigt werden. Im Interesse der Wissenscliaft wird gewiss Jeder letzteren den Vorzug geben müssen.

Werden somit einerseits anch Versuchsreihen, ganz abgeselien von den Ergebnissen derselben, durch Einfluss auf die Methoden der Uutersuchung von Nutzen sein, so liegt andererseits in der Sclıwierigkeit des Gegenstandes genügender Grund um etwas Vollständiges und Vollendetes nicht verwirklichen zu können und auch ein Hervortreten mit „Studien" zu rechtfertigen, welche plammässig die bekannten Untersuchungsmethoden und Hülfsmittel auf die Reilienfolge der organischen Wesen anzuwenden suchen. -

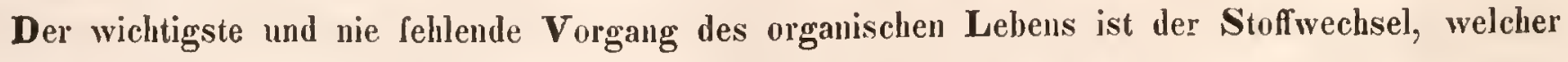
nicht nur überall in Pflanzen und Thieren zur Errhaltung desselben nothwendig ist, sondern auch in jedem einzelnen $\mathbf{O}$ rgane und Apparate, deren harmonisches Zusammenwirken das gesunde Leben bedingt, 

in steter Thätigkeit bleibt. Letztere vermitteln den Stoffwechsel jedoch mu indirekt, dessen eigentlicher Sitz bei grösseren Thieren meistens jene Verflechtung von Nerven, Blut- und Lymphgefässen mit dem Zellgewebe ist, welche unter ler Bezeichnung "Parenchym" aufgefiihrt wird, bei manchen anderen Thieren jedoch nicht selten durch eine scheinbar structurlose Masse ersetzt zu sein pflegt. In diesem Verhalten liegt eiı grosses physiologisches Rätlısel, dessen Lösung durch direkte Versuche bisher unmöglich gewesen ist und erst durch geschickte Combinationeı vielleicht zu erforschen sein möchte. Da Lebeu und Stoffwechsel in allen Fällen gleichzeitig vorhanden sind, sämmtliche Apparate und Organe des Lebens aher in Form und Bedentung so manigfach wechseh, so entsteht die Frage ob das Leben in abstractem Sime an letztere gehunden sei, oder ob es, wie der Stoffweclisel, im Parcnchyme seinen Sitz habe und die elementaren - die in gleichartigen Organen desselben und verschiedenartiger Organismen gleichartig gehilleten, zuerst Elementar-Organe genannten — Bestandtheile desselhen, seine eigentlichen 'Träger sind.

Bei den Vegetabilien liegt es klar vol Augen, lass wie in jedem Pflanzentheile die denselhen bildenden Zellen, so auch bei nielleren cryptogamischen Gewächsen nicht selten eine einzige, oder wenige oft lose zusammenlängende Zellen, das ganze Individunm bildend, die Lebensthätigkeit vermittelı. Die Untersuchungen der neneren Zeit scheinen auch bei den Thieren immer bestimmter darauf hinzuweisen, dass jedes Organ, friilı genug untersucht, als ans Zellen gebildet erkannt werde, welche durch noch unbekannte Verwandelnngen sich zu den späteren Elementar-Organen umbilden, und es bleibt die Möglichkeit gegeben, dass aus einer Zelle bestehende Thiere vorkommen, wie solche wirklich schon gefunden sein sollen, deren einzige Zelle dann sämmtlichen Funktionen, als del Ernährung, des Athmungsprocesses, des Kreislaufs, der Empfindung, der Fortpflanzung etc. vorzustehen hätte.

Anch die Bildung jeder primitiven Ei-Zelle redet jener Möglichkeit das Wort, und wie sich bei der Entwickelung einzelne Zellen zu bestimmten Gruppen ausbilden, denen verschiedene Organe ihre Entstelıung verdanken, so lassen sich auch die Verrichtungen dieser Organe als besondere Modificationen des Lebens selbst ansehen; denn zugegeben, dass der Stoffwechsel durch die einzelnen Zellen direkt vermittelt wird, so ist ja jedle physiologische Funktion nur ein in Qualität modificirter Stoffwechsel, den ein gervisser Zellen-Complex zu Wege hringt; um bei den durch Nerren vermittelten Thätigkeiten ist der Wechsel eines, minlestens füı unsere leiblichen Sinne nachweisbaren, Stoffes bis jetzt nicht darzuthun gewesen. Sowohl für die Lehre von der Gestaltung der Pflanzen und Thiere und ihrer Organe, die Morphologie, als auch für die Lehre von der Bildung der Zellen und ihrer Umwandelung zu Geweben etc., die Histiologie, bleibt diese Frage von ler höclısten Wichtigkeit, und der geeignetste Weg, um Anfklärung darüber zu erlangen, wird die Untersuchung solcher Organismen sein, bei denen in kleinerem Maassstabe der einfachste Baı sich zeigt, weil eben die grössere Complication der Organe und Apparate und das Wechselverlıältniss der verschielenen Functionen die Beurtheilung der Lebenserscheinungen bei lı̈̈ler entwickelten Thieren so ungemein erschwert.

Es gilt demnach diejenigen Thierformen zunächst der Reilıe nach zu prüfen, welche bis jetzt einen minder complicirten Bau haben erkennen oder vermuthen lassen, oder, wie auch in allen neueren 
Lehrbüchern geschieht, mit den Infusorien zu beginnen und durch die versehiedenen Abtheilungen dler wirbellosen Thiere bis zu den Glielerthieren und Fischen zu dringen. Hier müssen der bereits erkannte Bau und die Besehaffenheit der Gewebe mit den bei den unteren Thierklassen gefundenen physiologischen Gesetzen in vollstem Einklange stehen, oder die Beobachtung zeigt noch so wesentliche Lücken, die nur durch allmählige Bearbeitung vieler Forscher ausgefüllt werden können, und jenen Widerspruch genügend erklären, - oder die Errorschung des Lehensprincips liegt ïherhaupt ausserhalh der Sphäre menschlicher Fähigkeiten, und wir stossen auf eine Grenze, an der es für unser Geschlecht kein 2,Vorwärts" melı gibt.

So wie jede geistige Anffassung durch unsere Sinne rermittelt wird, sind wir auch bei diesen Lntersuchungen allein auf dasjenige angewiesen, was unsere Sinne, und bei allen feineren Untersuchungen darf man sagen, was unser Auge wahrzunehmen vermag. WVie weit dessen Hähigkeiten tlureh geeignete Iülfsınittel vielleicht noch dermaleinst gesteigert werden können, lässt sich freilich niclıt absehen; wir unterscheiden jedoch schon jetzt mit den besseren Mikroseopen die Körper, welehe 1/2000", und wenn sie bewegt sind, 1/3000" und weniger in Durchmesser lahen, wobei im letzteren Falle freilich nu die Existenz und höchstens eine bestimmte Form solcher Körperchen zu erkennen ist. Zwischen dieser Grenze und den thenretisch angenommenen Atomen der Materie erstreekt sich das unbekannte Reich der Sinnenwelt, und in ilm ruhen die böchsten Probleme der WVissenschaft. Dieses Reich war nicht inmer gleich begrenzt; vor Jahrhunderten unfasste es ganze Lehren, ganze Pflanzenund 'Thierklassen, welche die Erfindungen menschlichen Scharfsimes ihm abgewonnen haben; noch im Anfange dieses Jahrhunderts war es vielleicht nur wenigen Forschern vergünnt, mit einiger Klarheit Gegenstände von 1/500" zu erkennen und gegenwärtig kümıen die eifrigsten WVerkstätten kaum der Nachfrage nach Instrumenten genügen, welche überall den Beobachtern mindestens um vier mal kleinere Naturkörper zugänglich machen. Was hat diese Erweiterung unserer Macht gefruchtet? Zahlreiche Thiere und Pflanzen sind entdeckt, viele für gleichartig gehaltene Gewebe haben Unterschiede erkennen lassen und eine oft höehst complieirte Structur ist manchmal da nachgewiesen, wo fribere Forscher eine formlose Gallerte vor sich zu haben glaubten etc.; aber ist jener Weg his zu den Atomen der Materie kuirzer geworden? Gesetzt auch nenere Verbesserumgen setzten uns in den Stand 1/10.000" unterscheiden zu künnen, dureh die Beobachtungen organiseher Vorgänge wirl es wahrscheinlieh, dass jene uns desshall eben so unerreichbar bleiben wie hisher.

Auf eine direkte Erkenntniss der Hormen und Eigenschaften der kleinsten Körperchen und einzelner Atome durch unser Ange müssen wir daher verzichten, wenn nicht im organischen Leben durch logisclıe Schlussfolgerungen siclı aus dem zugünglichen Theile jenes Gehietes Gesetze ermittelı lassen, deren Macht sich auch ïher jenen unsichtharen 'Theil der Simnenwelt anstehnt, oder jene tiefe Kluft für wissenschaftliche Forsehnngen unschädlich nachen, inden geistiger Scharfblick die Blödigkeit unseres leiblichen Auges ausgleicht. — Es fragt sich hauptsächlich, ob die T'heilchen der organischen Materie jenseit der Grenze des Sichtharen andere Formen nul Eigensehaften vermuchen lassen, wie die bekannten. Die organischen Partikelehen erscheinen im Selfelde des Mikroscops in allen Ver- 

schiedenlıeiten der Form und Alıstufungen der Grösse, von ungemein durchsichtigen in allen Graden der Trübung und Färbung bis zu ganz schwarzen, oder, weil sie gar kein Licht durchlassen, schwarz erscheinenden; doch giebt es kaun Beohachtungen, welche die Amalıme rechtfertigen, dass gegen jene Grenze des Sichtbaren hin das Urtheil der Forscher über diese Eigenschaften allmällig unsicherer werde; es scheint vielmehr, als ob die Substanz der Thiere und Pflanzen in himeichend Jünner Schicht bei genügendem Lichte einer erschöpfenden Untersuchung meistens vollkommen zugänglich sei. was sich nicht allein auf die Jetztwelt beschränkt, soudern mit Hülfe der Clıemie und Mechanik sellıst die verkohtten Pflanzen und die Knochen riesiger Ungehener der Vorwelt in ihren Bereich zu ziehen gewusst lıat. - Eine leicht zu beobachtende 'Thatsache ist es ferner, dass die organischen 'Theilchen, je kleiner sie werden, und je nener sie gebildet sind, un so häufiger die Kugelform zejgen, und wenn bei organischen Bilungsprocessen eine Menge solcher Kugeln gleichzeitig entstehen, sind sie nicht selten von gleicher Grösse und oft so dicht gedräıgt, dass nur um vieles kleinere Körperchen zwischen ilnen Platz lıaben würden. Endlich lehrt uns die Entwickelungsgeschichte das Verhältniss der kleinsten 'Theilchen zu der veränderlichen Grösse und Ausbildung der ganzen Organismen kennen; wir sehen die einzelnen Organe aus winzigen Anfängen heranwachsen und ihre Elementartheile denselben Process durehlaufen: schou vorher entstehen aber Bildungen, welche das Erscheinen beider vorbereiten und in ihrem Gewebe weniger kleine Theilchen unterscheiden lassen. Dieser Cmstand berechtigte. schon den ersten Meister in der Entwickelungsgeschichte der Thiere zu den Ausspruche: „Der Embyo ist anfangs grob gebaut", und wir finden in der That die Berichte neuerer Forscher auf diesem Gebiete so ausführlich und klar, den dentlichen Abbildungen entsprechend, dass sich die Ueberzeugung aufärängt, die Schwierigkeiten, wclche hier noch in Wege stehen, seien nicht optischer Natur und Grösse, Form und Farbe etc., seien üherall, wo oft und genan genug zugesehen wird, erkennbar.

Setzen wir dalıer in Jen Raum zwischen dem jetzt überhaupt Sichtbaren bis zu den theoretischen Atomen, in Erwartung eines Besseren belelnt zu werden, vordäufig ähuliche Formen und Vorgänge, wie sie uns an der Schcidegrenze begegnen werden, und iibertragen ilmen solche T'hätigkeiten, wie wir aus der Gesammtwirkung erkennen, so wird jene Kluft für vorliegende Studien in dieser Hinsicht ohne Einfluss bleiben und getrost die Bahn in der Zuversicht betreten werden, dass die reine Dimension es nicht ist, welche die Lösung der Fragen ïher das organische Leben unmöglich macht, oder mit anderen Worten, dass wir die Form etc. erkenneu werden, so oft unser Auge dieselbe zu prïfen im Stande is?.

Bleibt somit die organische WVelt optisch zugänglich, so ist sie dagegen mechanisch und chemis ch desto mehr abgeschlossen. Schon die Handhabung ganzer Organismen, welche kleiner wie $1 / 2$ "' wird unsicher und schwierig, und einzelne Objecte, welche kleiner wie 1/50" sind, gestatten kanm noch eine Behandlung zu bestimmten Zwecken. Gilt dieses schon ron ganzen Organismen, so Jässt sich leicht denken, wie viel weniger ihre feinsten 'Theile sich präpariren lassen; das gewaltsame Zerquetschen des ganzen oder mehrerer 'Thiere bringt bei wiederholten Versuchen bald dieses bald jenes Organ zur deutlicheren Anschauung, durch deren Zusammentragen erst die Bildung des Organismus 
erkannt wird: ein Verfahren, welches nur zu leicht zartere Theile ïbersehen lässt und zu Täuschungen verführt. Isoliren lassen sich kleinere 'Theilchen aber sehr selten, und da solche überall bei Pflanzen und Thieren vorkommen, so ist ihre chemische Untersuchıng unter dem Vergrösserungsglase mehr ein Mittel, welches Zweifel löst, Vermnthungen bestätigt und schwierige Untersuchungen abkürzt, als zu einer genügenden Analyse führend. Ehen die Lücken, welche diese Schwierigkeiten in der Beobachtung einzelner 'Thiere und Pflanzen bedingen, lassen sich nur durch vergleichende Untersuchungen ausfüllen, und erst nachdem letzteres gelıngen, darf man mit Sicherheit aus den Erscheinungen des organischen Lebens die Gesetze, welchen dieselben folgen, abzuleiten versuchen, um damit dem allgemeinen Ziele aller physiologischen Studien näher zu kommen.

Zunächst suchen also in dem Hauptzwecke, die Wissenschaft mehr durch das Aufsnchen von Gesetzen wie von Objecten zu fördern, diese „Physiologischen Studien" des Verfassers ihre Berechtigung; letztere wird durch die oben angedeuteten, bei Verfolgnng eines systematischen Planes zu erreichenden Nebenzwecke schwerlich beeinträchtigt werden, und endlich wird ler Leser aus den mitgetheilten Versuchen ersehen, wie weit die Resultate anderer Beobachtungen des Verfassers Zutrauen verdienen. Sie erscheinen der Natur der Sache nach in zwanglosen Heften etwa von dem Unfange des vorliegenten, deren eins oder mehrere für sich abgeschlossene Monographieen der abgehandelten Organismen bilden, und sind begleitet von Tafeln, welche die untersuchten Naturkörper ausschliesslich nach Original-Zeichnungen des Verfassers in ilıren natürlichen Farben zur Anschaunng bringen. 


\section{A. Wirbellose Thiere.}

\section{Infusoria.}

\section{I n f us o r i a Polygastric a.}

Mögen tiefe seelenrolle Blicke sich weiter in die Dunkel rerbreiten! Ehrenberg.

D ass der ganze Umfang unserer Kenntnisse ïber eine reichhaltige Abtheilung des 'I'hierreiches fast ansschliesslich dem eminenten Scharfblicke und der rastlosen 'I'bätigkeit eines einzigen Naturforschers zu verdanken ist, wie dieser Fall bei den Infusorien vorliegt, möchte sich wohl kaum in einem verwandten Zweige der wissenschaftlichen Forschung wiederholen können. Demn vor Ehrenbergs Untersuchungen war iiber den immeren Bau dieser Wesen kaum etwas hekamnt, und was in Folge derselben, ausser Bestätignngen seiner Entdeckungen reröflentlicht ist, verschwindet gegen' jene grossartigen Leistungen so sehr, dass es bei einem historischen Ueberblicke unserer Kenntnisse von dieser Thierklasse fast ohne Nachtheil unberücksichtigt bleiben darf. Kaum haben die Beobachter früherer Zeit von der Physiologie dieser 'Thiere unbestimmte Alunungen gehabt und hei lem redlichsten Fleisse und sorgfältiger Benutzung der damaligen IIülfsmittel doch nicht vermeiden künnen, bei einer systematischen Anordnung die heterngensten Organismen als Species derselben Gattung einzureihen: und im Laufe weniger Jahre sind durch Ebrenbergs Untersuchungen nicht nur bei weitem die Mehrzahl der jetzt hekamten Infusorien entdeckt, sondern auch alle nach dem erkannten imnern Baue in ein wollgeordnetes System nach natïlichen Ordnungen und Familien gebracht, welches, obgleich neue Entdeckmngen und genanere Untersuchungen manches Kinzehe berichtigend und erweiternd abändern können, in seinen Hauptabtheilungen und Umfange wohl fïr immer festgestellt sein möchte. Denn seit der Aufstellung dieses Systemes sind die Entdeckungen nener Gattungen und Arten schon so zahlreich gewesen, dass die Leichtigkeit, womit sie den verschiedensten Abtheilungen eingereiht werden konuten, hinreichend als Prüfstein für das System selhst hetrachtet werden kann: ein System, welches nur ein so bewundernswerther 'Takt, - wobl als Folge der durch die Resultate der Untersuchungen selhst geweckten Begeisterung - in's Leben rufen komite.

Ohne Zweifel liegt der nächste Schlinssel zur Möglichkeit eines solchen Fortschrittes in der bestimmten Tremnung der Magenthiere und $\mathbf{R}$ äderthiere, und was frühere Beobachter anch iiber die Aufnahme von Nahrungsmitteln oder Farbstoffen gesehen haben mochten, komnte zu keinen Resultaten führen, so lange sie allgemeine Gesetze für so verschiedenartige Geschöpfe suchten. Es bleilht unwillkührlich auch für den denkenden Beobachter der Begriff der Grösse mit der physiologischen Funktion 
eines Organes verschwistert, und sobald im Selıfelde der verbesserten Mikroscope die einzelnen Organe der Räderthiere nach Umfang, Farbe, Durchsichtigkeit etc. sich absonderten, mussten auch die Funktionen derselben ihrer lage nnd Grösse nach zu denten versucht werden: ein einziger anatomischer Character - der fast gerade Verlaus des in wenige Abtheilnugen getheilten Darmes - reichte zui scharfen Sonderung der polygastrischen Infusorien hin.

Ausser dieser Abgrenzung nach oben, die somit leicht gefunden war, und nach der entgegengesetzten Richtmng, wo sich dieselbe in der Grenze unseres Selıvermögens verliert und also von den Verbesserungen der Mikroscope ablıängig bleibt, ist eine viel schwierigere Anfgabe die seitliche Verwandtschaft der Algen und Pilze in hestimmte Grenzen einzupfarren und eine auf rationellem Fundamente fussende Scheidewand zwischen Thier- und Pflanzenreich zu errichten. Dic allgemein den Physiologen vorschwebende, wenn auch selten ausgesprochene Idee, dass beile sonst iiberall scharf getrennte Reiche bei genanerer Erforschung anch hier bestimnte Verschiedenheiten erkennen lassen würden, blieb bis auf die letzte Zeit mangefochten; es ist jedoch wohl zu beachten, dass alle Zweifel und Fragen in dieser Beziehung sich nur auf die eine der grösseren Abtheilungen des Ely enbergischen Systemes del Polygastrica bezieht und in Irinsicht auf die übrigen nie ein begriunleter Zweifel wieder erhohen werden kann. Denn diejenigen organischen Wesen, welche sich freiwillig bewegen und durch verschluckte Nahrungsstoffe, deren Beschaffenlueit im Durchgange durch deı Körper sich verändert, ermähren, werden für inmer Thiere bleiben, und da in den folgenden Studien diese Vorgänge bei den Polygastricis, welchen Ehrenberg einen Darm zuschreibt (Enterodela), genauer beschrieben werden sollen, so wird es vorläufig geniigen eine Untersuchung der kleineren, darmIosen (Anentera) in Beziehung auf die Frage vorzunehmen, ob sie Charactere erkennen lassen, welche genïgen, um jeden Zweifel über ihre thierische Natur zu bescitigen.

Die stetigste Erscheinung, welche das organische Leben zeigt, ist der Stoffwechsel, durch den ein beständiger Verkehr mit der Aussenwelt, mit den das Individnum umgebenden Medien stattlindet. Unter letzteren gieht es nur zwei überall verbreitete Mischungen, in welchen das arganische Leben die Stoffe, deren es bedarf, vorfindet, die Luft und das Wasser. Die vollkommmeren Individuen des Pflanzenreichs nelmen die Luft durch die griuen Pflanzentheile, wie Rlitter und Stengel, das Wasser durch die Wurzeln auf, und ob nun das chemisch reine Wasser das Pflanzeulehen zu unterhalten vermag oder nicht, mag unentschieden sein; gewiss aber ist, dass meistens verschiedene Stoffe darin aufgelöst sind, welche in die Pflanze übergehen. Bei den niedersten Algen, welche hicr fast allein in Frage kommen, tritt anch die Luft nur durch Vermittelıng des Vassers an die Pllanzenzelle und weun ein entscheidendes Moment leicht gefunden werden könnte, um Pflanzen und 'Thiere zu tremen, so müsste es, da auch alle in Frage kommenden thierischen Geschöpfe im Wasser leben, in der Aufnahme dieses Mediums mit den darin gelösten oder vertheilten Substanzen sich zeigen, welche

bei den Pflanzen an jeder Grenze des Körpers durch Einsaugung vor sich geht, wobei nur aufgelöste Stoffe mit in das Innere gelangen,

bei den Thieren vorzugsweise durch bestimmte Oeffnungen des Körpers geschieht, wobei meistens auch nicht anlgelöste Körperchen mit eindringen und nach längerem Verweilen oft an anderen bestimmten Stellen des Körpers wieder ausgeschieden werden.

Dieser Unterschied, wo er sich zeigt, entscheidet bestimmt über die Frage: ob Pflanze? ob Thiel? Natürlich lässt sich eine an jeder Grenze des Körpers stattfindende Einsangmng von Wasser, darin gelöster Luft und anderer Stoffe, sellost bei den besten Iülfsmitteln nicht wahrnelmen, dagegen durch ilıre Erfolge als geschehen nachweisen, während die Aufnahme im IVasser vertheilter Stoffe in den Körper durchsichtiger Thiere sich unter den Mikroscope erkemnen lässt. Die natïrliche Folge davon blieh, dass soweit dieser Punkt der einzige war, an den man sich halten komnte, was feste Stoffe aufíahm, zu den Thieren, durch positiven — was es nicht that, zu den Pflanzen, durch negativen Beweis gerechnet werden musste. Ein anderes Unterscheidungszeichen, welches leichter in die Augen 

fält, ist die freiwillige Bewegung eines ganzen Individuums oder einzelner Organe desselben, und hat auf die erste Auffassung mancher zweifelhaften Formen grossen Einfluss gelıabt. Bald wurde jedoch beobachtet, dass angenscheinlich sehr nah verwandte Körper, ja selbst Arten derselben Gattung, in dieser Beziehung ein sehr ungleiches Verhalten zeigen, und dagegen bei anderen Gattungen mit zahlreichen Arten, die einen entschieden pflanzlichen Character lıaben, lebhafte, den thierischen täuschend ähnliche Bewegungen etwas Gewöhnliches sind.

Genug, ein 'Thier könnte essen, ohne dass wir es durchaus wahrnehmen müssten, eine Pflanze sich bewegen, ohne darum Thier zu werden. Diese Unsicherheit wies auf eine andere Reihe von Kennzeichen him, deren Untersuchung zu gediegeneren Resultaten zu führen rersprach, nämlich die Fortpflanzung und Entwickelungsgeschichte, und wo die Bildung eines Thieres aus dem Eie, oder einer Pflanze aus der Spore beohachtet worden, ist auch nie der geringste Z Zweifel ührig geblieben. Eine nicht unbeträchtliche Zahl jener zweifelhaften Körjer lat aber weder die eine noch die andere Fortpflanzung bis jetzt wahmehmen lassen; sie finden sich oft in zahlloser Menge vor, vermehren sich durch Queer- und Längstheilung, Gemmen- und Sprossenbildıng etc., wobei Jahreszeit und WitterungsVerhältnisse ron rerschiedenem Einflusse sind, und verschwinden später wieder, so dass unr einzelne zerstrente Indiviluen mit vieler Mülıe aufgesucht werden kömnen, die sich in Form, Farbe und Umfang nicht auszeichnen; - Beweis genug, dlass auch auf diesem Wege die Unterseheidnng von Thier und Pflanze nicht leicht und sicher erlangt wird.

Bei den hölıer entwickelten Pflanzen und Thieren findet sich der Gegensatz in dem Stoffe, woraus sie bestehen, dass bei den Thieren seltener stickstofffreie Verbindungen gefunden werlen, während sie hei den Pflanzen vorwiegen. Geeignete Versuche haben in neuester Zeit für manche Fälle die Möglichkeit nachgewiesen, selbst hei sehr kleiuen Gegenständen unter dem Mikroscope eine Bestimmung ihrer chemischen Natı zu erlangen; doch müssen freilich diese Beobachtungen noch eine breitere Basis schaffen, hevor die Folgermugen eine wünschenswerthe Sicherheit darbieten. Ausserdem aber bleibt es wahrscheinlich, dass wälırenı bei den böher entwickelten Organismen beider Reiche bestimmte Stoffe sich wesentlich rerschieden zeigen, bei den minder entwickelten die Reactionen immer weniger characteristiseh werden, und bei len zweifelhaften einzchne Elementarorgane weder für sich geprifft werden können, weil sie nicht zu isoliren sind, noch wenn dieses geschehen kann, eine genügende Reaction zeigen; die organische Chemie lat trotz der Riesenschritte, mit welchen sie im letzten Jahrzehent vorwärts gedrungen, bei der sorgfältigeren Analyse thierischer Substanzen so viel Neues entdeckt, worauf kaum die gewagteste Vermuthung fïlıren konnte, dass auch hier sich sehwerlich der Schlüssel zur Lösung der rorliegenden Frage finden möchte. -

Diese Betrachtungen fülıren zu ılem Schlusse, dass nur eine sorgfältige Beobachtıng der zweifellıfteı Geschöpfe durch alle Jahıeszeiten fortgesetzt, um wo möglich ilıe Entwickelungsgeschichte zu erforschen, eine Prifung ihrer Bestandtheile, wo sie ausfiilubar ist, und vorsichtige Anwendung des Schlusses durch Analogie zu einen Ergebnisse führen werdeı, welches dem gegenwärtigen Standpunkte des menschlichen Wissens entspricht, und, richtige Amahmen bestätigend, die Erkemntniss der noch heibehaltenen Irrthümer selbst anbahıt. Gewiss wäre es hier zu wünschen, dass die Untersuchung bei den Gesehöpfen beginnen kümnte, welche den einfachsten Bau und die geringsten Dimensionen zeigen; ron den kleinsten organischen Wesen kemnen wir aber leider nur die Existenz, höehstens eine von der Kugelform um ein Geringes abweichende Gestalt, und bei der offenbar sehr lebliaften und selbsttlı̈tigen Bewegung, bei gäızlichem Mangel aller Uebergänge zu bestimmt als vegetahilisch erkanıten Gebilden, wirl ihre thierische Natur kaum in Zweifel gezogen. Zu physiologischen Sudien eignen sich dieselben jedoch am allerwenigsten; denı wäre auch zunäclıst ihre geringe Grösse (von etwa $1 / 600^{\prime \prime}$ an und kleiner') ein durch Verbessernng der Mikroscope zu verringernder Uebelstand, so lässt sich doch ihre Form, Bewegungsorgane und ilı imnerer Bau um so schwieriger erkemen, als sie sich weder mit Sicherheit auffinden, noch durch geeignete Hülfsmittel unter dem Vergrösserungsglase 
festlegen und abplatten lassen, so dass in sehr vielen Fällen die Bestinmung der Gattung und Art selbst geübten Beobachtern unüberwindliche Schwierigkeiten darbietet. Zu einer genügenden mikroscopischen Untersuchnng ist es unerlässlich, dass jedes Object ruhig liege und eine gewisse, nach der Durchsichtigkeit verschiedene, Dicke nicht ïberschreite, wobei die Kugel- oder Cylinderform meistens für die Untersuchung die unguinstigste bleibt. Diese Umstände genïgen auch das sorgfältigste Studium der Monaden unl Vibrionen etc. fast ganz unfruchtbar für die Physiologie zu machen, während es fïr die Systematik nur zu fruchtbar zu werden droht, indem leicht dasselbe Geschöpf unter mehrfachen Benennungen aufgefiilıt werden könnte, je nachdem mehr oder weniger von dem inneren Baue dem jedesmaligen Beobachter klar wird. -

Nur um den Faden der systematischeı Anordnung so weit festzuhalten, dass späteren Rückblicken auch his an die Grenze der organischen Welt treier Raum bleiht, möge lier daher in gedrängter Kürze eine Zusammenstellung der Gattungen nach Ehrenbergs Anordnung einen Platz finden, welche bis zu denjenigen Gehilden reicht, die nicht zu klein sind, um eine sorgfältigere Untersuchung zu gestattell. -

Polygastrica $=$ vielmagige Infusorien lueissen diejenigen schı kleinen thierischen Oıganismen; bei denen aufgenommene Nahrungsmittel in mehrfaclien getrennten Höhlungen im Kürper verweilen, welche die Stelle mehrfacher Magen vertreten, weil die zur Nahrung dienenden Stoffe nach kürzerem oder längerem Aufenthalte in denselben wieder aus dem Körper entfernt werden. Letzteres kann an derselben Stelle des Körpers stattfinden, wo sie aufgenommen wurden, so lass Mund und After zusammenfallen, oder die Ausscheidung findet an einer anderen Stelle des Körpers statt, und die Nahrungsstofle gelangen auf verschiedenem Wege aus dem Magen und Körper des Thieres wieder nach aussen. Diese Verschiedenheit liefert die beiden Hauptahtheilungen der Polygastrica, indem jener Weg vom Munde his zum After als Darm bezeichnet wird und demmach im ersteren Falle ein solcher fehlt = Anentera, Darmlose, im letzteren ein Darm vorhanden ist = Enterodela, Darmfïhrende.

Gern gesteht der Verfasser, dass die Anfgabe fïr ihn zu schwer gewesen, ïber die Wege, welche Nahrungsstofle bei den Monaden und Vibrionen durch die winzigen Leiber gefülırt werden könnten, sich bestimmten Aufsclılıss zu verschaffen, und verweist auf die spätere Erörterung des Baues der darmführenden Polygastrica; gewiss aber fülırt die Untersuchung der A reellinen zu einer solchen Ansicht und es wird sicher die Abtheilung in älnlicher Umgrenzung festzuhalten sein, wenn anch einige Gattungen ausrangirt und selbst das Eintheilungsprincip mit einem anderen Namen ansgesprochen werden nuisste. - Die 'Thiere, welche in diese Abtheilung gehören, unterscheiden sich von allen übrigen durch die Art der Aufnahme und Ausscheidıng der Nahrungsstofle und unter sich durch die Grösse, Form und Farbe ihres Körpers, die Bewegungsorgane und Beständigkeit desselben, die Art der Selbsttheilung, und verschiedene Hüllen des Leihes etc: etc., so dass folgende iibersichtliche Zusammenstellung der Familien siclı ergiebt:

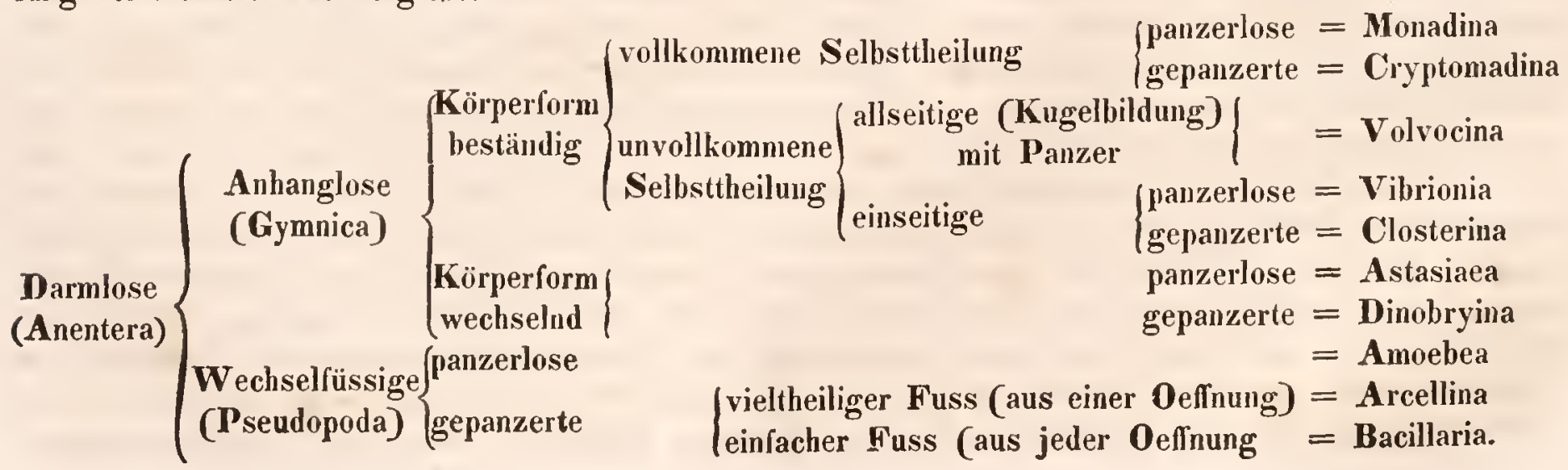



Zur Erläuterung dieses Schemas muss man sich vergegenwärtigen, dass angenommen wird, so wie die Aufnahme und Ausscheidung der Nahrungsstoffe - mögen letztere nun Farben, feste Substanzen oder anfgelösete Stofe sein - bei den Arcellinen beobachtet ist, dieselbe in der ganzen Abtheilung der Darmlosen vor sich gehe. Die Ammahme, dass diese Organismen 'Thiere seien, ist nur bei denen bestritten, wo sich nmregelmässige (willkührliche) Bewegungen nicht sogleich leutlich beobachten lassen, mıd dahin gehören nur ein Theil der Volvocina, die Closterina und Bacillaria; obgleich Niemand mehr daran zweifelı kanı, dass Bewegung an und für sich als Unterscheidungszeichen für die thierische Natur eines organischen Wesens ganz unbrauchbar geworden ist. Die Erörterung der Grïnde, welche für und gegen die eine oder andere Ansicht sprechen, soll in die folgenden Untersuchungen jener Organismen verflochten werden, bei den übrigen Darmlosen, deren thierische Natur bestritten worden, bleilıt nur die Anmahme ïbrig, Jass da, wo der Uebergang fester Siofle in den Körper nicht wahrzınehmen ist, eine Auflösung derselben im Wasser als Nahrungsmittel diene, welche im Parenchym der 'Thiere, weil beide fast in gleichem Grade tas Licht brechen, schwer zu unterscheiden ist. - Der Körper dieser Thiere ist entweder anlıanglos, olme Verläıgerungen, Fortsätze, Fiisse etc. mit Ausnahme sehr feiner Wimpern und fadenförmiger Riissel, - oder mit veränderlichen Fortsätzen (Füssen) versehen: die Form des Körpers ist an sich beständig oder durch abwechselnde Ausdehnung und Zusammenziehen veränderlich, und der Körper selbst nackt oder mit ein-oder mehrfacher Hülle versehen = gepanzert. Die bekannte Vermehrung der Individuen endlich geschieht. durch I_ängs - und Quertheilung, die vollkommen sein kann, wo beide Individuen nach vollendeter Theilung sich trennen, oder unvollkommen bleibt, wemn die mehrfachen Individuen auch ferner zusammenhängen, wobei allseitige Theilung zu kugelförmigen Monadenstöcken, einseitige zn fadenförmigen Gebilden führt.

Diese Unterscheidungs-Merkmale sind sämmtlich ohne Schwierigkeit wahrzunehmen und jellem Beobachter dentlich zu machen, - sie genügen, um die Melızahl der darmlosen Magenthiere in natürliche Familien zu vereinigen und möchten wohl stets ihren systematischen $W$ erth behalten; die physiologische Bedeutung dieser und anderer Eigenschaften ist noch bei weitem nicht immer genügend klar erkannt, und schaltet daher der Verfasser bei einer flichtigen Musterung der einzelnen Familien

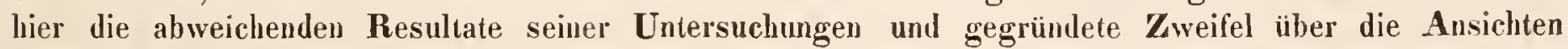
Anderer gehörigen Orts ein.

\section{Anentera (Darmlose.)}

Mangel des Rückenmarkes und des Pulses, in zahlreiche blasenartige Magen zertheilter Speisecanal, unabgeschlossene Körperform (durch Selbstheilung und Knospenbildung), beiderlei Geschlechtsorgane und Scheinfüsse (ohne wahre Gelenke) - bezeichneten für Elı r n berg bei Abfassung des grösseren Infusorienwerkes die Klasse der Magenthiere. Von diesen Kemueichen sind die Magen und Geschlechtsorgane theils ilıer Bedentung, theils ihres Vorhandenseius wegen von rerschiedenen Gelehrten bastritten; da jedoch in Beziehung auf diese Punkte zwischen den beiden grössern Abtheilungen der darmlosen und darmführenden kein Unterschied vorhanden ist, so kanı hier mii Recht auf die Untersuchungen der grössern darmfülırendeı Magenthiere, welche weiter unten mitgetheilt werden sollen, lingewiesen werden. Denn die Thatsache, dass Nahrungsstoffe oder Farben von den Magenthieren verschluckt und in getrennte Behälter, welche, da sie bei jeder Lage des Thieres rund erscheinen, hohle Kugeln oder Blasen sein müssen, aufgenommen werden, ist nicht mehr zweifelhaft, und nur die Wandungen dieser Behälter und ihre Verbindung unter einander sind streitig. Wie aber diese Frage auch entschieden werden mag, so wird doch stets ein Unterschied zwischen den Thieren bleiben, welche 
dieunverdauten Substanzen durch so be Oeffnung des Körpers, die deu Mund bildet, ausscheiden, und denjenigen, welche an einer andern Körperstelle eine bestimmte Oeffnung für diese Ausscheidung zeigen. Ersteres ist der Fall bei den darmlosen $\longrightarrow$ letateres bei den darmführenden Magenthieren, welche nach der gegenseitigen Lage dieser Oeffnungen in grössere Abtheilungen zerfallen.

So einfach diese Sätze zu sein scheinen, und so bestimnt sie jedes Thier in eine oder die andere Abtheilung verweisen, so schwer ist es in manchen Fällen über die Sache selbst in's Klare zu kommen. Viele dieser Thiere nelımen gar keine Farhstofe in sich auf, bei andern hält es schwer, Jas vordere und hintere Ende mit Sicherheit zu unterschejden, und die stete Beweglichkeit anderer würde es sehr selten glücken lassen, eine Ausscheidung unverdanter Stoffe ïberhaupt wahrzunehmen, geschweige denn zu entscheiden, ob dieselbe durch die vordere Oeflunng des Mundes, oder an irgend einer andern Stelle des Körpers ror sich ging. Die natürliche Verwandtschaft der meisten Familien ist freilich so einlenchtend, dass der Vorgang bei wenigen Arten mit Sicherheit erkannt, fiir alle übrigen maassgehenl sein wïrle; allein um nach $\mathbf{E}$ hrenberg's Rath durch das gleichzeitige Uebersehen vieler Individuen zu diesem Zwecke gelangen zu können, mïssten entweder diese 'Thiere oder das Sehfeld unserer Microscope bei so starken Vergrösselıngen wie erforderlich sind, um bei ihnen das vordere und entgegengesetzte Ende des Körpers zu unterscheiden, ganz andere Dimensionen darbieten. Nur ein Zufall kann einzelne Beobachter in solchem Falle hegünstigen, Niemand aber das beabsichtigte Resultat auf andere Weise erzwingen, als durclı eine solclıe Vervielfältigung der Beobachtungen, dass jener günstige Zufall dazwischen fallen muss; eine schwerlich dankbare Aufgabe! Denı bei den darmfülırenden Magenthieren ist eine solche Beobachtung $\mathrm{mm}$ Vieles leichter zu machen, häufig genïgt, um das Vorhandensein einer zweiten Oeffnung darzuthun die Auffindung einer Cloake einer stets an derselben Körperstelle sich ansammelnden Menge von Nahrungsstoflen, in deren Nähe die Afteröffnung sich zu fimden pflegt — und die zweifellıaften Arten würle man vielleicht so lange imthümlich zu den darmlosen zählen, bis andere Merkmale, ihre richtige Stellung ihnen anzuweisen, ermittelt wären. - Um diesem Unterschiede endlich jede Aussicht eines durchgreifenden Eiuflusses auf die Systematik zu entziehen, stellen sich auf die Grenze der darmlosen und darmfülıenden Magenthiere die Amoebeen und Arcellinen mnit stets veränderlichen Körper, wo die Stelle, welche den Mund, der gefressen hat, bildete, schon im nächsten Augenhlicke aus dem Parenchym des Körpers nicht wieder zu sondern ist, und selbst bei giinstigster Beobachtung eine Entscheidung iiber dlie Identität der Aufnahms- und Ausscheilungs-Oefhung ganz unmöglich bleiht. - Kur eine bestimmte Entscheillung dieser Frage ist einestheils sehr schwierig, und anterntheils von geringem Nutzen.

Die für Organe beiderlei Geschlechts gedenteten 'Theile hahen bei diesen 'Thieren nur die Deutung von den darmführenden ühertragen erhalten und kann daher von ihnen nur dasselhe gelten, was bei der später lolgenden Untersuchung der Letzteren sich herausstellen wird.

\section{Erste Fanilie. Momalina.}

Eine ganze Reihe negativer Kennzeichen macht es möglich, ein Thier als zur Monadenfamilie gehörig zu erkennen. Es sind die darmlosen Magenthiere: ohne äussere Organe, ohne besondere Körperhülle, und ohne die Fähigkeit willkürlich die Form des Körpers zu verändern, welche rumd lis länglich oval vorkommt. Die Individuen finden sich zu zwei, oder durch gleichzeitige Iängs- und Quertheilung zu vier vereinigt, bilden jedoch nie Ketten und Bänder.

Wahrscheinlich gieht es 'Thiere, die so klein oder so durchsichtig sind, Jass im Sehfelde des Mikroscops mur dichtgedrängte Haufen in rascher Bewegung wahrgenommen werden. Ehrenberg setzt die Grenze unsers Sehvermögens auf den Durchmesser von 1/3000 Linie, unl es ist riclitig, dass man so feine Objecte wahrzunehmen im Stanle ist; für durchsichtige und bewegte Gegenstïnde darf man jedoch die Hälfte ahrechnen, wenn von wirklichem Sehen die Rede sein soll. In einem Troplen, 

-

、

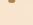


der von sehr kleinen Monaden winmelt, ist es schwierig zu einem wirklichen Sehen zu gelangen, weil je stärker die Vergrösserung, um so melı auch der Brenupunkt der Objective einem matheınatischen Punkte ähnlicher wird; es müssten deshalb die Monaden sich genau in einer Ebene bewegen, welche gegen die Selıachse des Mikroscopes einen rechten Winkel bildete, wenn mehr wie eiı flïchtiges durch den Brennpunkt fahren derselhen wahrgenommen werden sollte; höchstens lässt dabei sich Form und Farbe erkennen, und in anderen Beziehungen ganz verschiedene T'hiere könnten denselben optischen Eindruck machen, was eine grosse Unsicherheit zu Wege bringt. Bei Versuchen zwischen geschliffemen Glasplatten solche 'Tropfen ganz flach auszubreiten, nachdem sie mit reinem Wasser verdiinnt sind, sieht man zuletzt nichts mehr, wemn alle Bewegung aufgehört hat; weil die rohenden 'Thiere einzelı zu klein oder zu lurchsichtig sind. Eigenthümlich ist es daher auch, dass hei manclıen Gattungen dieser kleinsten 'Thiere, von Form und Grösse abgesehen, die Unterscheidung der Arten durch Kennzeichen möglich gentacht wird, zı deren Ermittelung es des Mikroscopes gar nicht weiter bedürfte, wie das Vorkommen, die Färbung, welche sie den Wasser nitheilen etc.

Genug! die Familie der Monaden verhält sich zur Zoologie, wie die Mythe zur Greschichte, und hier, wo crst ein System zu dännmern beginnt, ist noch kein nrbares Land für physiologische Studien.

Um so entschiedener gilt es aher Alles von diesem Gebiete zurïckuneisen, was in der That nicht hierhergehört. Eiıe voreilige Alschliessung der für die organische Welt gültigen Gesetze und taktlose Anwendung derselben zu theoretischen 'Trugschlüssen, statt sorgfältiger Prüfung in der Natur selbst, hat oft zu der jeden Grundes enthehrenden Auffassung verleitet, als ob organischer Ursprung, geringe Grösse und Bewegung genügten, un eine Monaden-Art zu characterisiren. Nicht hestimmt genug kamı es darum hervorgehoben werden, dass auch die Monaden wirkliche Thiere sind, welche entstehen, zu einer gewissen Form und Grösse sich entwickehn und wieder vergehen, welche an bestimmten Standorten in besonderen Jahreszeiten in überwiegender Menge gefunden werden und an anderen oder denselben zu anderen Zeiten fehlen - kurz, dass es die Consequenz erfordert, ihnen dieselbe scharfe Begrenzung der Species und die selbsständige Individualität der einzelnen zu iibertragen, welche allen anderen 'Thieren zukomint, wo dem letztere genigt, Alles Fremdartige mit einem Schlage abzusonderil.

Auf einen anderen anch physiologisch wichtigen Punkt sei es erlaubt, hier nochuals zurïckzukommen, nämlich die Grenze unseres Selıvermögens und die Durchmesser der Atone. Elreuberg fïhrt bei Monas 'T'ermo eine Berechnung anf, wonach die W'heilbarkeit der organischen Atome mindestens weiter wie his 1/12000 einer Linie reicht. Was jenseit dieser Grenze liegt, kann fiiglich unerörtert hleiben, da es nur larauf ankomnt, bis wie weit wir sehen kömnen. Eine Priifung der Angaben Ehrenbergs in der Natur, namentlich Messungen und Fiitterungen voı Monas Termo, wäre eine höchst schwierige Aufgabe, sobald das Resultat allseitiges Vertrauen verdienen soll. Ich habe daber vorgezogen, eine Gegenprobe an Objecten zu versuchen, wo mir die organische Materie äusserst fein vertheilt schien, und eine ziemlich genaue direkte Messung zulässig ist. — Vielleicht gieht es kanm organische Wesen oder Theilchen derselben, deren Durchmesser im strengsten Simne des Wortes gleich gross sind; es wird viehmelı eine individuelle Verschiedenheit ïberall anzunchmen sein und eine genaue Messung sehı kleiner Körper ist deshalb unmöglich, wenn nicht ihre Lagerung in geordneter Reilıe eine grössere Zahl zugleich der Prüfung darbietet. In letzterem Falle kanı jedoch ein Resultat, welches allen hilligen Anforderungen in practischer Hinsicht genügen möchte, auf folgende Weise erzielt werden: Da bei allen Methoden, welche zmr Bestimmung der Grösse durch das Mikroscop betrachteter Gegenstände vorgeschlagen sind, der Beohachter stets eine Reilıe von Vorsichtsmaassregeln im Auge behalten muss, um keine 'Täuschung mitunterlaufen zu lassen, so verdient die einfachste, das heisst die direkte Messung, vor allen den Vorzug, weil sie die sichersten und jeden Augenblick einer neuen Prüfung zu unterwerfendeu Resultate liefert. Zu diesem Zwecke legt man den zu messenden Gegenstand auf einen richtig getheilten Glasmikrometer, so dass die Theilung und das Object zugleich 
im Focus sind und die Grösse des letzteren gleich abgelesen werden kann. In diesem Falle ist man vor allen Einflüssen, welche durch ungleichen Druck, Federkraft, ungleiche Einstellung des Focus, todten Gang der Schrauben etc. bedingt werden, sicher und wird bei hinreichender Vergrösserung und Helligkeit stets dasselbe Resultat herauszälılen, nur müssen die Objecte sehr dünn sein und ganz flach aufliegen, um auch bei stärkeren Vergrösserungen mit der Theilung im Focus gehalten werden zu können. Um diesem Uebelstande zn begegnen, habe ich die Theilung des Glasmikrometers mit schwarzen Strichen auf ein Blatt Papier durch den Sömmeringischen Spiegel übertragen und die Objecte auf diesem Papiere ebenfalls durch den Spiegel nachgezeiclınet und gemessen, was gleich befriedigende $\mathbf{R e -}$ sultate gab, so lange nur das mittlere Dritheil vom Durchmesser des Sehfeldes zur Messung benutzt wurde.

Die Gegenstände, welche zu so feinen Messungen ausgewälılt wurden, zeigten anl einer ganz oder theilweise durchsichtigen Fläche sehr dichtgestellte und schmale Streifen, wie der RegenbogenAchat, Perlenmutter, Bacillarien, Schmetterlingsschuppen, oder feine Federchen und Härchen, wie die Ruderarme der Daphnien und einzehner Räderthiere etc. Fin solches Object liegt auf einem in 30 'Theile der Pariser Linie getheilten Glasmikrometer im Sehfelde, der Körper des Mikroscopes wird durch ein rechtwinkliches Prisma unterbrochen, vou welchem ein lıorizontaler Arm ausgeht, der das Ocular und deñ Sömmeringischen Spliegel trägt: letzterer wirlt das Bild des Objectes auf ein Blatt Papier, worauf die 'Theilung des Mikrometers in der angewandten Vergrösserung genau entsprechendem Verhältnisse mit schwarzen Linien angegeben ist; im $\mathbf{O c u l a r}$ befindet sich ein Spiunfüdenkreuz, als Marke, woran die Messung beginnt. Nachden unter einer schwächeren Vergrösserung die Streifung des Objectes so gelegt ist, lass sie mit einem Theilstriche ıles in Quadrate getheilten Mikrometers rechtwinklig steht, wird die stälkere Vergrö̈sserung angeschroben und das Bild der Theilung des Mikrometers durch den Sömmeringischen Spiegel zn der Theilung anf dem Papier so gestellt, dass die Theilstriche sich decken; dann wird der ${ }^{\circ}$ Spimfaden im Ocular auf einen Streifen des Objectes gedreht und ron diesem aus die Zälılung begonnen. Nach diesen Vorbereitungen habe ich zumächst die Zuverlässigkeit đles im Sömmeringischen Spiegel beobachteten Bildes geprüf, indem ich dasselbe Object auf dem Mikrometer direkt gemessen und dann im Sömmeringischen Spirgel an der ïbertragenen 'Theilung nachgezählt und dieses Verfahren so lange wielerholt, bis ich vïllig geniigente und ganz iibereinstimmende Resultate erhielt mol femerhin der Verpflichtung entging, jedes Ohject auf die Mikrometerplatte zu bringen, so wie auch auf nichi ganz ulurchsichtigen Splittern des Regenhogenachats, des Perlemmutter's etc. zuverlässige Messungen anstellen kommte.

So wurle der Zweck eneicht, die bei ler Messung sehr kleiner und einzeln vorliegender Körperchen noch möglichen Fehler aul viele jedenfalls so zu vertheilen, dass ilı Einfluss von geringer Bedentung sein konnte. Fullich wuden dieselben Messungen sowohl mit dem Schranbemmikrometer, als auch nach dem Mikrometer im Oculare wiederholt und ïbereinstimmende Resultate erzielt. Das Ergebniss drückt sich am klarsten in der Angahe ans, wie viele solcher Streifen etc. anf dem Ihaume einer Pariser Linie in der Wirklichkeit vorkommen wïrlen, was sich durch eine sehr einfache Rechmung ergab: die 'Theilung des Mikrometers zerlegt die Pariser Linie in 30 gleiche 'Wlıeile; die Zeichıung dieser 'I'leilung durch den Sömmeringischen Spiegel giebt bei einer gewissen Vergrösserung einen Abstand der 'T'lueilstriche anf dem Papiere von 12 Linien, so ist die Vergrössermug 360fach, und zähle ich auf jenem Alıstmule von 12 Linien 24 Streifen der 'T'heilung des Objectes, (also 2 pr. Linie in der Zeichnung), so ist die Streifung so lein, dass in der WVirklichkeit $2 \times 360$ also 720 Sureilen anf die Linie kommen. Bei feineren Streilungen wie diese trifft man hïufig den Uebelstand, wie namentlich bei den Bacillarien im. Kieselpanzer, dass die Zwischenräume mud die Streifen sellıst nicht in einer Ebene liegen; un bei der Zählung der Streifen sich nicht zn verwirnen kann die Vergrösserung lis 1000 mml selbst 1500fach gesteigert werden, und man muss, un dic Gränze der Streifen oder die ihrer Zwischenräume möglichst klar zı sehen, den Fucus verschieden einstellen. In diesen Falle 

halse ich die Streifen selhst möglichst scharf eingestellt und ihre Mitte bei der Zählung fixilt. — Bei nachstehend ver»eichneten Objecten ergaben sich folgende Resultate:

\begin{tabular}{|c|c|c|c|}
\hline Doject. & $\begin{array}{c}\text { Streifen-Zahl } \\
\text { pr. Pariser Linie. }\end{array}$ & Dbject. & $\begin{array}{c}\text { Streifen-Zahl } \\
\text { pr. Pariser Linie. }\end{array}$ \\
\hline 1. Gallionella sulcata & 600 & 6. Polyartha platyptera (Flosse) & 1560 \\
\hline 2. Perlemmuter (variirend) ...... & $600-800$ & 7. Navicula macilenta.......... & 1920 \\
\hline 3. Regenbogen-Achat......... & 900 & 8. Hipparchia Janira (Flügelschup- & \\
\hline 4. Navicula (Pimmularia) virilis .. & 1200 & pen, Queerlinien.) & 2600 \\
\hline 5. Navicula baltica ........... & 1300 & & \\
\hline
\end{tabular}

Die künstliche 'T'heilung bestimmter Masse lässt sich durch mechanische Mittel gewiss bis zu einem höheren Grade von Feinheit treihen, als mit den besten Vergrösserungen bis jetzt unterschieden werden kann; wie $\mathbf{N o h e r t ~ m i t ~ s e i n e m ~ s o g e n a n n t e n ~ P r i ̈ f e l ~ v e r s u c h t ~ h a t . ~ D i e s e ~ f e i n e n ~ ' T ' h e i l u n g e n ~}$ sind jedoch, wie ein Vergleich erkennen lässt, ungleich schwieriger richtig zu heleuchten, wie deutlich zu sehen. - Ein von Schiek in 1/30" getheilter Glasmikrometer (von 1838) zeigte mir 'T'heilstriche von 1/300" Breite. deren also bei gleichen Zwischenräumen 150 ant die Linie gezogen werden kömnten. $\mathbf{O b}$ erhä user theilt jetzt den Millimeter in 1/50 und 1/100 duch Theilstriche von 1/400 Millimeter Breite, deren bei gleichen Zwischenräumen also ungefälır 400 anf die Linie gezogen werden könnten. Noberts Priifer zeigt in 10 Gruppen 'Theilstriche von verschiedener kaum noch messbarer Breite, in folgenden Abständen (durch Rechmung gefunden?)

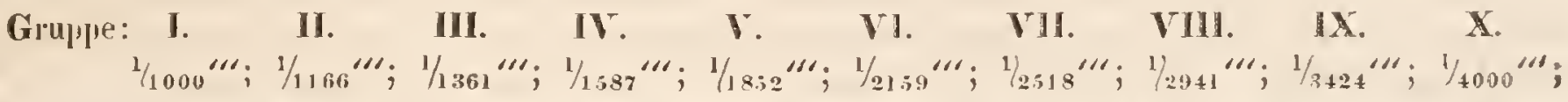

Fïr alle natiolichen Objecte tritt bei sehı starken Tergrösserungen (1000fach und mehr) der Uebelstand störend in den Weg, dass die 'Theilstriche nicht iiberall gleich scharf sind und nicht mit den Zwischenräumen zngleiclı deutlich im Focus erscheinen; nu vie uben angelïhten Objecte des Regenhogen-Achats, welcher in zu diesem Zwecke geschliffenen Platten untersucht wurde, und die Wlossenstrahlen des Buiderthieres Polyartha platyptera E hrlog.; welches leider selten zugänglich sein wird unl bei der ungeneinen Durchsichtigkeit der F'lossen ein höchst schwieriges Object liefert. sind frei von diesem Nachtheile. Von den Bacillarien scheinen last alle eine ziemlich gleiche Streifung zu zeigen, mit Ausnahme der 'Theilung auf den stielrunden, wie Gallimella sulcata z. B. wo llie Theilstriche gegen den Mittelpunkt convergiren und Navicula baltica. wo die Zwischenräune breiter erscheinen wie die Streifen selbst, wälıend bei Navicula virillis und macilenta fast gar kein Zwischenıaun wahrzunehmen ist. Die leineren Queerstriche zwischen den Längsstreifen der Flïgelschuppen mancher Schmetterlinge wie Hipparchia, Pieris, Lycaena etc. sind daher auch leichter zu zälleı, weil ihre Zwischenräume elwas grösser sind, und hei ihnen das Auge ehensoviel Zuwisclienräume als Streifer unterscheidet, also nach obiger Messung etwa 5000 0bjecte pr. "“. Zwischen einer solchen Sehuppe und dem Nobert'schen Priffer ist aber ein grosser Unterschied, indem man lie Streifen in der Schmetterlingsschupe ungleich dentlicher sielıt, wie selbst die erste Gruppe jener 'Theilung. was nicht durch die Alsstände, sondern nur durch die auch bei starker Belenchtung bestimmier bleibende Srliattengränze bedingt sein kann.

Obgleich bei ohigen Messungen nicht Alles erschöprt ist, was vielleicht durch Feinheit der Objecte oder Stärke der Vergrösserungen erreicht werden kann, so ergiebt sich loch zur Geniige, dass selbst bei der hier vorgeschlagenen Methode die Messbarkeit der Objecte bei 1/5000" aufhört practischen Werth zu behalten. Feinere Streifungen, kiornige Triibung und zahlreiche bewegte Objecte kann man olne Zweifel wahrnelınen, alıer unser Urtheil dariher sagt nur, lass sie kleiner sind wie 
jene Grenze, die jeder Beobachter auf die angegebene Weise für seine Individualität und jedesmaligen Hülfsmittel genauer feststellen kann.

Fïr mich diente als letz.te Probe in der Wirklichkeit die Theilstriche von Noberts Prïfer nachzumessen, welches ich mit $\mathbf{N o b e r t s ~ L i n s e n ~ a n ~ e i n e m ~ S c h i e k s c h e n ~ M i k r o s c o p e ~ b e i ~ 1 5 0 0 f a c h e r ~}$ Vergrösserung bis zur siebenten Gruppe ausführen komnte. Die Abstände betragen hier nach der Angabe $1 / 2518$ " und ich fand 2100 Theilstriche pr." ". Wenn sich jedoch für solche Messungen mur his zu 1/2000" die Richtigkeit sicher verbürgen liesse, so müchten kaum einige von den Lesern unbefriedigt hleiben. -

Alle Geschöpfe, deren Durchmesser den 200" Theil einer Linie nicht erreicht und welche sich lebhaft bewegen, bieten dem Beobachter die grosse Schwierigkeit, dass sie unter dem Mikroscope nur momentan im Focus erscheinen, um eben so schnell wieder daraus zu verschwinden; es ist fast unmöglich, sie zwischen Glasplatten festzulegen, und an getrockneten Exemplaren lässt sich so wenig bemerkenswerthes unterscheiden, dass es vor der Hand wohl nur möglich sein wird Monaden-\$ chwä Irme zu bestimmen, während die Entscheidung ïber vereinzelt vorkommende Indivituen noch immer zweifelhaft bliebe. Dabei ist wohl zu beachten, dass Monaden-Sclıwärme in der Natur mur zu gewissen Jahreszeiten unter giunstigen Bedingungen und selten längere Zeit liudurch an demselben Fundorte in reichlicher Menge angetroffen werden: dahei melren sich die Erfahrungen, dass wie die lılanen Blumen auch weiss und roth vorkommen, alle grimen Infusorien auch roth und farblos geselıen werden, theils im Entwickelungsznstande, theils als constante Varietät in besonderen Gewässern. Nimmt man zu diesen Bedingungen hinzı, ıass kein Natuforscher im Stande ist, die Veränterungen des Lebensprocesses oder von anderen Inlusorien abweichender Organe bei den Monaden, Vibrionen etc. zu verfolgen, so bleibt es sehr schwer, eine Species derselben zu characterisiren, da zu dem Ende im strengsten Sinne nur die Form der Monade ïbrig bleibt, ein Kennzeichen, welches nicht sowohl durch die Qucerund Längstheilung, - denn diese Schwierigkeit ist zu üherwinden -, sondern ehenfalls durch die vielleichı ungleichförmige Ausbillung, nur cinen precairen diagnostischen Werth lehanptet.

Bei dieser Lage der Dinge wird es jeder Vermiinftige mit mir für vergebene Mühe erklären uber den Werth der von Ehuenber"g aufgestellten Gatungen und Arten zu verhandeln, bevor nicht verbesserte Instrumente oder Methoden zu einer Prüfung berechtigen, welche positive Ergebnisse zu liefern verspricht. Ohme daher irgend eine nicht erwähnte Alt mehr verdïchtigen zu wollen, wie es Ehrenberg selhst zuweilen schon gethan, will ich nur an Beispielen zeigen, in welcher Beziehung seit der Veröflentlichung des grösseren Infusorienwerkes sich die Fragen, deren Beantwortung erforderlich wird, verändert haben: an Beispielen, welche nach der Reihenfolge jenes Werkes unter solchen Arten ausgewählt werden miissen, deren nähere Untersuchung mir zngänglich war. - -

Die erste Gattung Monas, fïr die nur negative Kennzeichen unterscheidend sind, mag leicht sehr verschiedenartige Whiere unfassen; welcher 'Wriunph ist es jedoch für die Wissenschaft, das ganze Chaos infusorium Linnés bis aú einzelne Arten dieser eiuen Gattung erobert zu sehen! Die Monaden haben mit len iibrigen polygastrischen Infusorien einen gallertartigen Körper, in welchem tribere Punkte vorkommen, gemein; dieser Körper ist nackt, nur ein einfacher Wimpernkranz oder walıscheinlicher eine stärkere, zum Rüssel verlängerte Wimper iiber der Mundölliung als Bewegungsorgan - also gleichsam das Minimum der Organisation oder lesjenigen, was zu einen 'Thiere überhaupt erforderlich ist — und dabei der Mangel aller Merkmale, welche andere Formen kenntlich machen, als besondere Bewegung, Schwanz, Lippe, Augc etc. machen es möglich, die Monaden zu sondern. Für die Zukunft der Arten dieser Gattung gicbt es zwei Möglichkeiten, inden schärlere Beobachtung vielleicht die Entwickelung einiger zu bekannten böhern Formen nachweist, oder Organe an ihnen ermittelt, welche andern Gattungen eigenthümlich sind: erst nachdem diese Beobachtungen erschöpfend durchgefiihrt sein werden, künnen für die wahren Monaden positive Kenneichen aufgeführt werden. In diesem Sinne ist folgende Uebersicht der Gattungen zu beurtheilen: 
, 


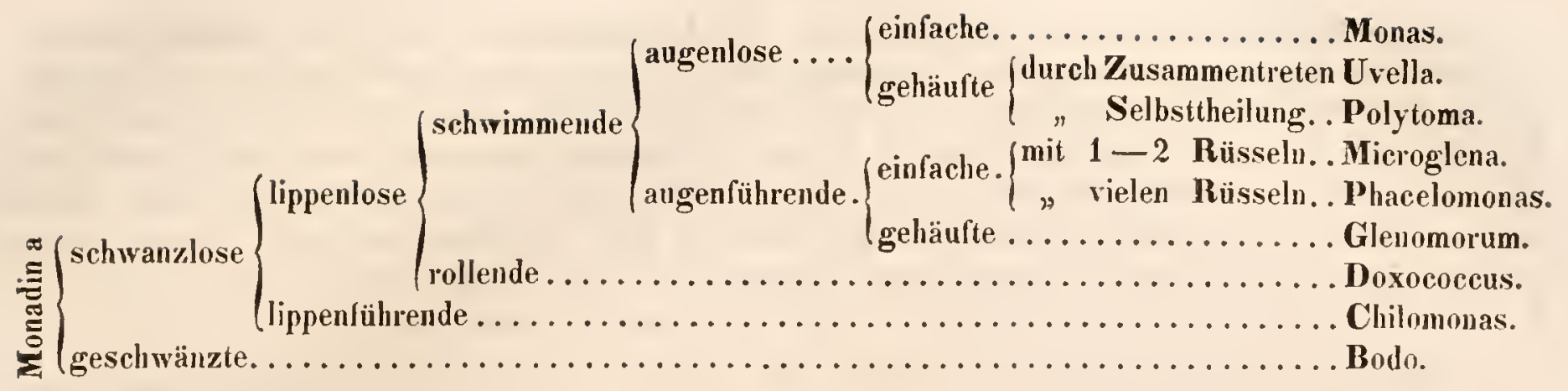

Eine Erläuterung dieser Uebersicht künnte, da dieselbe theoretisch so klar und einfach ist, nur niitzen, wenn sie practisch und duch Zeichnungen erläutert wäre; ich ziehe es jedoch vor anf die schwierigsten Punkte zurückzukommen, wenn die ganze Reihe der polygastrischen Infusorien geprüít worlen ist, und gehe daher zu einer Betrachtung ler Arten der Gattung Monas über.

1) Monas. Die ersten drei Arten: 1. M. Crepusculum, 2. Termo und 3. Guttula haben sich mir so zu erkennen gegeben, dass ich glaube sie wenigstens mehrfach richtig bestimmt zu haben, namentlich M. Guttula. Versuche diese Thiere durch das Zusammendricken plangeschliflener Glasplatten festzulegen, sie anzutrocknen; zu füttern etc., habe ich nicht bis zu dem Grade von Sicherheit fortgesetzt und wiederholt, dass ein nenes himeichend verbürgtes wisscuschafdiches Pesultat daraus gezogen werden könnte, weil mir ein solches Verfahren zu undankbar erschien, und aus den oben dargelegten Gründen auch kaum zu Aufklärungen lühren könnte. 4. M. vivipara habe ich nicht gesehen, doch möchte sie, da die angeführte Erscheinng sich bei vielen grösseren Magenthieren bcobachten lässt, iliren Speciesuamen wohl nicht mit Recht führen. 5. M. grandis ist zu selten beohachtet, um in allen Bezichungen scharf beurtheilt werden zu kümnen. 6. H. bicolor ist schon von Ehrenberg selbst als zweifchaft angeführt und auch 7. M. ochracea verdient eine schärfere Priffung; weil staubige Anflige anf dem Wasser im Frïhlinge so oft mit der Entwickelung anderer Formen zusammenhängen. 8. M. erubescens und 9. M. vinosa, wovon ich letztere allerdings häufig sah, bieten durch ihre langsame zittende Bewegung wenig Garantie lafür: dass sie wirklich Thiere sind; oft habe ich noch bevor jener rothe Anflug erscheint, welchen M. vinos a in abgestandenen Infusionen ron Pflanzentheilen bilden soll, nach lebhafter hewegten 'Thierchen gesucht, jerloch vergebens. Zudem ist es sehr wahrscheinhich, dass alle rothen Formen unter günstigeren Verhälnissen eine grüne Farbe annehmen, und sind laher dieselben mit anhaltender Aufmerksamkeit zu verlolgen. 10. M. kolpoda, 11. M. enchelys, 12. M. Imbra und 13. M. hyalina sind mir nicht vorgekommen, Elı enbergs eigene Angaben dariiber legen jedoch die Vermuthung nahe, dass bei minder klarer Vergrösserung und olme farhige 'Tribung im $\mathbf{W}$ asser etc. ein oler das andere Kennzeichen an diesen Formen iibersehen sein künnte. 14. M. gliscens habe ich oft genug gesehen, ohne bei Ermittelung der Organisationsverhältnisse glücklicher gewesen zu sein wie Ehrenberg; es scheint mir jedoch, als ob sie ron den wahen Monaden Juch die schon ron Letzterem beschriebene 'I'heilung etc. getrennt werden müsse. Von 15. M. oralis und 16. M. mica gilt dasselbe, was ron len ror M. gliscens aufgelülıten 4 Formen bemerkt ist und 17. M. pun ctum hat ebenfalls eine Organisation, die sie von den walıen Monaden sondert. - Demnach zerfielen die 17 Munt- und Fi-Monaden Ehrenbergs in 4 Arten M. Crepusculum, 'lermo, Guttula und vivipara, welche ziemlich sicher für Monaden genommen werden können 2 M. gliscens und Punctum, von denen sich vermuthen lässt, dass sie anderen Gattungen zugetheilt werden miissen, und den übrigen, von welchen es überhaupt zweifelhaft hleibt, was es für Thiere gewesen sind.

Unter den Stabmonaden, welche nun folgen, ist 18. M. cylindrica Ebrenberg selbst verdächtig, 19. M. Okenii schon der rothen Farbe wegen genauer zu prüfen; dass sie mit Euglenen und 
Ophidononas zusammen vorkam, dient nicht dazı, ihre Selbsständigkeit fester zu verbïrgen, woruber ich jedoch auf Euglena und Leucophrys verweisen muss. 20. M. deses, welche grün sein soll, in dem mir zugänglichen Exemplare von Ehrenbergs Werk aber farblos dargestellt ist, bietet gar keịne Sicherheit als vereinzelt betrachtete Form; 21. M. socialis möchte doch sehr schwer von Uvella glaucoma zu unterscheiden sein; 22. M. flavicans dürfte bei schärferer Beobachtung ein Auge zeigen und wäre dann zu Uroglena oder, wenn das Auge wirklich fehli, zu Synura zu ziehen, wie im ersteren Falle 23. M. tingens schon in Glenomorum verändert ist; von 24. M. simplex, 25 . in anis und 26. scintillans gilt das oben vom M. Kolpoda und den folgenden Arten gesagte.

Somit giebt es miter den 8 Stabmonaden (M. tingens bereits abgerechmet) keine einzige Form, welche ich hätte bestimmen kömmen, oder worüher die bisherigen Beobachtungen 'I'ıatsachen ermittelt. hätten, die \%ur Aufstellung einer bestimmt characterisirten Speries den Weg balınten.

Eine solche Kritik bedarf nicht der Wissenschalt, wohl aber den Lesern gegenüber eine Erläuterung. Nicht aus lusst zu tadeh ist sie geschieben, nicht aus Ehrfurcht vor dem Namen Ehrenbergs unterdrïckt, nur ganz eingeweilıte Sachverständige, deren es sehr wenige gieht, wiirden sie richtig beurtheilen künnen. Un Andere auf den rechten Standpunkt zu stellen, betlarf es zunächst der Erklärung, dass in dem ganzen Werke Ehrenbergs bei irgend einer anderen Gattung etwas Aehnliches gar nicht wieder möglich wäre, und die Gattung Monas, welche sich, wie angefïlıt, durrh negative Kennzeichen unterscheidet, natürlich Alles unfassen musste, wovon die Kennzeichen unter minder günstigen Bedingungen nicht beobachtet werden komnten. Was Ehrenberg zur Festhaltung dieser Formen hewog, mag neben dem Interesse, welche ihre Beobachtung in entlegenen Gegenden, in Geseltschaft von Alexander von Humboldt, nud beim ersten Erfassen lieser nenen Welt, zugleich in den riesigen Fortschritten gelegen haben, welche die Auffindung nener und die Srstematik ler gefundenen Formen unter seinen Händen machte. Letztere durten auch dem hesoniensten Forscher für eine Reihe von Schlussfolgerungen die Bestätigung in ler Natur in uahe Aussicht stellen, wovon auch nur Wenige noch anf ihre letzten Beweismittel warten. Dass während der Zeit des Sammehs und Beabeitens jeder Beobachter an seinem Stofe selhst sich billet, dass sein Urtheil über schwierigere Fragen nach Beenligung eines grösseren Werkes bei weitem mehr Zutrauen verilum, wie vorher, leuchtet von selbst ein; diese Ausbildung des Beobachters ist jedoch eine allmählige, wälnend jeller Beohachtnng dieselhe wissensehaftliche Sorgdalt, jedem Berichte dieselhe trene Unpartheiligkeit gewidnet scheint. Dazu kommt. dass alle Beohachtungen mit dem Mikroscope, vor dessen leizten Verbesserungen, zu einer Zeit genacht wurlen, wo man noch sagen konnte, Jeder sah durih dieses fustrument, was er wollte, und Jeder etwas Anderes; zu einer Zeit. wo es vor allen Dingen gali, diesem Insthumente den Credit zu verschaffen, welchen es gegenwärtig durch die mühvollen Untersuchnngen geschickter Beobachter mit vollem Rechte in Anspruch nehmen darf. Es musste bewiesen werlen, dass die 'Täuschmmen Anderer, bei geeigneter Sorgfalt vermieden werden kömnten, und es war besser keines der Resultate. welche dalurch geliefert waren, irgend einem Zweifel bloszustellen. Jetot ist fiir die streitigen dasselhe Verhälniss eingetreten, in welchem Ehrenberg von den Beobachtmgen O. F. M iillers sagi, dass, ob ihmen die identische Furn zum Grunde lag oder nicht, nie meh" wird sicher \%u entscheiden sein, weil Instrumente unl Methoden sich bis zu lem Grade verbessert haben, Jass Manches mit Sicherheit getrennt werden kann, was früher aus Mangel an Unterscheidungszeichen \%usammentallen musstc. - Fïr die Wissenschaft wäıe es daher jedenfalls ein Gewinn, die ohen als zweifelhaft bezeichneten Arten, obgleich sie nach allen Anfordermgen, welche in dieser Beriehmg \% machen waren, autgestellt sein mögen, dagegen aber sich der Kreis der IIülfsmittel, welche der Beohachter anwenden kann, erweitert hat, ganz fallen zu lassen, da an ein Wiederlinden dersellsen frormen in jenen Gegenden schon deshall, nicht zu denken ist, weil sie unter den stäıkeren Vergrösserungen doch jedenfalls einen anderen Eindruck machen wiirden, wie die Abbildungen auf $\mathbf{E}$ hre nbergs erster 'Tafel. 

Nan halte liese Wröterming anch nicht für eine mussige. Mit den Monalen hegimnt für uns die Reihe der Thiere, so viel wir wissen, freilich mur der Grösse nach; sie scheiden sich jedoch von ihren verwandien Gattungen durch negative Kennzeichen al,, und es giebt allerdings einen Unterschied, ob wir in diese Categorie 4 - 6 Arten zusammenstellen missen oder 25. - Vun zwei verschiedenen Ansichten üher den Thieruganismns, wo nach der einen: zn jedem 'Thiere ein gewisser Complex von Apparaten und Functionen gehürt, nach der anderen: auch das 'Thier, wie die Pflanze von einem r.infacheren Bane alluählig in der mganischen Reihe zu einem zusammengesetzteren aufsteigt, passt eine grosse Arten Zahl zu dem Begriff Jer Gatumg Monas schwerlich bei letzterer, wenn es je dahin $z u$ bringen ist, dass eine natürliche Systematik im Gegensatze zn einer künstlichen, wie bei den Pflanzen, sich his anf die Gattungen und Arten durchlühren lässt.

Wer einen Zeitraum hindureh sich auf den übrgen Seiten des Ehrenbergiseben W'erkes über die Infusorien Belehrung suchend beschäftigt hat und zu Monas zurïckkehrt, sollte glauben; diese Gattung sei von einem anderen Verlasser bearbeitet. so sehr sticht alles Sןätere durch Klarheit und Sclärfe in älmbicher Weise dagegen ah. wie die erste 'Tatel des Atlasses gegen die lulgenden. Diese Verschiedenheit ist aher vollkommen naturgetreu: jedem Beohachter, dem es nicht einzig und allein um Systeme und Klassen zn thun ist, wird sich dieselhe Vorstellung aufdrängen, wenn er von einem Gebiete auf das andere hinüher streift. als ob er bei der Gatmng Monas aus hellem 'Tageslichte plïtzlich in Dämmerung gerathe. mul die Ursache liegt offenhar allein in der Blödigkeit unserer Simne. Gleich die beillen folgenden Gatmugen 2) Uvella und 3) Polytoma zeigen den Beweis, durch die sichere Unterscheidung so klemer und sieh so ähnlicher Formen in überraschender Weise; hier lehlt offenbar nur eine sorgfältige Prüfung bestimmt vorhandener 'Thierformen. $11 m$ noch hörhstens ïher llie Stellung einer oder der anderen $\mathrm{f}$ 't $\%$ diesen Gatungen zu entscheiden.

4) Microglena. Augemmonade. Ein hesomderes physiologisches Interesse nimmt diese Gattung in mancherlei Beziehung in Anspruch: sie eröfner zunächst eine ganze Reihe gelärbter 'Thiere. welche nie farbige Nahrung aufnahmen, lagegen in ihıem Innern älntiche Blasen erkennen lassen, wie hei grösseren oft mit Wasser erfiillt vorkommen: dann ist es die erste Form, welche einen rothen Punkt (als Auge) zeigt, dessen Bedeutung so viellach hestritten worden ist, und endlich dentet ein constanter dunkler Körper in der Mitte les Leihes aul ein hestimmtes Organ, dessen Benlentung Ehrenberg als zu den Geschlechtsorganen gehörig ausgespruchen hat. In jeder dieser Beyiehungen mäge es hier genïgen, dass der Verfasser die M. monadina einer sorgfältigen Prüfnng unterwerfen kunnte und las constante Vurkommen ves rothen Punktes und dunkleren Organes bestätigte; eine Besprechung dieser Verhältnisse soll jedoch bei einer der folgenden Gattungen narhgeholt werlen, um hier die Angaben von K $\mathbf{K}$ tzing zu prïfen, nach welchen diese Form aus einer confervenartigen Alge hervorgehen und sich wieder dazu verwandeln soll.

In ciner Abhandinng: "Ueber die Verwandluns der Infusorien in niedere Algenformen* (Nordluausen 1844) behauptel l'rofessor $\mathrm{K}$ if $\mathrm{tzing}$ zunichst in der Vorrede, eine scharfe Grenze zwischen niedercu Thieren und Pflanzen zu ziehen sei nichl möglich, darum solle man liebcr gar keine annehmen, da es der gesunden Vernunft nicht widerstreile, dass beide geneinschaîtliche Anfangspunble hälten elc., fihrt sodann ( $\Gamma$. 2) eine Reihe Beobachtungen ïber Beweglichkeil ciniger Algenkeime und Saamenfäden an, die sebr scluwer mil lem folsconden in verniinftigen Zusammenhang gebracht werden können, und bestreilet ganz im allgcmeinen das Vorlandeusein thicrischer Charactere bei deu meisten von Ehrenbergs Polygastricis, beluauptet, aus diesem Grunde lube Ehrenberg auf die Vermehrung durch Theilung so grosses Gewicht gelegl und slellt dieser Theilung (der Individuen) die Theilung der Algenzellen (die doch Elementartheile desselben Individuums zı bleiben pflegen) als gleichbedeutend gegenüber. Vermisst man in dieser Einleitung lin und wieder eine ruhige Ktarheit und findel mancherlei, was offenhar gar nichl zusammengebört, in einem Athem genannt, so wiurde in ciner Einleitung darauf wenig Gewicht zu legen sein, senn aber Professor $k$ i $t z i n g$ (p. 5) anfijlırt bei Nayicula, Closterium elc. habe Ehre nberg die Aufnahtue von Intigo in die Magenzellen beobachtel, nnd dieser B e obachlung seine Behauptung: "aber diese Fäbung kamn ebensowol durcb nechanischen Einfluss slatılinden, " entgegengestellt, so hann derselbe dadurch nur sich uud seinen Geobachlungen scliaden, und es sprichi sehr frir die angefochtenen Ansichten Ehre ubergs, dass stall mil Thatsachen und Griinden, mil Behaptnngen dagegen zu Felde gezogen wird. Dann luejsst es: Bis dahin war nur Streit darum gewesen: 
1) "Ob die beweglichen Algenkeime wahre Infusorien seien oder nicht? " Das erstere ist nach meiner Ansicht ron keinem Naturforscher, der ein klares und geniigendes Mikroscop zur Verfïgung hatte, je bebauptet.

2) „Ob diese oder jene Organismen (Closterien, Desmidieen etc.) zu den Thieren oder Pflanzen gezăhlt werden müssten?" Dariber findet sich in der in Rede stehenden Sehrift nicht der geringsle Aufschluss.

3) „Ob sich niedere Algen oder andere l’flanzen aus Infusorien entwickeln könnten? "Ein solcher Streit ist meines Wissens, wenı von einer directen Entwickelung, ohne vorherige Auflösung in formlosen Stoff die Rede sein soll, nie gefïhrt worden, el ist von Professor $\mathrm{K}$ ii $\mathrm{tzing}$ zum ersten Male und hoffentlich zum letzlen Male auf solche Beobachlungen gestiitzl in die Wissenschaft eingeführt. - Die folgende Beobachtung soll diesen angeblichen Streit entscheiden:

Confera zonata W. \& M. (= Ulothrix zonata Ktzg.) zeigte am 8 . Nai 1842 bewegte grüne Körperchen in den Zellen, welche einen rothen Augenpunkt und eine Mundöfnung, wie die Monaden, hatten; spater 1844 wurde auch das fadenförmige Fiihlorgan (?) gesehen. K. behauptet, diese körper bätten sich mit der Mundstelle angesetat (gleichsaun festgesangt) und wären 2.1 jungen Individuen der Ulothrix zonata ausgewachsen. In der angefiihrten Schrift heisst es: ,ich habe mich aur das Bestimmteste iiberzeugt, dass die Microglena monadina Ehrbg. wirklich mit dicsen Körperchen identisch ist; 》auf die Ablzildnng in seiner Phycologia generalis verweisend. Dort befindet sielı auf Tab. 80 dieser Vorgang aligelsildet, im Texte heisst es jedoch daselbst bei Ulothrix zonata ( $\mathrm{P}$. 252): "Diese beweglichen hórperchen vermag ieh nicht vou der Infusoriengatlung "Microglena zu unterscheiden, und sie sind vielleicht mit Microglena monadina Elrenb. idenlisch. Diesc Annalıme scheint nmir $11 \mathrm{~m}$ so wahrscheinlicher, da dieselbe nach Ehrenb. unter "Conferven" vorkommen soll." Die Abbildungen auf Tah. 80 seiner Phycologia generalis zeigen einzelne Fäden der erwähnten Alge, nebst jenen griinen Körnchen mil einem rothen Punkle In verschiedenen Vergrösserungen; $K$ ii $I z$ ing giebt die Grösse dieser Köruchen, was allerdiugs auffallen muss, gar nicht an, in der 420fachen Vergrösserung anf Tab. 80. Fig. 11 messen in seiue r Zeichnung lie ausgetretenen rundlichen Körnchen etwa 1 Pariser Linie und wären demnach in der Wirklicbkeit 1/420", gegen Microglena monadina, die 1/on gross ist, also siebenmal kleiner. Wenn durch diesen Umstand Andere nicht in der Meinung ron der Identilät dieser kïrperchen mil Microglena monadina licfestigt werden, so wirl Professor kii $t z$ ing das nicht unbillig finden, so wenig wie die Frage, was denn ausser der griüen Farbe und dem rolhen Punkte bei so verschiedener Grösse noch Uebereinstimmendes an beiden zu finden sei? Nacls Ehreuberg Interscheidet sich Mieroglena monadina bestimmt durch eine dunklere, bandförmig plattgedriickte und hufeisenförmig gebogene Drise im milleren Theile des Körpers, von dieser fast dem Querlurchmesser des Thieres gleielıkommenden Driise ist jelloch bei $K$ ützing weler in der Beschreibung die Relle noch selbst in den 1800 fach vergrösserten Abbitdungen (Tab. 80 Fig. 15) etwas zu bemerken. In der erwähuten Ablıandlung: „Uelser dic Verwandiuıg der Infusorien ete. wird noch erwälnt $184 t$ also nach zweijiluriger Beobachtung sei auch: "das kleine fadenförmige Fïhlorgan (?) beobachtel, was die Vermuthung nicht eben ausschliessen lässt, es könne aucl, noch ein zwejtes der Art vorhanden

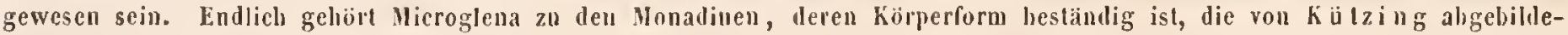
ten Algenkeime zeigen aber selır verschiedene Formen. - Somit slellte siclı folgendes Verhältniss heraus: Elırenlıerg bestimmle ein grïnes Infusorium mit Angenpmukt und I Riissel von beständiger fast lilgeliger Körperform mit einer milleren

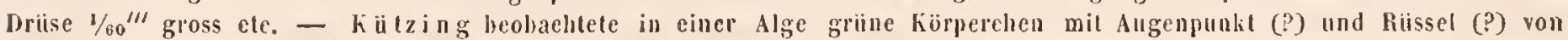
veränderlicher Körperform, ohne mittlere Driise und 1/420"Grösse. - Welches Zutranen verdient ein Beobachter, der sich

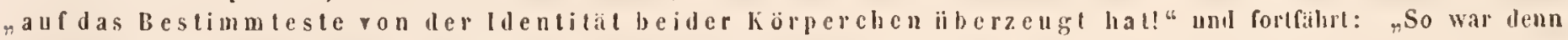
nachgewiesen, dass es bewegliche Algenteime gebe, welehe Elirenberg selbst für Thiere erklălt lial."

Hier könnte die heziehung jener Selırift zu Microglena erlöschen, die Wichligkeit des Gegenstandes irieischt jedoch eine Betrachtung des ganzen Inhaltes derselhen, welche daher lielier hier in Zusammenhange folgen möge, statt bei Chlamidomonas wieder aufgenommen zu werden.

Nachdem Professor K i t i ug (pag. 6) durch Erwhilınng der beobachuugen Ungers an deu Vaucheria-Sporen sich zu dem Ausspruche berechtigt glaulıt: „So wären denn anch bewegungsorgane bei den Algenheimen nachgewiesen." Folgen vier Citate von Gruithuisen, C. G. Nees von Esenbeck, Il ornscluch und Cassebeer, die gewiss kein Verniinftiger melır unterschreilsen wïrde und die Geschichte eigener, friblser von K. mit mangellaftem Mihloscope angestellter, lalier 2weifelhafter Beobachungen. Spiter sah $K$, dass die protococcoidischen Elementarformen auch unter ler schäifsten Vergrössermy manchen Monaden so ungemein ähnlich waren, dass sie sich wirhlich tuicht von denselben unterseheilen liessen. Ausfiihrlicher stellt lann K. die Geschichte der Ansichten iber den rothen Schnee und Ifaemitococeus pluvialis etc. zusammen, erwilint manchel Finwurfe, welche gegen El reubergs Deutung verschielener Organe hei Magenthieren gemacht sind, unl folgert aus dem historischen berieht: „dass man diese fraglichen Bildungen ehensowenig mit liestiumtleit zu den "Thieren als zu den Pflanzen zähen könne, und dass die Annahme in jeder Beziehnng gerechtfertigt erscheint, wenn man nhier cinen unmitteluaren beriihrungspunkt heiler arganische lieichen ancrkennt und den unmillellaren, dur:h gewisse Ent"wickelungsverhiltnisse begriindeten Uebergang alls dem eincn in das andere zugiebt." Fïr letztere Ansicht mö̈chte es Profezsor Kütziug doch viclleiclı schwer werden, Anhänger zn gewinnen, la jene Unentschiedenheit und Verwirung doeh wohl nur in der bis jetat so seltenen und naugelhaften Beolachtung jener Körperchen liegriudet sein möclate. Allerdings wird noch mancher Tag vergehen, bevor, was oft erforderlich, die fraglichen Bildungen wäluend eines ganzen Jahres Jureh alle Fntwickelungsstufen aus den verschiedenen Vermehrungsweisen, mit den möglichen Abindernngen nach Grösse, Form und Farbe etc. verfolgt, uml zwar unter Anwendung aller Ilülfsnittel, welche gegenwarlig cincm geibten Beobacliter zu Gelsole 
stehen, verfolgt sind. So auffallende Erscheinungen, wie der rothe und grüne Schnec dürften jedoch überhaupt nut zugălnglicher sein, $\| \mathrm{m}$ gleich darüber in's Reine zu kommen, wie im weiteren Verfolg dieser Studien noch nachizuweisen versucht werden soll. (Vergl. Euglena sanguinea). Mil grosser Wahrsiheiulichkeit lässt sich aber schon jetzl vermuthen, dass der angebliche dureh gewisse Enlwiekelungsverlitllisse begriindele unmiltelbare Beriihrungsunkt beider Reiche, wie ein schenes Gespenst, je weiter die Forschung dringt, um so liefer in das unseren bewaffneten Sinnen unzugängliche Gebiet von Monas Crepusculum ele. wird llüchten müssen.

Kü üing liefert dann eine Reihe Beobachtungen ïber Chlamidomonas Pulviseulus Ehrenbergs, um jeute Fehauptung dadurelı zu beweisen. Den Kern dieser Berichte bildell ausser ler Besehreibung dieses Thierchens una seiner Vermehrung durch Theilung folgende Stellen (1. 14): "Gleichzeilig bemerkle ich aber auch noch den Anfang eines confervenähll„lichen Gebildes, welehes mir ais diesen Thierchen hervorgegangen zu sein schen, denn es trug inı lumerı seiner Zillen „auffallende Merkmale, welehe man auch bei den rulsenden und bewegliehen Thierehen erkennen konute.... und (P. 16): „Es war klar, dass alle diese .... angeführten Körperehen eben auch nur Modificationen der Chlamidomonas Pulviseulus waren „.... und (p. 18): "Die Entslehung einer niederen fadenförmigen Algenbildung aus den Ueberresten der Chlamidomonas, "welche bei der vorigen Beobachtung nur angedeutet war, stellte sich hier in entsebiedener hlarheit dar etc." Zwischen diesen Behauplungen sind die Resultate cinzeluer Beobachtungen einer geschöpten Quantilät von Chlamidomonas Pulvisculus etc, welche längere Zeil iu Zimmer aufbewahrt worden, und wodurch nachgewiesen wird, dass in it und uach Cblamidomenas andere Gebilde iu solehen Infusionen vorkomnen, erzählt, weller aus den Berichtell noch aus den Abbildungen lässt sicl jedoch ein Uebergang der verschiedeneu Gebilde in einander enluehmen, den das Eimzige, was dazu verleiten hömnte, die Aehnlichkeit in Form, Grösse und Farbe, kann Niemanden täuschen, der uur einigeruaassen in diesen fraglichen Bildungen bewandert ist und weiss, welehe Mühe es oft kostet, bestimmt versehiedene Wesen, selbst wem man sie nebeneinander bcobachten kann, auch bestimmt als versehieden zu erheunem. Dennoch geniigt $k$. das Angefiilırte zu dem Selılusse: (1). 20)

rDass die Chtamidomonas Pulviseulus gar vielfacher Yeründerungen fihig ist, dass sich aus ihr eine cntschiedene "Algenspecies, Stygeoclonium stellare, entwickelt" - wofur auch nicht der geringste Beweis beigebracht worten ist "dass aber auch noch andere billungen aus ihr herrorgehen, welehe ebenfalls einen entschiedenen Algencharacter an siclı stragen, obgleich sie zum Theil der äusseren Form nach auch fiir ruhende Iofusorienformen in Anspruch genommen werden "köunen" - was offenbar dieSache gerade so zweifelhaft lisst, wie sie vor den Untersuchungen Külzings war. - Der ausgesprochene Satz, „das an den Grenzender beiden organischen Reiche kejue scharfe Trennugslinie ngezogen werden ka nu" - bleibt daher freilich in seiner alten Kraft, dass aber: "vielmehr dic niederen Formen beider "Reiche unmiltelbar in einander ïbergehen" - hat keine rieue Bestatigung erbatten! -

Gern würde ich damit diesen Gegenstand verlassen, wïe nieht die Sache zil wichlig, um aueh denjenigen Lesern nähere Aufschliisse dariber erwïnscht seheincı zı lassen, welche nicht selbst in mikroscopischen Beobachlungen geübt sind. Letztere werden natïrlich verwundert fragen, was K i lzing, ier über Algen und lnfusoricn doch schon so manclie Arbeit geliefelt, denu beobachtel habe und wie es anderweilig zu versuehen sein möchte, bestimutere Aufschliisse üher die Nalur solcher fraglichen Bildungen zu crlangen? In den meislen ahnlichen Fallen wiirle eine Beantwortung dieser Fragen ganz unuöglich sein: bei einem Beobachter, von dem so viele Bearheitungen vorliegen, welche allenthalben vorkommende und bestimmt zu erkennende Gegenstände betreffen, lässt es sich rersuchen, fur das Besehriebene und Abgebildele, lieides als wirklicb beobachtet angenommen, eine entsprechende Auslegung zu finden und die Mangel der Untersuchungsmethode anzudeuten,

Kïlzing fullut in derselben Abhandlung sowohl beim rolben Schnce, wie bein Haematococeus pluvialis die 'luatsache an, dass oft dieselben mikroscopiselsen objecte griin und roth vorkommen, so wie die liehauplung ron $M$ orren, die sogenaunteu rothen Augenflecke der Infusorien kömnten nicht Seborgane sein, weil sich mitumter llas hoth rom sogenaunten Auge aus über den gauzen Leib verbreiten köıne ele; Elı r uberg giebt von Euglena sanguinea und anderen rothen Thierchen ebenfalls an, dass sie ganz oder zum Theit auch grün rorkommen, bäll aber die griinen Foruen fiir Jugendzustiinde. Zahlreiche Beobachtungen und Versuche halen mich zu der entgegengesetzlen Ueberzengung gefuhrt. IVie im Pllanzenreiche die Färbung der blalter ele. rorzugsweise ron lichı und Wirme abhängl, so anel bei diesen Gesehöpfen; in Dunkeln bleiben sic farblos; im Winter, Fribling nnd Herbst so lange es kalt ist, lep Tag nieht länger als die Naebt und der Stand der Sonne niedrig ist, sind sie allfaugs roth und werden meistens von a us en nach innen griin; in Sommer sint sie gleich griin und verandern diese. Farbe nur indem sie dunkler werdeu. Nun beobachlel K. am 8 . Mai eine Alge, welehe Brithörner ausschibltet, die aussen grïn, innerlich einen rothen Punkl zeigen und eine (?) Wimper fihren; diese Körner wachsen zu jungen Fäden derselben Alge aus. Die Pflanze zeigt im Zimmer in einem Gefisse mit Wasser nach $\mathbf{8}$ Tagen, - wo es also wärmer und heller im Ganzen geworden, was in der Nitle les Monats Mai rou so entschiedenem Einflusse ist, und die Alge iu Zimmer und in einem Gefässe mit Wasser noch wälmer und rermulhlich den Lichte zugänglicher aufbewahrt war - dieselben Körner schon iı den Gliedern der Multerpllanze, ohne rothen Eunkt, zu jungen Pflänchen ausgewachsen. Stalt nun hieraus zu schliessen, dass jener rolhe Punkl eine voribergehende Färbung sei, worauf die Bcobachturg doch so deullich hingewiesen, nimmt K. dieselben fü identisch mit den Augenpunklen der Magenthiere, zieht daraus dic erwäbnten Folgerungen und bestreitel doch, was daun kaum noch Sinn lıat, die Analogie jener Punkle mil dem Auge hölıerer Thicre. - ludess ist durchaus nicht in Abrede zu stellen, dass solche Täuschungen atuch von geühten Beobachlerı oft nicht mit Sieherheil zu vermeiden sind; die nächste Anforderung bleibt jedoch, dass der Beobachter so vicl ähnliche oder gleiche Formen und Organe 
unter denselben Verhalluissen untersucht, wie möglich ist. Halle ki. zun Vergleiehe infusorien mit wirklichen Augenpunhten, 2. B. nur die Chlamidomonas Pulvisculus, welche ja in den Teiche vor seiner Wohnung zu finden war, beobaehtet, so wïrde zwischen dem lioth dieser Punhte und demjenigen in Jen Brutkörnern der Ulolbrix ein ahulicher Unterschied sich gezeigt haben, wie zwischen dem Blan des Veitcheus und dem des Vergissmeinnichts so leicht erkannt wird, (daher K. auch später bei Chlamidomonas den rothen Augempunt matl nennt); bei slärkerer Vergrösserung wïrde jenes gleichmässig gefärbl, dieses höebst walırscheinlich körnig ersehienen sein. Die Brulkürner der Ulothrix wiirden sich anch wohl durch andere Merkmale vou der Microglena nnterselsieden haben, ilı rother Punkt wiirde in auf Glas angetroekneten körnern sehr bald und sehneller wie bei Chlamidomonas Pulvisculns verblichen sein, beim Antrochnen wïrden jene verunthlielı eine doppelte Wimper haben erkennen lassen, wihrend Microglena unr einen Rissel führt, und die aussere Haut der Brulkörner wahrscheinlich viel schwärzere mul bestimmtere Unurisse behalten laben, wic ähliche Infusorien. Entscheidend wäe aber der Versuch mit wirklicher Hieroglena nonadina, welche im Mai eben nicht schwer zu finden, gewesèn, wenn bejde Objeete unler Ersatz des verdunstenden Wassers einen Tag in der sonne gelegen hälien, wo der rolhe l'nnkt in den Brutkörnern der Alge versclwumden, das heisst grün geworden, bei Microglena dagegen Inverănılert geblieben sein wärde. Dass jene firnthörner unmöglich mil einen augenfiilurenden Infusorium idenlisch gewesen scin können, ergiebt sich noch auf dis Bestimenteste aus K. Phycologia generalis Tal. 80 Fig. 15 a und b; bei allen angenführenden Mageubieren entsteht ein zweiter Augenpunkt

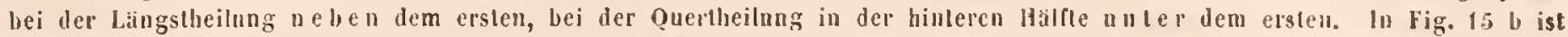
aber trolz der Verlängeruag der Zelle nur e in Punht und dieser in der Mitte nnd wandslanlig augegeben; in Fig. Is a dagegen hat die Einschürung zwischen dell beiden Zellen begonnen mal die rothen Punkte liegen beide der Verbindungsstelle au uächsten. Sowohl das Erstere wie das Lelztcre kann bci algenführenden Infusorien, die sich theileu, gar nicht vorkommen, and $K$. sellost hat das in der erwahlen Ahloandlung bei Chlamidomonas Pulvisculus ganz richtig erkannt und ahgebildet.

Dic Untersuchungen uher die crwahnte Chlamidomanas Pulsisculus, welche K. zur Yeröflenllichung dicser abhandlung ïber , die Verwandlung der Infusorieu in niedere Algenformen * rorziglich veranlasst zu hahen scheillen, lassen in Hinsicht jener vergleicheudeu Methode, welche so ebeu bei Clothrix zu empfehlen liureichende Veranlassung vorlag, nicht minder zu wünselien übrig. $K$. fiudet in den letzlen Tagen des Mai eine grüne Haut auf dem 'Teiclı vor seiner Woluung, welche sich alljährlich dort einstellt und durch Chlanidomonas Pulvisculus gebildet wird. - Schon diese Behauplnug zeugt davon, dass $K$. entweder etwas verschwiegen oder ïbersehen hat, denn ciue solche grune Haut auf eincm Teiche, welche a usschliess! ieh aus einem Infusorium gebillet wiirde, hommt wohl nie vor. K. Weist in seinen Sehriften oft genug darauf hin, dass licses Anhäıfen soleher Bildungen an ier Oberlliche les Wassers durch Gas-Enlwickelung bediugl ist, welehe durch intensives Sonnenlicht so gesteigert wird, dass auch sonst rulıeude Algeu dadurch emporgehohen werden, und auch solche waren gewiss am Grunde des Teiches vorhanden, ganz abgesehen von den farblosen Infusorien, Raderthieren ten Eulomostraceen etc., die gewiss nieht gefehlt hahen. Zul Entscheidung einer so wichtigen Frage war aber eine sorgfältige Aufzählung der ganzen Flora und Fauna jenes Teiches, die in Belracht kommen konnte, cin unerlassliches Erforderniss, namenllich mussle zu ermiltelu gesucht werden, was auf dem Grunle desselben, woher die ganze Hant gelsommen war, zu finden sei. - Es wird etwas von lev grinen $l 1$ aut in cin Cylinderglas geschöpf und sogleich ıntersucht; Chlamidomonas Pulvisculus zeigt sich in verschiedenen Zuständen der theilung mil Augenpuntit, liissel ete. Aber anch noch eill confervenähnliehes Gebilde, welehes aus jenen Thierehen herrorgegangen zu scin scieint, findet sich vor. In der Zeichnung misst dicses ohne Angenpunkt

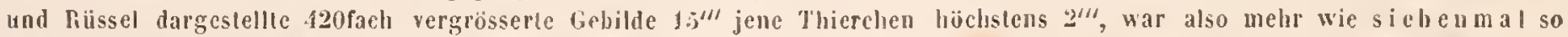
lang, und weil es im Innern seiner Zellon auffallende Merkmale, dic Jurchaus nichl näher angegeben werlen, trug, cntbehrl jeder wissensclaftlichen Berechligung. - Jene griine Hanl wird durch Gewilleviuirme elc. zerstreut und zerstort (?), zeigl sich auch au den folgeuden "lagen nicht wieder, und laher ist $K$. mil seincn Beobachlungen allein auf das eingeschopfte Wasser beschränkt. - Sollte denu ein so erfahrener Beoluachler nichl wissen, dass trolz jener Gewillerstiume am Rande des Wassers in jeder Leke und Bucht oder an jeder Wassejpflanze und namentlich im Bodensatze sich lieselben Thierchen in grösserer Menge wieder hälten iuffunden lassen, als zu mikroscopischen Präparaten erforderliclı ist. K. gesteht, dass eine absichtliche Verindernng der Localilat die fernere Entwickelung der niedern Organismen modificirc, scheint aber andenten zu wollen, dass eine Alweichung nicht sowohl in der Art der Eutwichelungsstufen, als vielnehr in ihrt: Folge einzulreten phege und bebanptet, dass dieselben daher leichter und sicherer in die Augen fallcu. - Van findet jedoch durchaus keine Reclutfertigung dieser Ansiclıt und iudere Beobachter klagen, dass bei den ins Zimmer geslellteu Infusorien die Entwickelung mil der in del freien Natur dnrchans nicht Sclıritt halte, selbst wenn in der günstigsten Zeit des rrijlıliugs und Herbstes die Zimmer uicht gelıeizt werden. In Winter und Sommer dagegen sterben einc Menge Thieve in jeder soleher Infusion selı bald al, waumenllich in Sommer, wenu die Menge der Thierchen im Verhallniss zum Wasser sehr gross ist oder sich rasch vermelır, es eutstehen neue Biliungen, die aber vielfach verkinmuert und krïppellaft sich haum classificiren lassen und nur die Beobachlung verwirren, wic ks. Aufahhlng dieser Gebilut nachher ebenfalls darthul; spater folgt ein oft selu schuell voribergehendes Faulen Jes Wasser's, wonach dasselbe die in jeder Infusion gemeincu Thierchen aufweisl. Solches Wasser in Glssern in Zimmer aublewahr, eignet sich im Soamer gar nicht und zu anderen Zeiten nur wenige Tage zu Untersuchungen, welche so oft es möglich, an frisch gescböpften Mcogen genau wieder verglichen werden mussen, ohue letzleres 

jednch allen IVerth einbïssen. - K. will nun dic Veränderungen verfolgen und macht währead 56 der längsten Sommertage - staune o Leser! - sechs Beobachtungen. - Da jedoch bei diesen Beohachtungen milunter schwimmende Floeken und Gebilde vou Rande des Wassers erwahnt sind, so hönnen viclleicht jedesmal z Wei Tropfen des Wassers untersucht sein, darüber. wird indess weller etwas erwahut noelı selıeint jemals elwas vom Grunde des Gefásses genommen zu sein, von wo doch alle Körner, dic zu Algen auswachsen, zu kommen pllegen.

Da diese Geschichte derselben jenen sechs Beobachlungen cinen wissenschaftlichen Werlh zuzusprechen nieht gestaltel, so wïrden sic hier fuglich ganz ibergangen, nur die Arl, wie sich $K$. dic erforderlicheu Briicken baut, ususs noch näher ins Auge gefassı werden: Pag. 16 liest man: „Es war hlar, dass diese Formen nur Modificalionen der Chamidomonas Pulvisculus waren" und darin hounle K. ganz reelı haben; es waren dann in der Theilung begriffen ahgestorbene Individuea, dereı äussere llaut uach den Tode aufgeıuollen; dass aber aul lieses melır oder minder Aufquellen dic grössere Nähe oder Entfernung vou der Ohernache des Wassers von Einlluss scin kijnute, ist nicht einzusehen. K. lıehanplet jedoch nicht uur dieses, soudern auch weiterhin, "dass atmosphirische Lufl, welele dn relı Wasserdiinste seht rerdii nul i,st, der "Verdichııng der Zellmembran niclıt giinstig sei etc." Abgeselıen davon, dass mancher Naturforscher sich vielleicht den

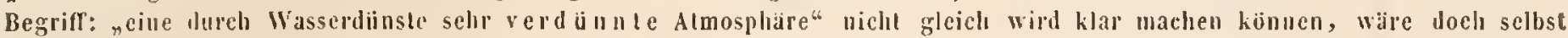
bei in der l.uft wachsenden Pllanzen und Thieren einc be sondere Einwirkung lerselben keineswegs unbedingl zuzngestehen, bei in Wasser lebenden Organismen diesellıe anzunehmen, ist jedoch völlig absurd. K. hedarf aber, nm seinc Ansicht leichter plansibel zu machen, wic es selıeint eines Grundes, wodurch es möglich wird, dass jene anfgequollene llanl sich hald verdichlen, bald auflockerı oler auch ganz auflösen köune, nimmı daher eine fortselıreitende und riicksehreitente Metanorphose in Folge jener Einwirkung nieht allein für die Itussere Jlant, sondern auch gleich mit fiir deu Inhalt llerselben an, und sagt dann: "Von der Enlwieklung der äusseren Zellenhille hängl ïbrigens ab, ob diese Elementarkürperehen ein bloss rein vege"Latives, oder cin animalisch-infusorielles Lehen fïluren elc." Ein solches Verfahren richtel sich ohne Zweifel selbst! wenigsteus lleibt durchaus keine Annahme iibrig, wofur sich nicht ehen so triftige Griinde erdenken liessen.

Wer nach allem diesen in dem der Ablıandlung beigefiglen Schlussworte liesl:

"Schleiden meinte, dass es sich hiebei nichl uu Thatsachen, sondern um richlige Deulung derselben handele, ${ }^{\star}$ wird das nicht fiir Sophisterei erklaren, sondern wahrscheinlich S chlejden liecht gebel, „Wo die Thatsachen so har und deullich sprechen, fahrt K. fort, wie - und nun folgen iu umgekelırter ordıung aufgezahlı:

1) bei Chlamidonınas Pulviseulus, wo wie oben gezeigl, K. bei sehr unregelnăssigen, verciuzellen, unvollsłändigen Untersuchungen nichts, was auf cinen Zusammenlang der Thiere und dlgen schliessen licsse, nachgewiesen hat;

2) bei den rothen Sclınec und Ilimalocoecus pluvialis, woruber noch durhaus keine Klarlueit in len Beriehten herischt;

3) bei den Keinen der Vancheria clavala, woriber Un ger selhst in seinen letzten Hittheilungen die nöthigen, der Ansicht Ks. lurchaus ungüustigen Aufklarungeı gegehen hat;

4) hei der Ulollırix zonala und llicroglena monadina, welehe li., wic nachgewiesen, in cimen gar nich! existirenden Causalncxus gezwingt hat elc, - uml doch wird mancher Leser sowohl dic klarheil und Deulliclıkeit als auch die Thatsachen gainzlich rermissen. - Vou allem diesen licsse sich jedoch olne Zwang anmehmell, dass $K$. es in gutem Glaulsen und fester Ueberzengung nicdergeselırieben. Wenn aber auch hier am Schlusse noch angefiultr wird:

5) wie hei den Spirillen der Clraren - so verdient das cine crnstliehe liige. - Pag. 3 fiilul K. die Samenthierchen vou Sphagnum, Chara uud Marchantia als in dicscs Gebiet gehörig an, pag. 6 heisst es: "Schon früher hatle עEhre uberg aber auch geăussert, dass die beweglichen Fijden in den sogenaunten Pollenfiilen der Clıaren inlliommen der "Gallung Spipillum glichew." In der Nole wird aber nicht auf Ehreubergs Infusorienwerk verwicsen, in welchen im Nachlrage zı der Gallung Spirillum die Achnlichkeit erwihul wird, aber mit diiren Worten dabei gesagl ist, dass Ungers Species Spirillum Bryozoon unhallbar sei, und wo in Naelıtrage zur Familie der Monadinen am Sehlusse gesagl ist: "Sehon * Werneck hal dieses (Spirillum Bryozoon) zuriekgewiesen und sie nicht fur Infusorien, sondern fiir geschnailizle Samen-

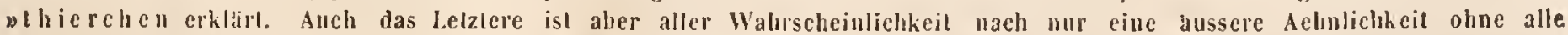
- Beziehung anf die innere, wahre Natur dieser Körperchen. Wo keine Organisatiou nachzuweisen, fehll es jedeu Urtheil iiber yAehnlichleil mil Thieren am ersten und wichligsten Grunde, — sonderu auf Frilzsehe's Abhandlung iiher den Pollen, und doeh wird hier unter den "Thalsa $\mathrm{che}$ " auch von den: "Spirillen der Charen "gesprochen. Man muss hier sclıon cinen Fiidıligkeitsfeluer bei eiren so wiclıtigen Thema zugeben, sonst wiirde ein solehes Verfalıen seines Zusammenhanges enthleidel ciner wissensehafllichen Perfille hei weilem ahnlicher sehon, wie die Brutkörner ıler Llolbrix zonala der llicrogtena mouadina. -

Obgleich nbige Erörterung so zu halten versuchl ist, dass len unhefangenen Leser kein Zweifel beiben hann, sie sei ciuzig und allein gegeu de $I$ Irllum gerichtel, welelien K. in die Wissenschan eimzufihren versucht hat, sn fallen doch hin unl wieder Streiflichler auf den Urheber, seine Bcobachlungen und Schlussfolgelungen, welche nael diesen Beispiele anl andere Aibciten Ks. iibertragen, zu cinem höchst ungerechlen Urlbeile verleiten künulen. Mluss es indess in solehen Fälen rou del Wichtigkeit des gesaeten Irrthums abhingen, ob ler Upheber desselben Seorpione oder Draelıen erndtet, so honntea hier die Waffen gar nicht seharf genug gespital sein, auch wenn sie dadureh repwudender werden nussten. Dic leser aber, welche dic Ausfihbliehkeit dieser Erörterung zu ermulew droble, bille ich sich mil der Ucherzeugung zu trösten, dass 11 i 
alten ehrwïrdigen Grenzen zwischen dem Thier-und Pflanzenteiche unangefochten dastehen, und es sich höchstens um den Allslausch dieser oder jener Enclare handell.

In der Familie der Monadinen erkennen wir also das thierische Leben in verschiedlenen, jedoch so kleinen Formen, dass physiologische Untersuchungen derselhen mit mehr Schwierigkeiten und Uusicherheit verbunden bleiben, als dass die im glücklichsten Falle mïhsan zu erlangenden Resultate dankbar sein kïnten. Dennoch gebüht dem Auftreten lerjenigen Organe, welche hei den grösseren Magenthieren, weil sie constant vorkommen, eine entsprechende Function haben miissen, die schärfste Aufmerksankeit, wenn auclı nur ilıe Forn und Grösse crkannt zu werden vermag. Als solche Organe sind bereits ein fadenfürmiger Büssel, der rothe Augenpunkt und eine dunklere Drïse (?) so eben bei Microglena monadina erwähnt; ansser dieser bemerkt man trübere nud hellere, meistens in allen Lagen des Körpers rund erscheinende und daher kugelförmige Stellen, welche theils verschluckter Nahrung entsprechen, theils mit Wasser erfüllt sind, oder periodisch zu verschwinden plegen etc. Sämmtliche Organe der Art lassen sich ohne Schwierigkeit in ler Familie der Monadinen nachweisen, und ılemnach ihr Vorhandensein bei den ïhrigen der Beobachtung minder zugänglichen oder grössere Sichwierigkeiten darbietenden Arten, solern sie mit Pecht zu lieser Familie gezogen sim, nit ler grössten Wahrscheinlichkeit voraussetzen. Ich füge der Vollständigkeit wegen meine Ansicht über die folgenden Gattungen bei.

5) Glenomorum und 6) Phacelomonas sind mir entweder gar nicht rorgekommen oder zu einer Zeit, wo ich den Unterscheidungszeichen die nöthige Aufmerksamkeit zu schenken noch nicht hinreichend eingeübt war. Von 7) Doxococcus glaube ich allerdings die entsprechenden 'Thierformen zum Tlieil aufgefunden zu liaben, ohne jedoch eine besondere Gattung für dieselben erforderlich zu halten, indem sclıwierig zu erkemende, und dalıer leicht zu übersehınde, Organe dieselben zu anderen Formen olme $\mathbf{Z}$ wang einreilien. Ich würde eine Dentung der von $\mathbf{C}$ henberg anfgestellten Species dahin versuchen, dass:

1) Doxococcus Globulus, die rollende Bewegung durch eine leine Bewimperung des ganzen Körpers, welche vielleicht beim Antrocknen zu erkennen gewesen wäre, bewirkt lä̈te und dann farblosen Individuen von Pantotrichum Volvox gleich zu achten wäre;

2) Doxococcus ruber, wie schon Ehrenberg selbst angiebt, zu 'Irachelomonas zu rechnen sein möclıte;

3) Doxococcus Pulvisculus die oft sehr zahlreichen kleinsten Kugeln von Pandorina Morum dargestellt hätte, deren rollende Bewegung durch die (1829 noch nicht entdeckten) Rüssel der Einzelthierchen bedingt gewesen wäre;

4) Doxococcus inaequalis endlich etwa ebenfalls zu Pantotrichum (P. Enchelys mit grüner Nahrung erfiillt?) zu rechnen sein möclıte, und eine allgemeine Bewimperung des ganzen Körpers die rollende Bewegung vermittelt hätte.

Diese rollende Bewegung, das einzige Unterscheidungszeichen für die Gattung, will doch ihre Ursache laben; es soll eine Fortbewegung in gerader linie mit einigem Wanken und einer Drehung um die Qucerachse, d. h. einem Rollen ïber Kopf, sein, was durch einen einzelnen oder mehrfachen Rüssel, wie sie den Monadinen zukommen, unmöglich bewirkt werden kanı. Die grössere Zahıl der Infusorien, welche überhaupt einer solchen Bewegung lähig sind, zeigen dicse rollende Bewegung in der ersten Zeit nach Anfertigung des Präparates, weil sie aufgestört wie es scheint irgend einer Gefahr glauben entfliehen zu müssen, während sie bald nachher sich heruhigt hahen und obgleich sie überall bewimpert sind, auch diese Wimpern in hestänliger Bewegung bleiben, doch für längere Zeit ruhig im Sehfclde verlıaren kömnen. Jene rollende Bewegung rïhrt also von ciner sehr schnellen Bewegung jener Wimpen her und letztere köınen in diesem Grale von Schnelligkeit bewegt, wie die Erfahıung zeigt, in der Melızahl der Fälle gar bei stärkeren Vergrössermgen nicht durch das Mikroscop wahrgenommen werden. 'Thiere der Art kömnte daher leicht ein Beolachter, diese Ver- 


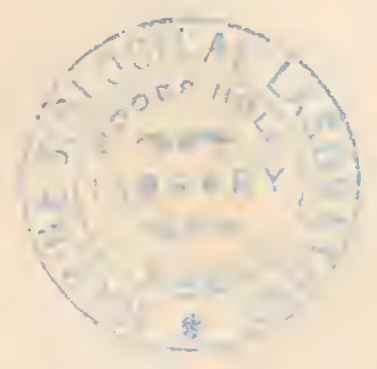



hältnisse ausser Acht lassend, gleich naeh Anfertigung eines Präparates zur Gattung Doxoconcus und schon eine halbe Stumle später nach erkannter Bewimperung etc. zu den entsprechenden darmfiilnenden. Magenthieren rinreihen; für die Loupe aber, zur Beobachtnng in ihrem Elemente, olne dass sie gestört wïrden, sind diese 'ihiere, wie alle die weniger wie $1 / 50$ "' messen, sellost un mur üher ihre Bewegung zu urtheilen, nicht erreichbar.

Diese Grïnde bestimmen mich dazu die Aufgebung der ganzen Gattung Doxococcus anzurathen, bis fernere Wutteckmngen geeignete Thiere mit Sicherheit erkemen lassen, für welche nicht die rollende Bewegung, somlern das Organ. welches dieselbe vermittelt. das unterscheidende Kenmzeichen abgiebt.

Die achte Gattung 8) Chilomonas. Lippenmonade, kam mir nur in der dritten Art Ch. destruens vm; obgleich letatere läntig ist unl fist alle leeren Entomostraceenschalen etc. im Bodensatze der Infusionen des Herbstes erfüllt, so lialse ich doch keine llas Thierchen anszeielnende Eigenschaften wahrgenommen. Das 'P'hier ist sehr unruhig und behende, dahei von eincr wolkig trüben Lörpermasse, in ler sich sc.nwer elwas nnterscheiden lïsst, und heim zerdrücken der todten Körper anderer 'Thiere, in denen sie leben, whil meistens das ganze Präparat für feinere Beohachtungen zu sehr getribt.

Die letzte Gatmug der Monadinen

9) Bodo. Schwanzmumade, vercinigt freilich noch vielleicht sehr ungleiche TVesen, lient jedoch anch in ihrer sichersten Art zur Vervollständigung der bei den Monaden beobachteten Organisation, um sie mit allen Magenthieren auf dieselbe Stufe zu stellen. Whrenberg emähnt bei Bodo socialis, dass ein einfacher Rüssel in Zukmnft wohl dieses 'Thier ron jungen Vorticellen, die Wimpern am Munde fiihren. muterscheilen liesse. Sthon 1838 konnte ich diese Voraussetzmng bestatigen. - W We

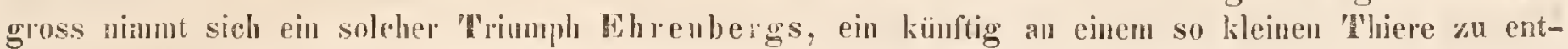
deckendes Organ richtig vorherzusagen. gegen die uft so kleinlichen Verdïchtignngen anderer Beohachter aus, welche Nebentinge hervorhehen, m daran zu makeln, und doch zngleich den Mangel eines reifen Ueberblicks ïber das gewonene Material durch die Art ihrer Schlussfolgerungen geniigend zn beweisen pflegen! Wälıend Bodo saltans so leicht imere Blasen mit farbigem Stoffe erfült bei einer Grösse von 1/1000", hat Bodo socialis selbst hei 'Thieren ron 1/300" Jäuge mich einen feinen Rüssel von mehr als doppelter hänperlänge erkeimen lassen und ansserdem bei vielen 'Whieren constant in derselben Lage und Grösse in linteren Theile des Körpers ein dunkleres driisenartiges Organ und eine hellere scharl umschrichene Blase, welche wahsscheinlich contractil ist, was mir jedoch zu beobaelıten nicht gelingen wollte. Begünstigt durch den Umstand, lass diese Thierchen in zahlıeichen Exemplaren an den Fälen einer dicht verfilzten Alge sassen, konnte ich sie ruhig bcobachten und eine 600fache Vergrösserung anwenden. Der Rüssel schien an seinem Ende etwas anfwärts gebogen und geknöpf zu sein, war derber wie dieses Organ bei verwandten 'Thieren oft nach vieler Mühe erkannt wird, und zeigte statt der zitternden ungestimen Eile, womit jene zu schwingen phlegen, nur ein pendelartig regelmässig sich folgendes Zucken. wodnrch fïr den Angenblick eine kleine Bewegung des Körpers zur Seite hervorgebracht wurde, ohne dass dieselbe anf den sehr feinen borstenarligen Schwanz, womit las T'hier an der Alge festsass, von Kinfluss schien. Da dieses 'P'hier im Verliälniss zn seiner geringen Griisse mir die vollständigste Organisation gezeigt hat, wie sic nur bri den grössten Magenthieren beobachtet wird, so gebe ich lie Grisse ler cinzelnen 'Nheile nach cinem Durchschnitte von mehr wie zwanzig Messungen:

Schwanz 1/160-1/250", Kölper 1/270". Hiissel 1/120", Iluklere Driise 1/500", hellere Blase 1/450". Bis jetzt haben last alle Magenthere mit einfachem rigiterem Rüssel die Aufuahme von Farbestofien beharlich verweigert, weshall es zweilelhaft wirl, ob Bodo saltans nicht vielleicht noch eine Organisation erkennen lässt, welche beide Formen trennt, was anch wohl mit Bodo grandis der Fall sein möchte, da die Anheftung der Schwamzhorste unter dem Munde sich bis jetzt nicht erweisen lässt, diese mehr wie doppelt so lang als der Köper des Thieres ist und heim VYenden des lethteren gan\% passiy in 
winklig gebogener Krümmung nachschleppt. Eine constante hellere Stelle fand ich anch bei Bodo grandis; da sie jedoch dicht unter der Anheftungsstelle des Rüssels liegt, so könnte es auch der erweiterte Eingang des Mundes sein und kann also nicht darüber entschieden werden, bis etwa ein periodisches Verschwinden derselben beobachtet wïrde. Auch dass Bodo grandis leicht Farbestofl aufnimmt, spricht nicht dafür, dass Bodo socialis damit zu einer Gattung gehört. Die übrigen Arten sind mir unter Verlıältnissen, wo ich sie mit einiger Sicherheit hätte bestimmen können, in letzter Zeit wenigstens nicht vorgekommen.

Ein Rückblick auf die Familie der Monadinen zeigt also bei den kleinsten 'Whierformen, die wir kennen, eine bestimmte Organisation, welche zur Annahme einer Individualität fïr jede Monade rollkommen berechtigt. Vor der Hand muissen wir uns begnügen, die Existenz von Organen bei ilmen zu erkennen, was der Physiologie zu begründeten Rückschlüssen von den grösseren Magenthieren, bei denen die Funktionen dieser Organe zu elmitteln sind, vielleicht bald dienen kann. Es sind dieses die kleinsten Thiere und die kleinsten Organe: Was liegt in beider Hinsicht jenseits lieser Grenze? -

\section{Zuweile Familie. Cryptomonadina. (Panzermonaden.)}

Die Umhüllung des Körpers mit einer dünnen gallertartigen Haut bis zu einem harten, wie Glas zerspringenden Panzer unterscheidet diese 'Thierchen von den Monaden, während die Kennzeichen der Monaden sie wieder von allen übrigen Magenthieren sonderm. Augenpunkte und die Form des Danzers etc. scheiden die Gattungen nach folgendem Schema:

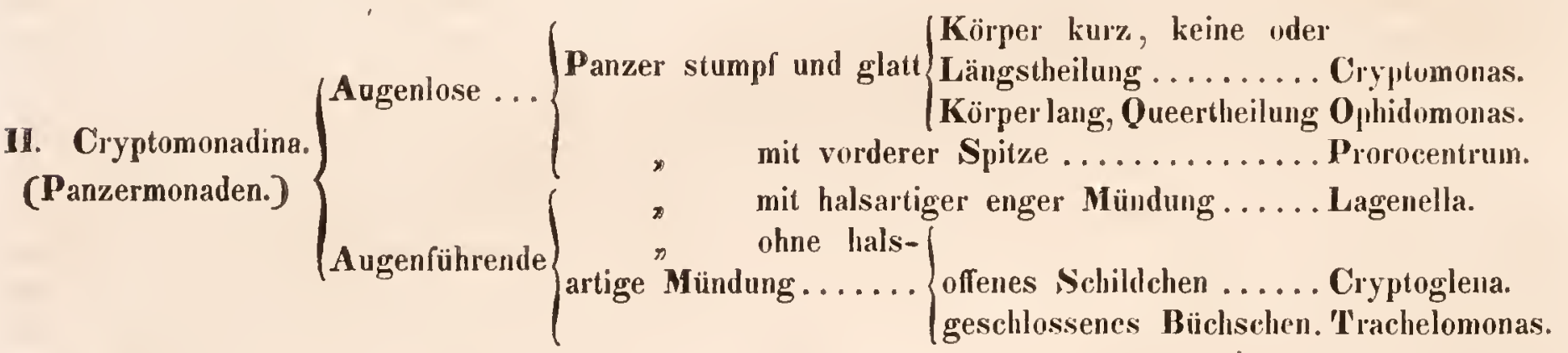

Ein Blick auf die Abbildungen und Diagnosen dieser 'Thierchen reigt gegen die vorige Familie sogleich den Unterschied der grösseren Sicherheit und klaren Erkenntniss bestimmter ausgeprägter Formen. Mit Ausnahme von Cryptomonas fusca und C. lenticularis, Ophidomonas und Prorocentrum konnte ich sämmtliche Formen mit Musse prïfen, ohne zu ahweichender Anordnung irgend einen motivirten Vorschlag machen zu miissen. Hier wird daher die Bestätigung des physiologischen Details, des Panzers, Rüssels, Auges etc. sowie der dunkleren Drüse in der Mitte und ler lıelleren Stelle am Ende des Körpers, welche ich auch bei Cryptoglena pigra und C. cörulescens erkannte, um so eher genügen, als alle anderen Verhältuisse bei der lolgenden Familie gan\% ähnlich gefunlen werden. Die Vermuthung lässt sich jedoch nicht ganz von der Hand weisen, eine oder die andere Form kömte später als vorübergehender Entwickelungszustand anderer Gattungen erkannt werden, weil sie mur im Frühlinge und dann in grosser Menge vorkommen, später im Sommer dagegen noch nicht beobachtet zu sein scheinen. Ohne vorherige Erörterung der Fortphlanzungs - und Vermehrungsweisen der Magenthiere überhaupt, wie solehe bei den grösseren Darmführenten an geeigneter Stelle versucht werden soll, bleibt die weitere Ausführung solcher Vermuthungen jedoch hïchst ungenügend, und muss daher verschoben werden. 
- 
- 


\section{Dritle Familie. Volvocina. (Kugelthiere.)}

Diese interessanteste Familie der ersten Abtheilung der Magenthiere umfasst diejenigen gepanzerten Monaden, deren Panzer bei der 'Theilung zusammenhängend heibt, wodurch Monadenstöcke, vom olt zahlieichen Einzelthierchen zusammengesetzt, gehildet werden. Die Gatungen unterscheiden sich sehr leicht:

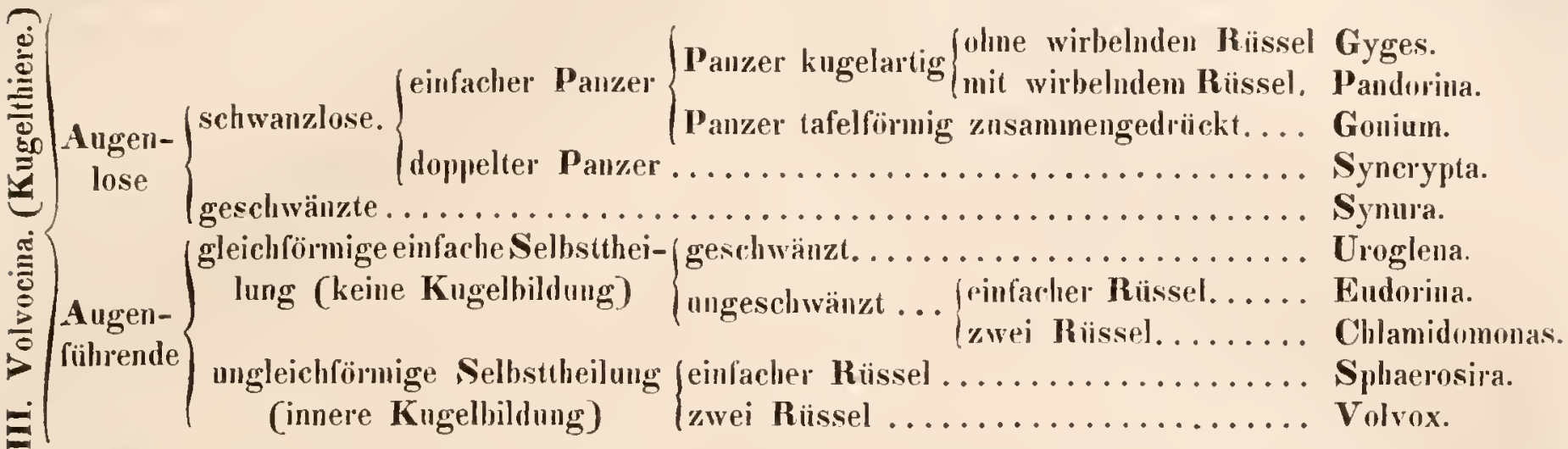

War schon das herühmte Kngelthier; ler Volvox Glohator Le euwenlouks, als umschuldige Veranlassung zur Entstehung der Einschachtelungstheorie, geeignet in der Naturgesehichte eine dauerude Aufmerksamkeit zu erregen, so lat es mit Ilen verwandten Formen dazu eine nene Veranlassung durch die Hartnäckigkeit gegeben, mit welcher einige Naturforscher für diese Organismen eine vegetabilische Entwickelungsform in Anspruch genommen hahen. Die Bekanntschaft mit den Panzermonaden und nur einiger Ueberhlick ïher verschiedene Arten, welcher hinreicht die Verwandischaft der Gattungen zu erkennen, genügt schon jeden Gedanken der Art fïr immer zu beseitigen. Die allerdings nicht immer ganz leicht zu ermittelnden Organisationsverhältmisse sind denen der Panzermonaden gleich, nur deutlicher zu erkemen, weil diese Monadenstöcke viel häufiger gefunden werden und auch solche Behandlung unter dem Mikroscope gestatten, welcher die Panzermonalen sich oft durch ihre Kleinheit entriehen. Die einzelnen Gattungen hieten in sehr verschiedener Hinsicht physiologisches Interesse dar.

16) Gyges. Gyges-Ring.

Diese Gatıng gehört nach meiner Ansicht zu denjenigen, welche nie hätten anfgestellt werden miissen, und deren Eingehen fast als Nothwendigkeit erscheint. Es liegt jedoch nicht in den Unterscheidungszeichen der Grund dazo, obgleich es immer bedenklicher werden möchte, Thiere olne wirbelnden Rüssel mit in diese Familie aufznnehmen, sondern in der Unhaltbarkeit der aufgestellten Arten.

1) Gyges Granulum, ein kugelınder griiner Körper von wasserhellem Panzer umgehen, welcher scheinhar wie ein krystallener, bei hellem Lichte schwer sichtharer Ring die grijne Kugel umgiebt, ist gewiss nichts anderes, wie ein 'Theilungszustand von Pandorina Morum, welche durch alle Uebergänge bis zu noch kleineren Furmen gefunden werden, wie sie schon Elı $\mathbf{E b} P \mathrm{rg}$ mit abgebildet hat. Sie zeigen oft lange weder Bewegung noch Büssel und doch kann man bewegte Formen danehen legen und mit denselhen rerdrücken. ohne aluch in dem Inhale die geringste Verschiedenheit walırumelımen.

2) Gyges bipartitus, eine grüne Doppelkugel in klarer Hülle, gehört nach Lhrenbergs Vermuthung mit der vorigen zusammen. Da sie jeloch gelbgrün sein soll, so ist wohl zu beachren, dass seitdem bei den Desnidiaceen in der Gatung Xanthidium constant ein sehr durchsichtiger Panzer beobachtet ist, diese Form genan einem stachellosen Xanthidium entsprechen wiude, wenn die jener Gattung eigenthümliche Vermelırungs-Art daran zı heohachten wäre. Da mir heides gelungen ist, so stehe ich nicht an, diese Form zu Xanthidium zu ziehen, woriiber bei dieser Gattung das Nähere mitgetheilt werden soll; die Gattung Gyges dagegen in der Familie der Kugelthiere für vollkommen iberfliissig zu halten. 


\section{7) Pandorina. Beerenkugel.}

Innerhalb des wasserhellen Panzers sind grüıe 'llierchen ohne Augen mit einfachem Ruissel, einzeln oder in allen Stalien der Theilung vereinigt und hilden so kugelige Monadenstöcke von oft ansehnlichem Durchmesser. Die drei grünen und sehr hïnfigen Gattungen der Kugelthicre Pandoriua, Gonimm und Volvox unterscheiden sich auf den ersten Blick, olme auf den rothen Augenpunkt Rücksicht zu nelımen, dadurch, dass der ganze Monalenstock bei Goninm talelfürmig zusammengedrückt ist, yon den beiden kugeligen aber Volvox die Einzelthiere dicht an Rande fülnt, während sie bei Pandorina um die Breite ihres Durchmessers weiter nach innen liegen.

Pandorina Morum erscheint meistens so häufig beisammen, lass sich die einzelnen Entwickelungszustände leicht aneinanderreilıen lassen. In Gläsern an Fenster aufbewahrt, nimmt die Zahl des Monadenstörke häufig ab, dagegeı durch das Verkïmmem mancher Bildungen die Zahl der Entwickelungsformen zu, so dass man nicht allein einfarhe Beeren in Kugehn von 1/80" Durchmesser, daun 2, 4 etc. bis zu 36 mul mehr in entsprechend grösseren Kugeln antrjff, sondern es bleiben in anleren auch stets wieder Eimzelthiere und Becren auf jeder Stude der Entwickelung stehen, und sterben ab, wobei sie eine branne Farhe annehmen, so dass man das Junteste Gemiscl von allen diesen Formen von einer gallertartigen Kugel umschlossen linden kann. Diese Art der Theilung zeichnet die Kugelthiere vor allen anderen Monaden ans, während die Organisation der Einzelthiere Jen übrigen Monarlen sehr ähnlich zu sein scheint. Auch mir hat der innere grime Körper des 'I'hieres für nälsere Erforschung seincr Organisation zu vicle Schwierigkeiten dargeboten, als dass cine klare Erkenntniss möglich gewesen wire. Der feine Canal, welcher vom 'Thiere bis zur Peripherie der Gallertkugel reicht, und den Riissel umschliesst, bewejst jelloch, dass an Grunde des Ruissels die Mundstelle sich findet, was zu weiteren Folgerungen berechtigen wird, wenn die Organisation ähnlicher Thiere, welche sichlich Nahrung verschucken, weiter lat geprüt werden kömen.

18) Gonium. 'Tafelthierchen.

Der tafelförmig zusammengedriickte Panzer dieses Wünglthitres entsteht durch regelmässig wiederholte läugstheilung der 'l'heorie nach. In der Wirklichkeit scheint jedoch alles fertig vorgebildet zu sein und die letzten Fragmente älterer Stöcke \%eigen deuthich jedtes Finzel(nier von eines kugligen Gallerte umbiillt, welche mit den nehenlicgenden kugehn an schmalen Berührugspunkt'n verwachsen ist. Diese Verhindungsstelle, whele durch die gegensertige Ahplatung der Panzer lreiter wird, ist endlich durch zwei parallele linien begren\%, wie des Interellulargang \%wischen zwei Pilanzenzellen im Längsschnite, und dem entsprechend bildet sich zwischen drei his viel dieser. Kugeln ein ecliger leerer Raun, wie ein Interccllulargang im Querschnite. Diese scheinbaren Canile hat o hrenbesg vermuthet, kümten zu ciner organischen Verbindung zwischen den ejuzchen phieru dienen, was mir bei der gar nicht zu misskemenden Entstehung bei Goniun pectorale höchst unwalıschejulich geworden ist, und auch für die Dentung der ähnlichen Erseheinung bei Volvox alc. manssgebend sein dürfte.

1) Gonium pectorale ist vihleicht die vingige gute Speries dieser Gatung; und hinrehend als Wunler des Mikmscopes bekannl gewesen, bis Whenberg anch diesen Zauber lïste. Die ïhrigen Arten würde sehon der Mangel eines Rïssels tremen lassen; zudem simd diescllhen so unsicher mul so selten beobachtet, dass wenig Gewicht daranf gelegt werden lianm. Br, bei gentuerel IDrüfung, wenu man den Grundsat\% festhalien will, dass Grisse, Finlung mol Fundort lieinen Artennuterschied fïr sich bedingen kïnnen, ist es schwierig, sich cinc andere Species für diese Gattung zu denken, welche sich nicht durd die Furm der Einzelhiere unterschiede, was bei strengstor Conseguen\% doch wieder eine neue Gathung brgründen kïmnte.

Gonium? glaucum. welches ich oft und sorgrailigg beohachtete und noch in diesem Augeublicke, seit etwa siehen Monaten von Zeit zu Za'it nachsehend, vergleichen kann, zeigtr mir nie etwas, das an einc thierische Organisation erinnerte. 


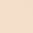


Bei den folgenden Gattungen:

19) Srncrypta. Doppelmantel.

20) Symura. Strahlenkugel.

21) Uroglena. Stralılenauge, will ich nur bemerken, dass ancu mir, seit ich das Auge bei Uroglena kemnen lente, keine Syuma melı' vorgekommen ist, im Uebrigen die 'Thiere dieser Gattung zu keinen plysiologischen Aufschlïssen Gelegenlieit gehoten haben. Dasselbe gilt von

22) Eudoriua. Angenkugel, welche auch ich gar nicht sah,

23) Chlamidomonas. Hüllenthierchen, woriber Microglena (pag. 21.) zu rergleichen ist und

24) Sphaerosira. Ruderthierchen,

in dem bei den berühmten

25) Volvox. Kngelthier, auf alle interessanten Punkte dlrch zurückzukommen wäre. Ohne Zweifel ist Volvox Globator von allen 'Thieren dieser Abtheilung am hänfigsten beubachtet. weil bei der grünen Färhung der Gewässel die grösseren Kugeln desselben schon mit unbewaffnetem Auge erkannt werden kömnen, und daher muächst die Aufmerksamkeit fesseln; dennoch blielı das Kugelthię weit lïnger wie ähnliche Billungen ein plıssiologisches Rätlısel und noch jetzt findet Ehrenbergs scharfsimnige Lösung lesselben so oft ganz unhefugten Widerspruch. Gewiss war es zu entschuldigen, wemn man ein lebendig gebärendes Wesen fül eiu räthselbaftes 'I'lier hielt; seit aber uaclıgewiesen, dass dieses rermeintliche 'Thier eine Colonie ron zahlreichen Einzelwesen, fragt man mit Recht verwundert, warum dieselben in las Pflanzenreich degradirt werten sollen? - Die Untersuchung dieses so leicht aufzufindenden Kugelthieres bietet jedoch mitunter Schwierigkeiten dar, welche nicht in jedem Exemplare die Nachweisung der thierischen Organisation gestatten und rornehmlich durch eine Verschiedeuheit in der Grösse der Einzelthiere hellingt scheinen. Im Frühlinge findet man in ler Regel nicht ganz so grosse Kugehn, wie gegen den Herbst, dagegen die Einzelthiere in Durchschnit grösser. Die grossen schwimmenlen Kugehı fand ielı im Frïljalı bis 1/2" gross, die jüngeren Colonien in Innern derselben maassen ror dem Verlassen der grossen Kugeln 1/6" und die in letzteren neu begounene Vermehrung 1/4" ", die einzelnen Thiere in der grossen Kugel selbst endlich 1/280 — 1/300" und ihre Entlermung von einander durchschnittlich 1/70". Die Gallerthiille zeigt zwischen den letzteren feine Streifen, welche stets senkrecht auf eine an der Peripherie des Finzelthieres genlachte 'Tangente zulaufen und nach der Analogie vou Gonium pectorale unzweifelhaft die Grenzen kugeliger Gallerthüllen der kleinen grinen 'Thiere anzeigen. Das Verbälniss der Einzelthiere zu diesel Hïlle ist ein wechselndes. Man findet im lıohen Sommer die Mehrzahl der Kugehn blasser und durchsichtiger; mischt man bei schwacher Vergrösserung Farbe zum Wasser, so ist der durch die Rüssel erzeugte Strudel ungemein lebhaft und rasch; bei stärkeren Vergrössermugen findet man aber ılie 'Thiere selbst änsserst klein, blassgelblich, nu den rothen Punkt und die Blase oder Drüse sichthar, die Rïssel äusserst schwer zu erkennen. Anf solche Exemplare altein angewiesen hätte ich schwerlich die eigentliche Natur dieses merkwïrdigen 'Thieres sogleich erkannt, da hiel' auch die Gallerthülle un ein bedentendes trüber zu sein phegt, wie im Frühlinge, und Allen, welche die ron Ehremberg uachgewiesene Organisation des Volvox nicht wiederfinten komnten, ist daher zu rathen, im ersten Friillinge die mittelgrossen Kugeln zunäclıst zur Untersuchumg auszuwählen umd nachlıer lie abweichenden Formen zu rergleichen.

Das Verhältniss der Gallerthülle zum 'l'hiere selbst scheint nach dem was Gonim pectorale zeigt und Chlamidomonas ahnen lässt, eine sorgfältigere Prülung zu verdienen. Sowohl bei Gonimn wie bei Volvox liegt jedes 'Thier in einer Gallertkugel, welche ein feiner Canal zum Austreten der Rüssel durchbohrt, dessen Mündung hei Volvox etwas unter die Oberfläche der grüssten Kugeln versenkt bleibt. Bei den meistens doppelt so grossen Einzelthieren von Pandorina Morum \%eigt sich gleich im Beginn der 'Theilung ein hellerer Saum um die griune Kugel, den man hei einiger Sorgfalt auch bei Gonium und Volvox stets wiederfindet, der aher bei Pandorina sich oft verdoppelt und verdreifacht, vermuthlich je nachdem die Theilung rascher oder langsamer fortsclıceitet. Späterhin wird 
sich Gelegenheit darbieten, solche Formen von Pandorina Morum durch Albbildungen zu erläutern, wo einzelne grüne Kugelı mit vierfacher Ilülle von verschiedener Dicke, oder zwei Kugeln, jede für sich in doppelter und daun 'ussammen in vierfacher Hülle, welche von innen nach aussen an Dicke zunehmen, beobaclıtet sind. Aufmerksames verfolgen dieser Vorgänge führt unabweishar auf die an und für sich schon plansibele Ansicht, dass die ursprüngliehse Hülle des Einzelthieres bei der Theilung durch nene Hüllen ersetzt werde, gleichviel ob die alte noch unter dieser oder jener Form mit ilem 'Thiere in Zusammenlang bleibt oder nicht, mithin eine jede 'Theilung zngleich eine lläutung bedingt, wobei dann die äussere Uülle plötzlich absterben kann und vergeht, oder alhülılig aus der organischen Verbindung scheidet und noch eine Zeitlang um die getheilten Indiviluen einen änssern Schutz bildet, wie bei Chlannilomonas unl Pandorina, oder für immer die Wohnstätte des Einzeldhieres mit sämmtlicher Vermelurung desselben bleibt, wie bei Volvox. Und doch hei so ähnlichen Verlıälunissen welche Verschiedenheit in der Anordnung! Bei Gonium liegt das einzelne Thier in ler Mitte einer Gallertkugel, welche bei Pandorina so gross wird, dass sämmtliche 'Thiere der ganzen Colonie dlarin Platz finden, wärend bei Volvox dagegen die Hülle ans lauter kleinen Gallert-Zellen bestelı, zwischen denen die Thiere in Intercellular-Gange gelagert sind; so dass in doppelten Gegensatze zu Gonium das Einzelthier in einer Hülle ans mehreren Zellen gehildet liegt und diese Zellen inmer mehreren Einzelthieren gemeinschaftlich als lä̈lle dienen. Bei Volvox pflegen $3-7$ solcher Intercellulargänge radienartig von jedem einzehnen Thierchen auszugehen, dahes meistens die Zellenflärhe hreieckig erscheint und an jeder Ecke derselben cin 'Thierchen wohnt.

Diese Modificationen neben der jedesmaligen Häutung bei der Läıgstheilung deuten auf eine wichtige physiologische Function jener gallertartigen Hiille hin, wie sicls weiter unten deutlicher herausstellen lassen wirl.

Volvox anrens und Volvox stellatus dü̈ften bei genaner Verfolg'ung der Uebergänge nur als Varietäten von V. Globator erkannt und mit Recht von einer zweiten Speeies wohl anatomische Verschiedenlıeit in den Einzelthieren gefordert werten künnen; goldgelbe Kugeln fand ich auch in Pandorina zwischen den griüen und die eigenthümliche Gestaltung der Gallerthïlle in $\mathbf{V}$. stellatus kommt much lıänfig bei anderen lufusurien vor und ist vielleicht von der Jahreszeit ablängig. Die Abweichungen, welche Ehrenberg an den Einzelthieren hemerkte, kommen aber wie nben erwähnt in viel höherem Grale bei Exemplaren ror, deren innere Kugehı weder gelh, noch sternförmig sint. Nur die Bedingungen, unter welchen diese Abweichugen vorkommen, sinl noch zu ergrüuden; da eine stärkere Loupe in geeigneten eckigen Glasgelässen bei einiger Uebung sie erkennen lässt, so darf man nur die an demselben Fundurte rorkommenden Volvox Globator etwa alle 14 Tage, so lange sie wälıend eines Jahres zu finden sind, mustern, und lic Sache wirl sich wahrscheinlich aufkliiren.

Fällt dam die Entscheilung zu Gunsten der hier angedenteten Ansicht aus, so ergiebt sich bei einem Ruickblicke anf die Fanilie der Kugelthiere, lass. wem Gyges wegfällt, sïmmlliche uibrige (mit Eimschluss der zweifelhaften Gattung Symura) 9 Gatungen lois jetzt jede mu eise sichere Species aufunweisen haben, welche an günstigen Standurten meistens im Frühlinge un Vursummer in nugeheures Anzahl die Gewisser zu bevölken pflegen. und die alle, bei hinreichender Verschiedenheit der ganzen Bildung und vielleicht noch grösserer des reineren Banes, sich als geringe Modificationen des Begriffes geselliger Panzermonaden erkrunen lassen. So \%. B. haben bei Pandorina und Lutorina alle Einzelthiere eine gemeinschaftliche Gallerthülle, in velelser sie malse der Prripherie gelagent sind; jedes Ein\%elthier vermehrt sich gleichzeitig mit allen übrigen derselben Kugel durch allseilige 'Theilung und verlässt bald früled bald spüter; direkt nath anssen frei werdend, diese Bildnugsstättc.

Bei Gonimm hat jedes 'Tlhier seine Haille fiu sich, die Vermehrung durch einseitige 'Theilung

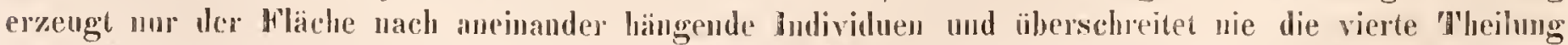

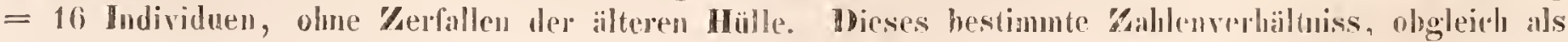



Möglichkeit ganz plausibel, kommt doch so regelmässig vor, dass eine Nothwendigkeit dafür gefunden werden muss, wie später nachzuweisen vielleicht möglich sein wird.

Bei Syncrypta bleiben die Einzelthiere in doppelter Hülle und liegen im Mittelpunkte der gebildeten Kugel dicht aneinander.

Bei Uroglena (und Synura) bleiben die Thiere ohne bestimmtes Zahlenverluältniss in gemeinsclıaftlicher Hülle dicht an der Peripherie gelagert beisammen, welche bei der ganz unregelmässigen Theilung in verschiedenen Richtungen eine strenge Kugelform niclıt lange beibehalten kann.

Bei Chlamidomonas scheint mit der Theilnng anch das Zerfallen der äusseren Hülle zu beginnen, welche, je nachdem sie langsamer oder schmeller vergeht, höchstens 6 bis 8 'Vhierchen ohne hestimmte Anordunng derselben nuschliesst.

Bei Sphaerosira liegen, wie bei Volvox, viele Thiere in einer, walıssheinlich bei beiden Gattungen vielzelligen, Gallertlülle, und zwar zwischen den Zellen derselben im Intercellulargange dicht an der Peripherie; die Theilung beginnt nur bei einzelneı in regehnässigen Abständen von einander dazu geeigneten 'Thieren gleichzeitig, bei Spluerosira durch einfache lä̈ngstheilung bei sehr vielen die nach a 11 ssen frei werden.

Bei Volvox bei wenigeren ( $8-20$ ?) durch allseitige Theilung, woturch Töchterkugeln gebildet

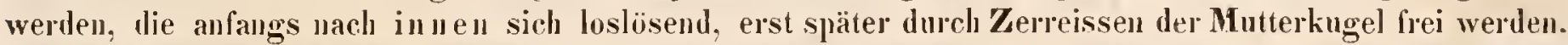

In höchsteı Grade unwahrschemlich und ohne alles Beispiel in der ganzen organischen Welt wäre es, wenn äusserlich so physiologisch verwaudte Gattungen durch spätere Entuleckungen in ihrem feineren Baue als rerschiedenartige erkamt wïrden; für die vergleiclıende Plysiologie ist es dagegen hüchsst wichtig durch die Kugelthiere zu Rückschlüssen auf die Panzer-Monaden und die eigentlichen Monalen besechtigt zu werden, weil letztere leicht aufunfulen, durch die loupe zu bestimmen sind und daher anf jedes neu heobachtete Organ oder Verloalten sofort geprift werden kïnen. Cueider sind alle Füterungs-Versuche hisher erfolglos ggeblieben; denuoch verspricht das ausschliessliche Vorberschen eines Kugelthieres selbst in grösseren Wasserbecken vielleicht einen Weg zu Beurtheilung ales Einflusses der Gesammthätigkeit so vieler Geschöpfe zu bahnen. Bis auf einige Fuss unter dler Oberfäche sind zu Zeiten manche 'Teiche gleichmässig so dicht mit Volvox Globator erfiillt, dass die Kugehn ıur um das 4-6fache ihres Durchmessers von einander entfernt sind; cine Kugel von 1/3" Durchmesser zählt auf ilırer etwa 1" messenden Peripherie 1/280" grosse, 1/z0" vom cinander entfernte 'T'hierehen 56. Bei Annahme pralleler Cirkellinien, mit im Quncunx stelienden Thierchen nud im Aequator und Meridian gleicher Anzahl, wiurde jede Halbkugel 14 Cirkellinien, die engste etwa 4 , die weiteste 56 in Mittel also 30 'Thiere führend, tragen, mithin zusammen 420 uml die ganze Kugel 840 Individuen beherbergen. (Ehrenberg herechnet eine viel höhere Zahl nach ciner Zählung der 'Thierchen an der Peripherie: letztere erscheinen dabei aher in solcher Verkiurzung, dass unser Auge die parallelen Reihen derselhen nicht mehr trenuen kann, daher Ehrenberg wohl die Indiviluer aus 3 Reihen zusammengezählt haben mag, denn: 140 Thierclien zu 1/288" gross und 140 Zwischemräume, die auch nach Elrenbergs Zaeiclnumg mindestens 3mal so gross wie ler Durchmesser des Einzelthieres waren; gieht für dle Peripherie ${ }^{76 \%} / 288^{\prime \prime}$ also fast $3^{\prime \prime \prime}$ und der Durchmesser der grossen Kugel hätte daın fast 1"' betragen miissen, währeml er zo 1/3" angegehen ist.) Ohige 840 Individuen bewohnen aber nu die Peripherie einer Kugel, welche 8 kleinere beherbergt. deren jelle wieder bis 8 noch kleinere umschliesst, die alle zu derselben Entwichelung, wie die grösste der Kugeh, gelangen sollen, welche demuach in günstigsten Falle $72 \times 840=60.480$ Individuen als Wohnumg dient. 100 solcher Kúlgeln, die man wälırend des Sommers leicht in einem Esslüffel voll Wasser haben kann, wirrlen also etwa auf 5 Millionen Einzelthiere geschätzt werlen müssen. Eigenthümlich ist es, wie regelnässig vertheilt, in fast gleichen Abständen, Volvox Globator im Sonnenscheine die Teiche bis anf mehrere Fuss 'Tiefe erfüllt, wonach sich die Individuenzahl für ein bestimmtes Wasserbecken ziemlich gut würde schätzen lassen. 
Von Volvox Globator sind nur die Kugeln, welche immer gleich eine grosse Anzahl von Thieren beherbergen, bekannt und zwar in einer Grösse, welche mehr durch die Eutwickelung del Gallertlülle, wie der Eimzelthierchen zu variiren scheint; Gonium pectorale komnt last in allen Grössen gleichzeitig vor, enthält aber immer 16 Thierchen, oder es sind Bruchstiicke soleher Gruppen von 16; Pandorina Morum fiihrt in ihrer Gallerthiille 1, 2, 4 bis 36 Kugehn ete., zeigt aher während des ganzen Sommers diese ungleiche Entwickelung, mur im Friillinge giebt es eine Zeit, wo die Gewässer nit kleinen Kugelı derselben erfïltt sind, deren Grösse fast übereinstimmt, welche vermuthlich dann entstehen, sobald die Vermehrung durch Theilung ihr Maximum enreicht hat und bei gïnstiger Wittermng einige Zeit ungestört bleibt. Chlamidomonas Pulvisculns scheint in jeder Grösse und jedem Stadimm der Entrvickelung immer gleichzeitig gefunden zu sein. Wie überwinten diese Thiere? Gewiss bleibt, dass sie im Sommer die Gewässer in zahlreichen Schwärmen erfüllen, gegen den Herbst hin seltıcr wrerlen und beim Eintritt des Winters ganz fehlen, das heisst nahe der Oberfläche, während olme Z Zweifel am Grunde die Thiere selbst oder ihre Keime vorhanden sind. Im ersten Somnenseheine des Frühlings steigen einzelne Häufehen von Oscillatorien, Conferven und anderen Algen durch im Lichte entwickelte sauerstoffreiche Luftblasen getragen an die Oberfläche und bringen alle diese Keime nud 'Thierformen mit lieraur, so dass man schon an Rande des schmelzenden Eises ïher eine Welt von Räılerthieren und Polygastricis verfiigen kam. Unter diesen schwankt Gonim pectorale mu in kleineren mud selmeren Exemplaren herum, wie im Sommer; Pandorina Mormm findet sich lıäıfig in einzelıen Kingelı, welche 1 grosses Indivilumm enthalten und nicht selten eine doppelte Gallerthülle zeigen, deren innere jüngere das Licht stärker bricht mul die optische Täuschung veraulasst, als ob in einiger Entfermug von der grünen Kugel ein heller Ring sichtbar würde (siehe Gyges Granulum); es kommen aber auch umegelmässige Gallertmassen mit sehr kleinen grünen Thieren in allen Stadien ler kreuzweisen Theilung vor, die sich durch ihre Lagerung in einger Entfernung von der Peripherie, den Mangel des rothen Punktes und die innere grüne Färbung als zu Pandorina gelıörig erkennen lassen; Clılanidomonas möchte in einzelnen beweglichen Exemplaren während dieser Zeit schwer von Microglena zı unterscheiden sein. Volvox Globator findet sich hier aber noch gar nicht vor. Ich vermuthe daher; und hoffe diese Vermuthung hald hestätigen oder herichtigen zu kümen, dass die Billung der ersten und zweiten Generation in den grossen Kugeln im Spätherbste minder rasch vor sich geht, zahlreiche und kleinere Kugeln gehildet werden, die of ganz absterben und daun goldgelb erscheinen (V. aureus?), oft nehrfache Schichten der Gallerthülle üher die halbkugelförmig hervoragenden Einzelthiere ablagern ( V. stellatus?). Letztere innere Kugeln würden frei werlend, durch das abweichende Verhältuiss der Gallerthülle zи den grünen 'Thieren, nicht an die Oberfläche steigen müissen, und kömnten am Grunde der Gewässer wärmeren Somnenschein nnd längere 'Tage gleichsam schlafend ahwarten.

Wer diese Verhältnisse sorgfältig geprüft hat, muss über die thierische Natur und die nalıe Verwanitschalt dieser Formen unter sich und mit den Panzermonaden ausser Kweifel sein, ganz abgesehen von der imneren Organisation; eine Verwechselung derselben mit Algenkeimen atc. bleiht um dadurch möglich, dass ganze Schichten fest eingetrockneter oder in Entwickelung begriffener 'Thiere der Art in Folge flüchtiger Untersuchung für Algen bestimmt sinl, wie Gleocapsa ampla, 'Ietrasjora

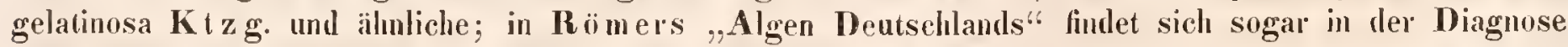
von Gleocapsa stillicidiorum $\mathbf{K g}$. angefïhrt, „mit se hr feinen gebogenen Fii den - (den Riissch der Monalen) - Interm is cht", während Kii tring die grosse Aehnlichkeit von Botryocistys Mormm mit Pandorina zugieht, als Unterschied hei Gleocapsa ampla aber anführt, dass rlie eingeschlossenen grünen Körperchen von einer hesonderen und weiten Ilülle ungeben sind, eine Anordnng, welche wie oben gezeigt, bei Pandorina wohl übersehen werden, aber nie fehlen kann. Wer solche Formen, die mangehaft entwickelt, verkümmert, oder nicht ausreichend untersucht sind, gewalisam zu neuen Algenspecies presst, kann natuirlich einelı Uehergang von Algen zu Infusoricn elc. nicht entbehren; das Bemühen denselben wissenschafilich nachzuweisen wird aber zu immer soıgfäligerer Untersuchung und 

- 
besserer Erkenntniss dieser Formen leiten, welche höchst wahrscheinlich ein Beweismittel für solchen Uebergang nach dem anderı richtig wird beurtheilen lehren.

Dann wird auch ein muschuldiges Geschöpf endlich zur Ruhe kommen kïmmen, womit bis jetzt zwischen beiden Reichen Fangluall gespielt ist, weil es selten unter das Mikroscop gelangen konnte, das Thier meine ich, welches die Hauptmasse des rothen Schmees bildet. Schom im Jahre 183!) erzeugte sich bei mir in Iyacintlenglaisern mit Flusswasser im Winter Agardls Protococens uivalis, erschien aber als Panzermonade mit Riissel md lebhafter Bewegung; im September 1842 hei der Versammlung ider Naturforscher zu Mainz (Bericht p. 217) wies Dr. C. Vogt nach eigenen Untersuchungen die thierischr Natur des rothen Schnees und die Uebergänge desselhen 'Thieres in alle von Shuttleworth nach flichtiger Untersuchmg als Astasia. Gyges und Pandorina unterschiedene Formen nach unt theilte mir nicht nur getrockneten rothen Schnee. somlern anch die ganz natürliche Entstehungs-Geschichte desselben mit. Durh Anfweichen der eingetrockneten Kugeln umb ih. Rullen unter dem Mikroscope komnte ich die Identität derselhen mit den von mir benhachteten Rüsselmunalen dureh Anffulung der feinen Oeffunng zum Austritte der Riissel an jeder Kugel nachweisen, mul glimbte mu an die Existenz einer solchen Panzermonade oder Kugelthieres, welches farblos. roth und grün gefïrht rorkommt, je nach der Entwickelung, Unterlage. Witterung und Jahreszeit. — Auf den weiten Schneegefilden der Alpen schmilzt die Frïlılingssonne die Oberfläche des Schuees $1 m$ in den Vertiefungen bilden sich kleine Lachen: unten in 'Thale jedoch, zwischen den Bergen erzengi die Somne eime viel höhere 'lemperatur und gegen Abend steigt die erwärnte Iuft in dej helannten Erscheinung des Thalwindes zu den Gletschem hinani, je năher der Schneegränze in um so rascherer Strömung. Dieser warme $\mathbf{V}$ ind trocknet manchen keinen Timpel und die Rïmler der grösseren anf seinem Wege aus, führt regetabilische Leberreste. Blätler. Hahme, anch Bruchstïcke ron Flechten und Monsen so wie kleine Glimmehbiutchen. Sandköner ete. mit Allem. was ron diesjähriger und letzter Flora und Fanna daranhängt, in jene Region mit hinauf mol setzt sie in die neugebildeten Lachen des rwigen Schnee's zn weiterer Entwickelung ab, daher anch alle Beobarhter zwischen den rothen Schnee die Glimmerblätchen beobachtet hahen, welche doch nicht auf orler ans dem Silnee gebildet sein kömen. Mit ilnen weht natülich auch manches andere ans jenen ganz oder theilweise trocken werdenden Sümplen hinaul, welches Keim zu künftigen Pflanzen unl Thieren werden kömte; in jener Temperatur des ewigen Schnees, muter ranhen Vinden und intensivem Lichte in dimmerer Atmosphäre gedeihen aher nn änsserst wenig organische Wesen, und die Art ihrer Entwickelung weicht von der an anderen Fundorten ab. - Die Vermehrungsweisen sind folgende:

1) Durch Bruthömer (Eier?) - Die Hiille ler Körper vergeht oder platzt und es treten eine Menge sehr kleiner rother Könchen aus, deren jedes sich zunächst zu einem neuen Individumm entwichelt;

2) durch Gemmen oder Sprossen-Bilklung; indem einzelne Kürnchen des Parenchyms sich abschuirren, durch allmähliche Vergrösserung ganz ablösen und zu neuen Iuliviluen heranwachsen;

3) duch Längs - nud Qneertheilung, wobei doppelte und vierfache Exemplare noch von einem gemeinschaftlichen Panzer umschlossen vorkommen. -

Von diesem Gesichtspunkte ans betrachtet, bietet die Abhandhug ron r. Flotow (Verhandlmogen der kais. Jeop. Carol. Akademie der Naturorscher XII. 2. 1844) über Haematococcus plurialis v. Flw., jede un zu wünschende Bestätigung del Ansicht. dass die Masse des rothen Schnees, so wie manches Blutregens, von einer Panzermmade gebildet werde, obgleich das mnglickliche Vorurtheil dieses Gebilde sei eime Alge, und jede durch äussere Einfiusse. durch Verkümmern und Absterben erzengte Entwickelungsstufe sei eine Jebensform. zu Mbyrinthisch verwickelten Versuchen, Messungen und. Benemungen fülıte, welche die ans Licht tretende Wahlleit abstreifen wirl, wie der Schmetterling die Raupenhülle. - Nur die Frage schwebt noch: bahen wir ein neues Thier von uns, oder ist es ein bekamntes durch jene Einflïsse in seiner Ausbilung gehemmtes Wesen? - Eire kugelige grüne Panzermonale, olme rothen Augenpunkt, mit doppeltem Rüssel findet sich in Ehrenbergs Werk 
noch nicht aufgeführt, aber schon geahnt und bei Cryptomonas? glanca als Diplotricha angedeutet; Panzer, Rüssel und Augenpunkt gehören aber zu den schwierigsten Kennzeichen und sind häıfig von verschiedenen Beobachtern übersehen; bei den rothen Formen würde ein Angenpunkt schwieriger zu erkemnen sein, und manche für eimrüsselig gehaltene Monaden lassen vielleicht später noch einen zweiten Ruissel erkennen, so dass hier die Bestimmung noch einige Schwierigkeiten darbietet. Es darf aber nicht unbeachtet bleihen, dass auf dem ewigen Schmee nichts anderes gedeihen zu scheint wie diese (fraglich als Diplotricha? nivalis zu bezeichnende) Form und Philodiua roseola, erstere jedoch; zwischen der reichhaltigen Fauna unserer Gewässer zerstrent vorkommend, selır sclıwer zı unterscheiden ist, wenn sie grün gefärbt elscheint und nicht festgelegt oder zerdrückt werden kanı. Enıllich stimmt die vollkommen ausgebildete Form ganz z, einem Linzelthiere ron Gonimn oder Pandorina, die Grösse und imnere Färbung können, wie sich später bei Euglena zeigen wird, durchans nicht als triftige Gegengrïnde angeführt werlen; wie! wemn die 'Temperatur des ewigen Schnees nur die Ausbildung vollkommenerer Monadenstöcke ganz verhinderte, die ja in unseren stehenden Gewässern gegen Mitte Sonmers ¡hr Maximum erreicht, gegen den Spätherbst sinkt und im Winter ganz aufhört? Der rothe Schuee wäre dann nur die Winterform von Pandorina, wo die Theilung langsam vor sich ginge, und lie Hiille friiher die imeren 'I'hiere frei liesse, oder die Diplotricha wenigstens lie angenlose, ler Chlanilomonas entsprechenle Form, der Kugelthiere? - Solche Fragen dürfen nur aufgeworfen sein und ein geülter Beobachter findet Gelegenheit anls nene jene 'Thierchen des rothen Schnees zn untersuchen, so wird sich das Räthsel lösen. - Auf unseren Gewässern bilder sich oft gleich nach dem Schmelzen des Eises in Mär' eine grine Hant, welche aus ganz ähnlichen Monaden besteht, die bestimmt angenlos sinı, als gepanzert und mit zwei Rüsseln versehen, sich freilich nicht olne Schwicrigkeit erkennen lassen, und in der Mitte des Körpers eine rumle Drïse mit zwei contractilen Blasen zu jeder Seite anfweisen. Diese Thierchen theilen sich in zwei und vier noch immerhalb ihres Panzers: aber zwischen ihnen kommen auch schon die entsprechenden Formen von Pandorina Mormu vor, welche nur runder erscheinen, aber zu dieser Jahreszeit wirklich kleiner gefunden werden, wie einzelne Panzcrmonalen daneben.

\section{Vierie Familie. Vibriouia. (Zilterthierchen.)}

Die Monade war kugelig bis zur Ei- und Cylinderform, die Panzermonade durch äussere Hülle, das Kugelthier durch unvollkommene Selbstheilung unterschieden: die Zitterthierchen sind Monaden ohne Darm, ohne Anhänge, olne Panzer — die sich unvollkonmen y ueer theilein, laher fadenartige, wie Perlen auf der Schnur aneinanlerhängende 'I'hierformen bilden.

Physiologisch ist diese Familie fast ganz unfruchtbar geblieben; die sehr kleinen Eimzelthiere haben nirgend eine Organisation erkennen lassen, welche an rerwande Furmen uml Erscheinungen sich anreihen liesse und nur die Beweglichkeit und ungeheure Anzahl, in welcher sie heisammen gefunden werden, zengen für ihre thierische Natur, welche nie in Zweifel gezogen zu sein scheint.

Eine weitere Erörterung dieser Familie ist hier demnach ganz überflissig und führe ich nur der Vollståndigkeit wegen die Unterschiede der Gattungen an:

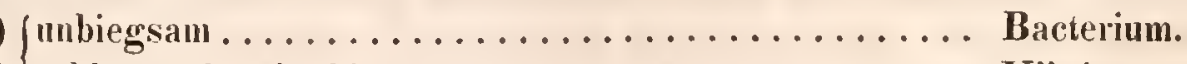
als geradelinige Körper (durch schlangenförmig biegsam .............. Vibrio. rechtwinklige Queertheilung) (gewundene Gliederfäden biegsam............ Spirochaeta. Gliederfäden als spiralförmig \{ gekriimmte Körjer (durch schiefe (?) Quecrtheilung) 
Also nur die äussere Form, wie sie durch Modificationen der Theilung entstelıt, und bei den Bewegungen naclıgiebig oder starr bleibt, giebt hier die Unterschielle für die Gattungen, welche immer nur als Monadenstöcke, nicht als Individuen hestimmbar sind.

\section{Fünfte Familie. Clostelina. (Spindelthierchen.)}

Nach Ehrenliergs Eintheilung sullen die Spindelthierchen gepanzerten Vihrionen gleichgestellt sein, während die Bacillarien gepanzerten Amiben entsprechen; die Eudeckung von Oeflnmgen und hervorragenden Organen an den Spitzen hestimmte diesen Forscher zu der Ansicht, als sei ein Closterium, wie zwei mit den Rücken aneinanter geheftete Diffugien zu hetrachten. Diese gewiss hüchst geistreiche Dentung war hei dem zu damaligerZeit vorliegenden spärlichen Materiale um so mch" zu hewundern, aber leider war sie keine glückliche $\mathbf{W}$ ahl unter den verschiedenen Möglichkeiten. Die Ergehnisse neverer Beohachtungen haben unter mancherlei Aufklärungen über die Entwickelung und Vermelıung dieser Körper anch dargethan, dass:

1) die Oeflnungen an den Spitzen sich selbst bei eingen griisseren Arten durclans nicht nachweisen lassen;

2) ebensowenig die Organe, welche daraus lıerorragen sollen, und

3) jedes Closterium, ans zwei symmetrischen Hälften bestelıend, fiir ein Individunm anzusehen ist.

Mit diesen Er'mittelungen bleibt aber jene Ansicht mmsereinbar mol zu älmlichen Schlïssen müssen anch neuere Entdeckungen in einer anderen Fanilie, den Desmidiaceen, führen, welchen die Closterien jetzt so nalıe verwanlt erscheinen, dass eine 'Tremmıng unmatürlich wäre und namentlich die neue Gattung 'Tetme morus - Ralfs, soweit his jetat musere Kemtnisse darïher reichen, mit völlig gleichem Rechte zu beiden Fanilien gezogen werden könnte. In der Voraussetzung, dass eine nälıere Untersuchung zu einer Verschmelzung der Closterina mit den Desmidiaceen fiilıen köune, stelle ich zunächst eine Vergleichung des Banes, der Entwickelung etc. einer Gattung der Desmidiaceen mit den Closterien zusammen·und habe von ersteren diejenige, welche die grössten Formen aufweisst, gewählt: die Gattung Eu astrum.

Diese Gattung gehört zur Familie der Desmilliaceen, welche die einschaaligen Bacillarien umfasst. Folgen wir zunächst der Fihlenhergischen Eintheilung bis zu dieser Familie. - Die Monaden characterisirten sich als darmlose und anhanglose Polygastrica, deren Körperform beständig war; es folgen nun ganz älnliche 'Thierformen, deren Gestalt durch abwechselnde Contractionen und Expansionen des ganzen Körpers veränderlich ist, und welche panzerlos = Astasiaea, oder gepanzert = Dinobryina sind, womit die erste grosse Alitheilung der Auhanglosen schliesst. Die folgende Abtheilung der Wechselfüssigen umfasst Thiere, dereı Körperform veränderlich ist, aber nicht durch abwechselnde Zusammenziehungen des ganzen Körpers, sundern durch das Vorstiilpen einzeher Parthien der Oberfläche in Fortsätze, Iaapıen oder Fäden, welche den Fusse der Nacktsclmecken ähnelı, aber ganz. zuriickziehbar sind; an jeder andern Stelle les Körpers unter jeder beliebigen Form sich neu bilden kömneı, ınd in welche das Parenchym des Körpers nachrïckt; daher Wechselfüssige= Pseudopoda. - Sie sind panzerlos = Amoeboea oder gepanzert, und strecken dam einen vieltheiligen Fuss aus einer Oeflumg = Arcellina, wer einen einfachen Fuss aus jeder Oeffnung = Bacillaria.

Diese Familie der Bacillarien umfasst somit die gepanzerten polygastrischen Infusorien, welche darmlos und mit veränderlichen Fortsätzen ıles Körpers versehen simd, die aus jeder Oefluung des Panzers als ungetheilter Fuss hervorgestreckt und wieder eingezogen werden können. Sie zerfallen in einschaalige $=$ Desmidiacea und $\%$ weischaalige $=$ Naviculacea.

Die Desmidiaceen sind mikroscopische Gebilde des süssen Wassers, welche in einem häutigen gallertartigen oft doppelten Panzer einen sehı zarten, wasserhellen, weichen Körper umschliessen, dessen grösster 'Theil in der Regel grün gefärbt ist. (Die Gattung Microtheca lıat einen Kieselpanzer 
und gehört zu den Naviculaceen.) Die bekamnten Gattungen umíassen freie, nicht angeheftete, stiellose Organismen, aus zwei symmetrisch gebildeten Körperhälften bestehend, welche sich durch vollkommene Queertheilung vermehren oder durch unvollkommene Theilung kettenartige Bänder bilden, worin je zwei Glieder einem Individuum entsprechen. Sie zeigen deutliche, wenn auch langsame Ortsverändermug, eine lebhafte Bewegung imnerer kleiner Kügelchen und beim Absterben eine Veränderung der grünen Farbe in lorann, während der ganze Inhalt des Panzers siclı in kleine unregelmässige Klumpen zusanmenballt, bis später die beiden Iälften auseinander fallen und ler Inhalt im Wasser aufgelöst wird. Ihre Verwandtschaft zu Closterium wird sich im Verfolg dieser Untersuchungen feststellen, von den Naviculaceen unterscheidet sie ilır weicher nicht kieselharter; verbrennlicher Panzer und von den unbezweifelten Algenspecies die bestimmte Gestaltung und Aligeschlossenheit ihrer Körperform, so dass jeder geülte Beobachter eine neue Art auf den ersten Blick als zu den Desmidiaceen gehörig erkemen wirl.

Die hiel zum Vergleiche ausgewälılte Gattung:

Euastrum. Sternscheile - zeichet sich unter den Desmidiaceen durch einen flach zusammengedrückten, daher scheibenfürnigen, meistens lïnger als breiten Pamzer aus, dessen seitlicher Rand Lappen, Ausbuchtungen, Einkerbungen oder Zähne trägt, und ans zwei symmetrisch gebildoten Hälften besteht. Der innere gailertartige, wasserhelle Körper erfiillt den Panzer his dicht an den Rand, den feineren Einschnitten in Aacherem Bogen voriberstrcichend, und enthält selten grössere Blasen, zeigt unter stärkerer Vergrössermug eine sehr feine Punktirung und ist mit kleinen dunkel begränzten Pünktchen, die in lebhaftester Bewegung sind und ron einem Cude zum anderen streifen, in grösserer oder geringerer Anzahl durchsäet. Die sehr grosse Anzahl solcher Piunktrhen in einigen kleineren und dickeren Arten gieht lenselhen hei durchfallendem lichte nicht selten ein bräunliches Ansehen, sonst hat man bis jetzt mur gr ï ne Euastra beobachtet, deren Färbung an der Verbindungsstelle beider IIälften und den Endpunkten der Längsaclıse hlasser ist oder ganz fehlt. Bei den verschiedenen Arten bildet die grïne Färlung oft dunklere unregeluässig gefaltete und geschlängelte Längsstreifen, häuft sich in dunkleren Massen in der Nähe der Verbindungsstelle an. oder zielı sich auch in breiterem Samme von den seitlichen Contonren ganz zurick. Die einzige bekannte Vejmchrung gescheht durch eine eigenthümliche Art der Qneertheilung, indem sich zwischen beiden Hailften, von jeder Seite eine neue bildet, die anfangs als hlasenartige Hervortreilung nur von fabloser Gallerte und einzelnen grösseren Kügedchen erfüllt ist, in welche allmählig die grüne Färbmng narhriokt, während bei fortschreitender Vergrösserung auch die Form der Mutterhälfte sich tlaran entwirkelt. Nach vollenteter Ausbildung derselben, olt früher, tremen sich die vier Hälften in zwei Individuen.

Die Sternseheiben kommen in süssem und selbst hrackigem $1 V^{\top}$ asser vor, einige Arten fast überall zwischen Conferven, andere seln selten und die grösseren und zierdichsten Species meistens nur in 'Torflachen oder den Abzugsgrälen der 'Torfmoore. Die Grösse der hekannten Arten wechselt von $1 / 200 "$ " his 1/6"'; hei derselben Art zeigt sich jedoch häulig eine anllallende Verschiedenlieit der Grösse und Ausbildung, nach dem Fundorte, der Jahreszoit und viclleicht lde IVitfrong. wovon bri der Beschreibung der Species Beispiele erwähnt werlen.

Die zusammengedrickte Form des länglichen Panzers giebt den Sternscheihen nach den drei Dimensionen der Länge, Breite und Dicke Achsen von verschiedener Länge, da viele Arten mannigfach gestaliete Auftreibungen des Panzers hald anf dieser hald and jener Fläche zeigen, so bleibt es ein unerlissliches, aber anch geniigendes, Erforderniss, jedes Euastrmu von drei Seiten zu hetrachteu, so dass jedes Mal eine dieser Achsen mit der Sehachse des Mikinscops zusammenfällt, oder um ein dentliches Beispiel zu geben, sie zu betrachten wie eine Münte auf der ein láopf geprägt ist, so lass man ersi senkrecht anfs Ohr, dann senkrecht auf die Nasenspitze und endlich senkrecht ant den Scheitel sähe. 

Die von mir bis Mitte 1845 beobachteten Arten sind auf der ersten 'Tafel alle in gleicher Vergrösserung neben einander gestellt, zunäclıst wie sie von der Fläche gesehen erscheinen. In den beiden anderen Lagen sind fast alle Arten bei solcher Vergrösserung undurclisichtig und man kann nur durch intensives Licht die äusseren Umrisse, idealen Durchschnitten entsprechend, erkennen, welche neben und über jeder Figur angebracht sind. Zu diesen Abbildungen sind die griossten und schïnsten Excmplare, welche mir zu Gebote standen, ausgewälılt, und diese Darstellungsweise macht die Ausarbeitung concisel Diagnosen für jede einzelne Species ganz ïherflïssig, da die Form und Grösse des Panzers lier allein den Unterschied der Arten bedingt, und ijber beide Punkte kein Zweifel bleiben kann; so dass jeder Iseser im Stande ist, die Diagnosen nach diesen Abbildungen mit Sicherheit festzustellen. Uebrigens liegt bei der Gattung Euastrum gerade der Fall vor, welcher bei einer Monographie stets der sclılimmste ist, nämlirlı die Schwierigkeit in Unterscheidnng bestimmter Arten. Bei Euastrum ist ein grosser 'Theil dieser Schwierigkeiten allerdings in der Natur selbst begründet, allein die Śchriftsteller lıaben die Sache unendliel, viel schlimmer gemacht und eine schwer zu ordnende Verwirmng angerichter, welche sich von dem ersten Beobachter (1819) bis auf msere Zeit, wie eine in Fortriicken stets wachsende Isawine, heralgewälzt lat. Obgleich die Verzeichnung wissenschaftlicher Irrthümer eine traurige Pflicht, wïrle ich mich gern der Ausarbeitung einer pragmatischen Geschichte dieser Gattung unterziehen, wenn es möglich wäıe, sclın eine dauernde Clıaracteristik der einzehnen Species zı geben; so wie ich aher jetzt die Sachlage finde, muss folgente fliichtige Skizze gentigen:

Der Entdecker der Gattung, der verdienstrolle Algologe Isyngbye, verzeichnete unter seinen Algen 1819 ein oder mehrere Arten als Echinella radiosa, denen A gar li 1824 den Namen Echinella ricciaeformis gah. Der schon 1803 ron Agarlh verwantte Name Echinella liat aber vielleicht die verschiedenartigsten Naturkörper unfasst, die je einen gemeinschaftlichen Gattungsnamen führten, wie Insekteneier, Desmidiaceen, Naviculaceen, Oscillatorien etc., und ist schliesslich von Ehrenlı rg fiir die angehefteten, kieselschaaligen Bacillarien verwandt. So lange die Euastra nur für Algen galten, erhielten verschiedene Species mancherlei Benennungen wie Helierella und Heterocarpella, B ory de $\mathbf{S t}$. Vincent, Micrasterias Agardh, Ursinella Turpin, Oplarium Losana etc., unter welchen wirkliche Algen und gauz zweifellafte Organismen mit begriffen wurden, oder deren sprachwidrige Zusammensetzung eine Beibehaltung uicht empfehlen kounte, so dlass Ehrenberg, als ilm dieselben mehr thierische wie pllanzliche Kemzeichen boten, den neneu Gattungsnamen Euastrmm einfülıte, um weder botanisch schon verwendete oder fehlerhafte Namen in die Zoologie zu ibertragen. - Nun aber entstand eine förmliche Sprachrerwirrung. Die Algologen glaubten sich nicht verpllichtet bei ihren Bestimmungen auf alle für Infusorien veröffentlichte Synonyme Rücksicht zu nehmen, neu entdeckte, aber unvollkommen beobachtete Arten wurden zu besonderen Gattungen erlıolsen, und verschiedene Synonyme neu hervorgesucht, um durch ihre Priorität die Gattung zu zersplitteru. Diesen fruchtlosen Bemülungen rerdanken wir noch die Einführung der Namen Cymbella (Agardh), Cosmarium und Colpopelta (Corda), Eutonia (I arvey) und Holocystis (Hass al), alle aufgestellt, weil die Autoren unwesentliche Charactere als unterscheidende Gattungsmerkmale glaubten ansehen zu diirfen, oder die vorhandene Literatur unberiicksichtigt liessen. Zu verwundern ist es daher nicht, dass der ausführlichste Bearbeiter auch dieser Gattung der Desmidiaceen $\mathbf{R}$ alfs, ubgleich er dieselbe umöthig zersplitterte, keines neuen Namens bedurfte, indem er nu für eine selı verwandte, von ilm zuerst heschriebene, aber stielrunde Gattung den Namen 'Tetmemorus einfiilıte. - D Die Ansichten und Grundsätze der einzelnen Antoren liessen sich mur bei den einzelnen Species selbst einer griundlichen Kritik unterwerfen, die wesentlichsten Monente boten jedoch Zufälligkeiten, wie das Verhältniss der Länge zur Breite, die Beschaffenheit des Randes oder der ganzen Oberfläche, die nach dem Entwickelungszustande wechseln und dalıer nie als Gattungsmerkmale dienen kömnen. Ich verweise den Leser daher auf nachstehend mir bekannt gewordene Abhandlungen, worio eigene Beobachtungen der Verfasser veröffentlicht sind: 
1819. Lyngbye. Tentamen hydrophytologiae danicae.

1820. Turpin. Dictionnaire des sciences naturelles.

1824. Agardh. Systema Algarum.

1825. Bory de St. Vincent. Dictionnaire classique d'histoire naturelle.

1827. Agardl. Flora oder botanische Zeitung.

1828. Turpin. Mémoires du Museum d'histoire naturelle. VI.

1829. Losana. Memorie di 'Torino XXXIII. (Isis 1832.)

1830. Greville. Hooker: British Flora.

1830. A garll. Flora oder botanische Zeitung.

1831. Ehrenberg. Abhandlungen ver Akademie der Wissenschaften zu Berlin.

1833. Kützing. Linnaea.

1833. Ehrenberg. Abhandlungen der Akademie d. W. zu Berlin.

1835. Corda. Almanac de Carlsbad.

1838. Ehrenberg. Die Infusionsthierchen etc.

1840. Meneghini. Linnaea.

1841. Baily. Sillimans: American jommal for science and arts. XLI. 2. October.

1844. Ralfs. Annals and magaziue of natural history. XIV.

1845. H assal. Britislı freslı water algae.

Für die Aufstellung einzehner Arten der Sternscheiben müssen leitende Grundsäize angenommen werden, um die vielfachen Fehler fruiherer Beobachter in Zukunft vermeiden zu lernen. Einige Schriftsteller, namentlich $\mathbf{R}$ alfs, lıaben sclıon früher Seitenansichten etc. gegeben, manche Verwechselung der kleineren Species ist aber leicht möglich, wem man nicht auch den Quecrdurchschnitt kennt und ganz sicher stellen nu' perspectivische Zeichnungen, wie ich einige auf Tafel II. Fig. 22 lois 26 darzustellen versuchte. Die Geschichte der Entwickelungszustänle bleibt anch hier die sicherste Lehrerin, aber selbst günstiger Zufall und eifriges Nachsuchen machen ilıre Lehren nur spärlich zugänglich. Die bekannte Vermehrungsweise fudet durch Bildung nener Hälften zwischen den alten statt, leren erste Anlage als ungeformte, blasenartige Hervortreibung zwischen den Hïliten erscheint (I'afel II. Fig. 5, 13), wobei sich durch das Nachrïcken des grün gefärhten Inhaltes die freie Communication zwischen beiden, der alten und nenen, unzweifelhaft darthut. Zunächst sind die heiden Generationen, obgleieh oft schon völlig abgetrennt, aus höchst ungleichen Theilen gebildet ('Tafel 11. Fig. 4, 5, 6, 11), nicht nur in der Aufsicht, sondern auch im Längendurchschnitte ('Tafel II. Fig. 3), wo beide ältere IHälften noch wesentliche Verschiedenheiten zeigen. Erst allmählig bilıtet sich die feinere Zeichmmg des Randes auch in der nenen Hälfte scharf aus, je schneller sich die Theilungen wiederholen, desto verwischter und minder tief werden alle Ausbuclıtungen, Zähıe und Einschnitte gefumlen werden, und ein so wechselndes Verläluniss kann folglich nicht zu Untersobejdung von Gatungen und Arten dienen. Dasselbe gilt von griisseren und kleineren Auftreibungen. T'Tijpfolı und feines Stachelı des Panzers, deren minder oder stärker und schärfer Hervortreten durch Altersverschiedenheit bedingt wirt. Endlich die Verbindung zwisolsen beiden Hälften ist stets eine fïrmliche Naht, die sich heim Alsterhen trennt,

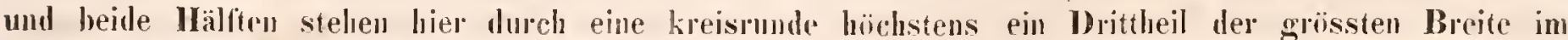
Durchmesser halfende Oeflumg in freicr Verbindung; bei den dickeren um kleineren ist diese Verbindung oft sclower zu selsen und dahin gehörige Arten siud als in der Mitte zusammengesclunürt anderen, welche tief in zwei Abschnitte getheilt sein sollten, gegenuborgestellt. Solche Unterschiede sind gar nicht vorhanden und die Nothwendigkeit durch ganz unwesentliche Formverschienlenheit differirende Species, die in allem Wesentlichen glcichartigg gehildet sind, in verschiedene Gattungen zu vertheilen, wird einem Physiologen nie einlenchtend gemacht werden kämnen. 


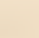


Euastrum. Steruscheibe. Ehrenbelg. - Tafel I.

Euastra sind mikroscopische Organismen des süssen Wassers von bestimmt abgegräızter aus zwei symmetrischen Hälften gebildeter Körperform, die einen flachgedrückten verbrennlichen Panzer haben, deren Körper grösstentheils griun gefärbt ist, die sich durch vollkommene Qneertheilung vermehren, nie eine zweite Gallerthiille um sich zeigen und länger als breit sind. - Verwechselungen mit Infusorien sind kaum möglich, von den eigentlichen Bacillarien durch den Kieselpanzer derselben bestimunt unterschieden, von den Desmidiaceen durch die flachgedrüekte For'm des Panzers, welche nur bei Xantlidium aber mit doppeltem Panzer wieder vorkommt.

1) E. minutum. 1/120". - Diese kleinste Art findet sich häufig zwischen Conferven und besteht aus zwei flachgedrückten, ganzrandigen ovalen IIälften. Bisher hat man sie überselen oder junge Exemplare anderer Species vor sich zul laben geglaubt; da ich jedoch Queertheilung beobachtete und läufig im Bodensatze der Gräben leere Hälften sets rou derselben Grösse fand, so ist an der Arten-Verschiedenheit nicht zu zweifelı und ein kleineres Euastrum möchte schwerlich gefunden werden. In der Mitte jeder Hälfte zeigt sich ein dunklerer Körper, wenn nicht die Form eine optische 'Täuschung bedingt, worïber bei so kleinem Objecte auch die zur Einstellung des Focus benuzte Mikrometerschraule keinen bestimmten Aurschluss giebt.

2) E. ornatum. 1/60". - Cosmarium ornatum. Ralfs. - Doppelt so gross wie das Vorige, nicht so flach und die Mitte jeder Hälfte anf der Fläche in eine halbkuglige Blase aufgetrieben, wie im Queerdurchschnitte Jeutlich ist. Aeltere Exemplare werden breiter wie lang und die Hälften gegeneinander gebogen, so dass neben der Verbindungsstelle ähnliche Aushiegung entstelı wie in Fig. 6 und 10, 'Taf. I. Der ganze Panzer ist mit feinen 'Tüpfeln besetzt und das Innere oft dicht mit tanzenden schwälæzlichen Käruchen erfüllt, wobei zugleich eime lebhafte Ortsveränderung statt zu finden pflegt. Queertheilung ist noch nicht benhachtet, doch ist sicher keine zweite Gallerthülle zugegen, wodurch die Species zu Stanrastrum gehören würde. -

3) E. crenatum. 1/65"“. - Cosmarium crenatum Ralfs. - Etwas kleiner, ganz flach und mit regelmässig ausgekerbtem Rande. Ich lıabe diese Art selır läufig mit den vorigen gefunden, doch wahrscheinlich nie ältere Exemplare, deren Panzer in torfigen Wasser zuletzt eine bräumliche Färbung annelmen, Queertheilung und viele leere Hälften von fast gleicher Grösse sind heobachtet, auch hat der Längsdurchschnitt etwas eckiges gegen die Mlitte und die Spitze, was keine andere Art wieder zeigt. -

4) E. spinosum. 1/50". - E. spinosum und hinale $\mathbf{R}$ alfs. - Der Unterschied zwischen den beiden von $\mathbf{R}$ alfs aufgestellten Species beruht in Wesentlichen auf den scharf zugespitzten Randzähneı, welche doch alle Uebergänge vou der abgerundeten Spitze bis zum scharfen Stachel zeigen. Ich fasse daher die beiden Arten unter dem zuerst von $\boldsymbol{k}$ alfs gegebenen Namen spinosum wieder zusammen und muss Heterocarpella binalis (Turpin) und Cosmarium binale (Meneghini) als fragliche Synonyme beifiigen, weil ich keinen stichhaltigen Unterschied nachweisen kann. Leider passt die Benenunung spinosum zn der gewölunlichsten Form Tafel I. Fig. 4 selır schlecht und erst bei solchen Uebergangsformen wie 'Tafel II. Fig. 16 ist dieselbe angebracht; es schien jedoch nieht zweckmässig durch einen neuen Artnamen noch grössere Verwirrung der Synonyme zu veranlassen. Bei dieser Art zeigen sich znerst grössere und his um die Hälfte kleinere Formen in demselben Gewässer, was auf eine besondere Art der Vermehrung hindeutet, wenn nicht die Queertheilung viel früher beginnt und länger dauert. Bei den grösseren Arten lassen sich alle diese Verlültnisse weit leichter verfolgen.

5) E. ovale. 1/s0". - Cosmarimm ovale Ralfs. (Die Synonyme der übrigen Schriftsteller sind, wo keine bestimnte Vergrösserung angegehen und nur die gewölunliche Auf́sicht gezeichuet ist, selten zu deuten: Elıenbergs E. integerrimum und Cordas Cosmarium Cucumis gehören fraglich hieher - Baily bildete in seiner Fig. 28 dasselbe, aber dreifach 'so gross und mit einem helleren Längsstreifeu durch die Mitte, als ob sich eine Längstleilung vorbereitete, ab). Diese durch ihre 
einfache Form und ein sehr saftiges Grün ausgezeichnete Art giebt den eigentlichen Euastruın-'Typus, von welchem durch geringe Abänderung der Gestalt mittelst Auftreibungen anf der Fläche und am Rande oder tiefere und flache Einsclınitte des letzteren alle übrigen Arten abgeleitet werden können. Leider ist mir diese zierliche Form nur selten vorgekommen, loch salı ich dergleichen mit glatten und getiipfeltem Panzer; Queertheilung kam mir nicht vor.

6) a. E. margaritiferum. 1/24". - Diese läufigste Species ist am leichtesten zu finden und variirt nicht allein in der Grösse sondern auch in der Form, daher die vielfachen Benemungen. Bis vor Kurzem glanbte ich alle Uebergänge von Ehreubergs E. margaritiferun, integerimun und Botrytis gesehen zu haben, wie solche zum T'heil auf Tafel II. Figg. 17-21 abgebildet sind; später fand ich jedoch, dass Fig. 18 daselbst eine hestimmte Species sein diirfte, da ich es von verschiedenen Fundorten in derselben Form erlielt. Letzteres ist Ehrenbergs E. Botrytis des griisseren Infusorienwerkes ( $=$ E. angulosum Elır. 1835). $\multimap$ Als Synonyme bliehen danach anlinfülıren: Heterocarpella pulchra (Bory) - Ursinella margaritifera ('Turpin) - Cymbella reniformis (Agardh) - Heterocarpella tetrophthalma, polymorpha und ursinella (Kïtzi ig) - Cosmarium deltoides und dentiferum (Corda) - Cosmarium margaritiferum (Ralfs). - Natïrlich haben Verwechselungen mit E. ornatun, wo nur die eine Isage beobachtet ist, nicht vermieden werden könsen mul ist eine richtige Vervollständigung der Synonymie unmöglich. - Die Häufigkeit dieser Art und die Möglichkeit grüssere Exemplare mit der Loupe aufzusuchen, gab mir Gelegenheit, umfassendere Beobachtungen anzustellen. Die auffallende Verschiedenlıeit in der Grösse schien auf die Möglichkeit hinzudenten, dass die kleineren Exemplare ihren Ursprung einer anderen Vermehrungsweise verdanken, wie der Queertheilung, und schon hatte mir die Erfahrung das Vorkommen dieser Species an gelegenen Fundorten während der ganzen frostfieien Zeit des Jahres bestätigt und war mir die Ueberwinterung mehrfach gelnngen. Ich sammelte viele łer grössten Exemplare in einer kleinen, flachen, kantigen Flasche (1 Zoll breit und 9" dick - aus einem Reise-Necessaire), welche ich geöffuet ans Fenster stellen, oder auch, ganz gefüllt mit dem eingeriebenen Stöpsel verschlossen und vorsichtig umgelegt, direkt unter das Mikroscop bringen konnte. Bald hatten sich hie ınd da an die Wand dieses Gelässes einzelne Exemplare festgesetzt, durch die Loupe liess sich die Queertlıeilung beobachten und unter dem Mikiwscope zeigte sich in der Mitte jeder Hältte die in den Figuren 6 der 'Tatel I. und 17, 19, 21 des. 'Tafel II. gezeichnete hellere Stelle mit dunklen tanzenden Punkten. - Die Gelegenheit in solchem Falle die Ortsveränderung zu beobachten war sehr günstig und während des Sonmers verschwand stets jedes einfache Exemplar binnen 2 Stunden aus dem Sehfelde, während in der 'Theilung hegriffene fest liegen blieben, und selbst nach erfolgter 'T'leilung noch läıgere Zeit nur' um ein Geringes auseinander rïckten. Die Fortschritte der Queertheilung erlaubte die schwächere Vergrösserung (die Dicke der Glaswand war grösser wie die Focaldistanz ler stärkeren Linsen-Combinationen) und die stets schiefe Lage der Körperchen nicht genugsam zu verfolgen; dagegen zeigte sich die merkwürdige Erscheinung einer die Queertheilung begleitenden Häutung. Schon vor derselben finlet man Exemplare wie..Taf. I. Fig. 6 . mit einer zweiten Gallerthülle umkleidet, die nach der Theilung fehlt, und oft als abgelegtes Kleid noch in der Nälı zu sehen war, wälırend kleinere Exemplare selhst in durch Farbe getrühtem Wasser zwischen Glasplatten keine solche Hülle erkennen liessen. Auf diese wichtige Futdeckung muss ich bei Euastrum Rota zurückommen. - Eine andere Vermehrungsart während des Sommers und Herbstes zu entdecken gelang mir nicht, gegen den Winter verminderte sich die Zahlı der an den $\mathbf{W}$ änden des Gefässes haftenden Exemplare und ich fand sie nur im Bodensatze des Wassers mit zahlreichen leeren Panzern und getrennten Hälften. Ende Januar bemerkte ich in diesem Bodensatze zahlleiche grüne Häufchen von verschiedener Grösse und Intensität der Färbung, welche in feinen Streifen in zwei Ecken des Gefässes gegen die Oberfäche heraufstiegen, und glaubte durch die Loupe lıetrachtet die jungen Euastra gefunden zu haben; leider war dieses eine T:iuschung: einzelne Häufchen bestanden freilich später wirklich aus jungen Individuen, neben diesen kamen jedoch in grösster Menge runde und 
orale grüne Körperchen vor, welche in weitabstehenden kugligen Gallertlın̈llen eingeschlossen waren, die wieder eine formlose zerfliessende Gallerte zu umgeformten Massen verband, worin aber durch gleiche Grösse sich immer je 2 oder 4 und melır als aus Theilungen hervorgegangen auswiesen. Diese grïnen Anfänge können sich vielgestaltig entwickeln, und ich wïrde nach dem Erfolge sie vorzugsweise \%u Pandorina Morum haben ziehen müssen, deren Kugehn sich im wärmeren Frühlinge zahllos in diesem Gefässe einstellten; \%wischen den grössten Fornen des K. margaritiferum und jenen Haufen kleinerer Inlividnen fand sich aber durchaus kein Verbindungsglied, wenn es nicht in diesen Körperchen zu suchen ist, ron welchen iblerdiess einige stärker ovale Form annehmen und eine mehr blaugrüne Farbe zeigen, wie bei Pandorina vorgekommen ist. - Angenommen eine andere Vermehrung wie durch T'heilung sei durch das Erscheinen von einzelnen Häufchen kleinerer Exemplare erwiesen, so bedarf es nur ıles glïcklichen Zufalles, dass eimem Beobachter ein E. margaritiferum in dem Zustande in's Selıfeld kommt, wo diese kleineren im ersten Anfange daraus entstehen, um die Sache vollkommen aulzu klären: bis dahin muss dieser Vorgang nach der Analogie verwander Organismen zu deutcu versucht werden und liegt die Vermuthung nahe, dass jene ersten Anfünge mit der späteren, entwickelten Form gar keine Aehnlichkeit haben. Unter den Enastren bictet diese Species durch ihre Häufigkeit und Grösse, unl weil sie immer in verschiedener Grösse rorkommt. unstreitig die giinstigsten Verluältnisse dar, um eine solche Vermehrungsweise zu entdecken, welche ohne Zweifel im Lanfe des Winters und im Schlammiiherzuge 'des Bodens der Gewässer' ror' sich geht.

6) b. E. Botrytis. 1/35". 'Tafel II. Fig. 18. - Die Synonymie ist beidieser Art noch schwieriger zu ermittelı, wie bei ler rorigen; zu erwähen möchten seiu Euastrum angulosum (Elıenberg) 1835 und Heterocarpella Botrytis (Bory de St. Vincent), Cosmarinm Botrytis (Meneghini), Cosmarium deltoides (Corda), welche oft nur auf einen Theil der gegehenen Abbildungen passen, während $\mathbf{R}$ alfs und Hassal eine Zeichunng gaben, die offenhar zur rorigen Art gehört und doch das Cosmarium Botrytis (Meneghini) darstellen soll. - Der sicherste Cutersehied von E. margaritiferum ergicbt sich in der Seitenlage, welche ähnliche Hervorragungen zeigt wie F. verncosum T'af. I. Fig. 11 und Tafel II. Fig. 23, wovon ich leider keine Abhildung mehr aufuehmen komnte. Zudem erhielt ich viele Exemplare von verschiedenen Fundorten alle von lerselben regelmässigen Gestalt, sah die Queertheilung und fand leere Schaalen und Hälften von derselben Form und Grösse. Die Tiipfel des Panzers, welche den $\mathbf{R}$ and gekerlst erscheinen lassen, sind bei älteren Exemplaren grösser und in regelmässige Reihen geordnet.

7) F. gemmatum. 1/60". - Cosmarium gemmatum (Meneghini), Euastrum gemmatum (Ralfs). Die Form dieser Art ist wegen ilıer Dicke sehr schwer zu ermitteh, die Figuren der ersten T'afel geben sie jedoch ganz genan wieder. Die Form kan selten doch in limreichender Anzahl und selbst in Queertheilung vor, so dass die Art ganz sicher ist. Die Gestalt ist fast cubisch und überall durch halbkwglige Auftreilıungen des Panzers rerziert, dalier von dem Inhalte desselben wenig zu sehen ist und hellere Stellen mit tanzenden Körperchen nicht heobachtet werden konnten. - F. rostratum $\mathbf{R}_{\text {alfs }}$ war vielleicht nur ein älteres Exemplar dieser Species? -

8) E. ansatnm 1/4:" und

9) E. didelta $1 / 27^{\prime \prime}$ sind \%wei so verwandte Arten, dass nur die sorgfältigste Untersuchung einen bestimmten Unterschied auffinden lässt, wenı überhaupt ein genügender Grund zur 'Trennung in zwei Species vorliegt; welche von beiden den verschiedenen Beolachtern vorgelegen lässt sich selten entscheiden, da ausser der Grösse auch der Queerdurchschnitt berücksichtigt werden muss. Die Synonyme fallen daher zusammen: Heterocarpella didelta ('T urpin), E. ansatum (Ehrenberg), Cosmarium lagenarium (Corda), Cosmarimm didelta (Meneghini), Euastrum didelta (Ralfs). — Ich fand beide Artnamen gegeben, sah E. ansatum flacher, von verschiedener Grösse, im Längendurchschnitt nach beiden Enden spitzer, im Queerdurchschnitt fast gleich hreit und tiefer eingekerbt, wie eine Vergleichung der Abbildungen besser wie jede Beschreibung darthun wird. Anch andere Arten bieten jedoch 6 * 
ähnliche Verschiedenheiten dar, und nur der Umstand, dass ich viele abgestorbene Exemplare und leere Hälften von beiden fand, ohne Uebergänge dazwischen, bestimmte mich, die beiden Species getrennt aufzuführen. - Auch dieser Umstand findet jedoch vielleicht laviı genïgende Erklärung, dass die kleineı Art einjährige, lie grössere überwinterte Exemplare wären, in welclıem Falle auch beide Queertheilung zeigen künnten, wie etwas Aelnliches bei Closteriun Trabecula beständig vorkommt. Die Entscheidung muss sorgfültiger Prüfung vorhehalten bleiben.

10) K. Pecten. 1/12". - Der Kamm. - Oplarium pteroplsorum (Losana), Echinella oblonga (Greville), Euastrum Pecten (Elıenberg), Cosmarium oblongum (Meneghini), Cosmarium sinuosum (Corda), Eutomia oblonga (Harvey), Euastrum oblongun (R alfs). - Diese Form, noch einmal so gross wie lie vorige, wiederholt dieselhe genau, mu sind die schwächeren Ausbuchtungen des E. didelta tiefere Eimschnitte geworden. Diese ändem jedoch ab, wie schon aus sorgfältiger Vergleichung mit der Fig. 9 'Tafel II. erlıellt und bei den lolgenden Arten noch deutlicher wird, so dass eine weitere Verfolgung der eben angeregten Vermuthung auf den W Veg fiilıren könnte, E. ansatum und didelta für jüngere, vielleicht durch eine andere Vermelıung wie Qucertheilung entstandene Formen des Kammes zu lıalten, wo dam letzteres mindestens dreijährig scin dü̈fic. Man findet nur um etwas kleinere Exemplare und das ganze Jahr hindurch ausgewachsene in Menge, was zu einer Vermuthung der Art noch melı herechtigen kann. Die 'Thatsache bestimmt zu ermittelı lleiht jedoch unendich schwierig. Am leichtesten liesse sicl, an gelegenen Fundorten das zahlieichere Vorkommen des E. ansatum in Fruiblinge nachweisen, wo in Herbste nur F. didelia und Pecten vorkommen ıüssten. Aıch der Kamm zeigte mir bei der Queertheilung eine vollkoumene Häutung, wie E. margaritiferum, wobei eine dicke glashelle Haut genan von len zierlichen Umrissen dieser Sternscheibe sich langsam ablöst und das längere Zusanmenbaften der neugebilıteten Individnen zu ledingen scheint. Bei dieser Art sieht man seltener lıellere begrenzte Stellen, dagegen waren die kleinen tanzenlen Körper überall verbreitet, und in leblıftester Bewegung vou einem Eude zum auderen wandernd; zuweilen, wie es scheint bei bevorstehender Queertheilung, finden sich zwei dunklere parallele Läıgsstreifen T'afel II. Fig. 9 vor, welche auch in der daneben gezeichneten Seitenlage Fig. 8 zu selıen sind, und in ähnlicher Weise bei anderen Arten vorkommen. In den flacheren kleinereu Euastren kaun nan diese dunkleren Stellen meistens in lauter kleiue schwarze tanzende Körperchen aullösen, weun man intensives Licht durchfallen lässt, was hier die Dicke des Objectes nicht zulässt. Nicht selten bestelıt auch eine wesentliche Verschiedenheit in der Färbung beider Hälften, indem die eine selı dınkel gefärbt ist, wähıend die andere eiı lichtes saftiges Grüı zeigt, worin ınr wenige der kleine» lumkelen Kürperchen zerstreut sind.

11) E. verucosum. 1/25". - Euastrum verucosum (Ehrenberg), Cosmarium verucosum (Meneghini). — Ologleich ziemlich häufig scheint diese Art doch verhältuissmässig selteu beohachtet zu sein. Der Zufall liess mich bei der Zeiclınmng für die 'Tafel I. ein kleineses Exemplar benutzen, später fand ich sie viel grösser; wie die Abbildungen anf Tafel II. Fig. 12, 13, 25 zeigen. Die Form erhellt aus den Zeichnungen zur Genige und zugleich, dass sich E. Botrytis zu dieser Species ganz ähnlich verhält wie E. didelta zı E. Pecteı. Wegen ihrer Dicke erscheint sie meistens selı dunkel gefärbt, wozu aher auch die zalılseichen tanzendes Körperchen viel beitragen, welche untel deu laalbkugligen Auftreibungen des Panzers zusammengelıäuft in jeder Hälfte vier dumkle Flecken bilden, welche jedoch keise scharfe Begrenzung lıaben und auch theilweise versclıwinden kümen. Der Panzer ist in regelmässigen Reilıen getuipfelt, velche auf den Auftreibungen in concentrischen Kreisen stelıen. Die Queertheilung sahı ich im ersten Beginnen 'Tafel II. Fig. 13, wo zwei neue Hälften zwischen den alten als halbkuglige Blasen hervortreten, die sich an einander abplatten und bald eme konische Gestalt annehmen; ilır Inlıalt ist anfangs ungefärbt mit zahlreichen Körnchen durchsäct und zeiget oft grössere Kugeln (Tafel II. Fig. 13 a. a.), die von anderen Beobachter'u für Stärkemehl gehalten sind. Später tritt der grüne Inhalt von jeder Sejte mit drei zapfenartigen Fortsätzen in die neueı Hälften lıerein, 

welche bei fernerer Vergrössermug allmählig die Form der alten anmehmen, und oft bis zu völliger Ausbildung verbunden bleiben ('Iafel II. Fig. 12), oft viel frïher an ilirer Verbindungstelle sich tremıen, so dass man Individuen mit ganz ungleichen Hälften findet: die Häutung, bei welcher es interressant wäre, ol auch anf del algelegten Haut die 'Tüpfel zu sehen, was ich bei E. margaritiferum niclıt fand, heobaclitete ich noch nicht.

12) E. hifidum. 1/40". - Diese Form ist vielleicht von Ehrenberg heobachtet und in dem grösseren Infusorienwerke Taf. XII. Fig. 3 als jüngeres Exemplar von der folgenden Art abgehildet. Hassal in seinen Algenwerke p. 386 bildet Jafiir ein neues gewiss unnöthiges Genus Holocystis und beschreiht eine Ilolocystis oscitans, die aber nur in einer Lage abgebildet ist, welche allein durch den Mangel der Zähne an den Spitzen unterschieden wäre. Zu diesem Gems zieht $\mathbf{H}$ ass al fraglich die erwälnte Figur Ehrenbergs und Arthrodesmus convergens, wovon sich später herausstellen wirl, dass er ein Xanthilium ist. Die oben ausgesprochenen Vernuthugen über den Zusammenhang rerschiedener Arten mögen anch auf liese Forn und eine der folgenden Anwendung funden können; für jetzt erforderte die Consequenz diese Species gesondert aufznfïlıren, da Längen- und Queerdurchschnitt bestimmte Verschiedenleeiten zeigen, wie anch ans 'Tafel II. Fig. 22 erhellt. Ich fand nur wenige Exemplare und sah die Queertheilung nicht.

13) E. Crux melitensis. 1/18". Das Maltheserkleuz. — Echinella radiosa (Lyugbye), Echinella ricciaeformis (Agardh), Helierella Lyngbyi (Bory de St. Vincent), Micrasterias radiosa (Agardl), Enastrum Crux melitensis (Elıenberg), Micrasterias ricciaeformis (Kützing), Micrasterias melitensis ( $\mathbf{R}_{\text {alfs? }}$ ) - Eine Verweclsselung mit den folgenden Arten konnte frühere Beobachter leicht ire führen und macht die Synonyme sehr unsicher. Um die Verwirung noch zu vermehren beschriel, $\mathbf{R}$ alfs als Micrasterias melitensis eine Form, die gar nicht zu dieser Art passt und vielleicht ein Xanthidiun gewesen sein dürfte, welche II assal wieder als Micrasterias radiata aufgefülıt hat. - Das Maltheserkreuz ist die zierlichste Form von allen und eines der hübschesten mikroscopischen Objecte überhaupt. Die Verschiedenheit von den folgenden Arten zeigt sich ausser der Theilung des Randes durch zwei mittlere Anftreibungen im Queerdurchschnitte und den stets glatten Panzer; freilich ändern diese Verlıältnisse auch bei der grössten Art ab, bevor jedoch eine Entwickelnngsgeschichte die erforderlichen Uebergänge nachweisen kann, nüsseı die Formen einzelı im Systeme aufgeführt werden.

14) E. Scutum. 1/22". Der Schild. — Manche Abbildungen des E. Rota lasseu sich auf diese Form vielleicht beziehen, sicher jedoch bildete sie erst Elı ruberg in seinem Infusorienwerke Taf. XII. $1 \mathrm{~g}$ und $\mathrm{h}$ ah und bezeichnete sie als juingere Exemplare des E. Rota = Cosmarium truncatum (Corda). - Dem vergeblichen Versuclıe die Entwickelıng dieser Species zu E. Rota zu verfolgen verdanke ich die wesentlichste Belehrung über die Vorgänge bei der Queertheilung der Euastra, deren Erörterung bei E. Rota folgen wird. Durch Längen- und Queertheilung unterscheidet sich der Schild zur Genüge, die anf Tafel II. Fig. 10 und 11 in zwei Stalien gezeichnete Queertheilung und die leere Hälfte Fig. 26 tlaselbst erläntern die Bildung der Form noch anschaulicher. Aber auch eine Uebergangsform zu der folgenden Aıt kann der Schild nicht sein, weil alle Statien, welche eine Euastrum-Hälfte in ihrer Entwickelung durchlaufen kam, an dieser Art durch deutliche Kennzeichen nachgewiesen werden können. Endlich finden sich Gewässer in lenen E. Scutum selten und Rota häufig ist, oder ungekehrt, und selbst das ausschliessliche Vorkommen des E. Scntum in einzelnen Gräben ist mir sehr wahrscheinlich. - Die Dicke des Körpers erlaubt auch hier selbst bei intensivem Lichte nur undeutliche dunklere Falten und Streifen zu erkennen, welche olme Zweifel durch tanzende Kügelchen bedingt sind; eine hellere Stelle findet sich wie bei anderen Arten an jedem Ende der Längsachse, zuweilen auch zu beiden Seiten der Verbindungsstelle beideı Hälften und danı bei der Queertheilung in den älteren Hälften deutlicher, wie in den jüngeren. Die Queertheilung beginnt ganz wie bei E. verrucosum; nachdem die neuen Hälften sich vergrössert haben, entstelı die Form von 
Tafel II. Fig. 11 durch Einbuchtung des Randes; wie dick die neuen Hälften jetzt sind, vermag ich nicht anzugeben, da leider es bisher nicht gelingen wollte in diesem Zustande eine Seitenlage ru erhalten; sehr häufig erfolgt schou jetzt die Trennung ler beiden Individuen, wo nicht so bildet sich durch allmählig tiefere und zahlreichere Einkerbung des Randes das 'Taf. II. Fig. 10 gezeichnete Doppelexemplar. Von einer Häntung habe ich nichts beobachtet, aber auch, seit ich auf dieselbe aufmerksan wurde keine Queertheilung dieser Species verfolgen kïnnen. -

15) E. Rota. '/8"'. Das Rad. - Micrasterias rotata (A gardh), Echinella rotata (Greville), Euastrum Rota (Ehrenberg), Eutomia rotata (Harvey), Cosmarium stellinum und C. truncatum [?] (Corda). — Was die bislıer erwähnten Arten an Formveränderungen wahrnelımen liessen, verliert sich gegen die mannigfaltigen Gestaltungen des Rades in's Unbedentende und ein sorgfältigeres Studium derselben führte zu so eigenthümlichen Anfschlüssen, welche für diese Gattung und die ganze Abtheilnng der Desmidiaceen ron wesentlichem Einflusse bleiben werden, dass eine ausliihrlichere Darstellung derselben hier gewiss Platz finden darf:

Die natüliche Voraussetzung, dass diese Organismen wachsen wie andere, und un so grösser vorkommen, je älter sie sind, erweist sich zunächst als trïgerisch. 'Taf. I. Fig. 15 stellt eines der grössten Exemplar vor. die ich gesehen, oft waren jedoch nu hall so grosse allem Anseheine nach älter. Diese Verschied(nheit kann wie andere Abweichungen von dem Fundorte abhäingig sein, indess haben auch die Umstände, unter welchen die Queertheilung vor sich geht, darauf Einfluss. Ehl enhe l'g sagt, wenn zweiScheiben zusanmenhängen sind allenal die heiden mittleren Hälften kleiner, bei 'Taf. II. Fig. I. sieht man aber, dass die ältere Hälfte des oberen Individuums kleiner ist, wie die jüngere neu gebildete, und lieses Kennzeichen daher nicht entscheident sein kanı. Vergleicht man dagegen die verschiedenen Stadien der Queertheilung 'Tafel II. Fig. 5, 4, 1, 6 so findet man die Einschnitte des Randes der neu gebildeten Hälften allmählig tiefer und häufiger, die Zähme des Rades zahlreicher und schärfer werdend, und die Hällte, welche die meisten nnd schärfsten Randzälme hat, ist siclıer die ältere. Jede Hälfte zerfällt durch 4 tiefe bis auf $1 / 3$ des Radius gegen den Mittelpunkt convergirende Einschnitte in 5 Lappen, von welchen der mittlere ungetheilt bleibt, anfangs nur drei flache Ausbnchtungen zeigt, deren mittlere allmälılig tiefer wird, während die seitlichen zuletzt am Rande noch zwei oder drei kleine Zähne erhalten, wie bei E. Crux melitensis. Jeder Jer 4 seitlichen Lappen wird wieder durch einen etwa hall, so tiefen Einschnitt getheilt, wodurch 8 secundäre Lappen entstehen, die wieder hallı so tief in der Mitte eingeschnitten simd, so dass 16 seitliche Randzühne auf Iler Stirn des Rades erscheinen. Jeder dieser Randzähne verhält sich wie der mittlere ungetheilte Lappen; ist anfangs nur ausgebuchtet nnd erhält zuletzt durch 3 Einkerhnngen, deren mittlere etwas tiefer ist, 4 Zähnchen, oft auch mehr. - Der Queerschnitt iiber Fig. 15 ' ' 'afel T. und die Ahbildung der leeren Hälite 'T'afel II. Fig. 25 zeigen in der Nähe der Verbindung beider Hälfien 3 kegelförmige Auftreibungen vles Panzers, unter welchen sich das Material für die neuen Hälften zu bilden scheint, und in denen oft Verlaingerungen der grünen Färbung zapfenartig hrvorragen 'I'al. I. Fig. 15, währenl in der Regel un die Mitie ein rundlich algegrenzter Fleck ungefärbt erscheint 'Taf. 11. Fig. 6; bei älteren Exemplaren, vielleicht nach rascher sich folgenden Queertheilungen nehmen die heiden seitlichen dieser Anftreibungen rerschiedene Gestalten an, indem sie sich bauchig erweitern, ihre Spilze sich verlingert und aul die Fläche des Rades umbiegt parallel mit der Berïhrungsfläche beider Hailften. In flach liegenten Exemplaren erscheinen sie dann selı dmkel wie 'Tafel 11. Fig 1 an den iilteren Hälften. Audere conische Erhabenheiten funden sich oft auf der Fläche des Rades balıl regelmässig, hald muregelmässig vertheilt, meistens am schmalen Verbindungstheile der 4 grösseren und 8 secundären Lappen neben dem Grunde jedes Einschnittes Taf. II. Fig. 1; diese conischen Anftreihungen sint in der Regel schwer zu sehen, weil die Färbung der Scheiben zu dunkel ist, lässt man jedoch intensives licht durchfallen und entfernt, wenn das Object ganz flaclı liegt und die Randzähne im Focus waren, die Linsen allmälılig vom Objectische, so erscheint bald nachdem das ganze Bild les Euastrom schon undentlich geworden ist. 


\section{•}

, 

über jeder dieser Erhabenheiten eine viel blasser grïne kreisförmige Scheihe durch eine optische Täuschung, welche die kegelförmige Gestalt derselben bedingt. Im Längendurchschnitt, der genau durch die Mitte fällt ('Taf. I. Fig. 15.), sielıt man keine derselben, weil der mittlere Lappen keine trägt, verstellt man jedoch den Focns, so erscheinen sie und man kann oft mehrere solcher Durchschnitte übereinander zeiclınen, wie Taf. II. Fig. 2. lei 600facher Vergrösserung versucht ist: nur bleiht es sehr schwierig, das Ohject in der Lage zu erlıalten, dass die längste und kürzestc Achse genau dem $0 \mathrm{~b}$ jecttische prallel liegen. Das in der Queertheilmug begriffene Exemplar (Taf. II. Fig. 4.) zeigte in einer solchen, in Figur 3. daneben gezeichueten, Lage nicht nur eine wesentliche Verschiedenheit der beiden älteren Hälften in dieser Bezielıng, sonderı auch den gänzlichen Mangel jener Auftreilrungen auf den beiden jüngeren, doch bereits zı $2 / 3$ ihrer wahrscheinlichen Grösse herangewachsenen Hälften. - Es wäre schwierig, aber zu erreichen, die Lage und Beschaffenheit dieser Erhahenheiten zu ermitteln, wenn — irgend eine Regelnässigkeit darin gefunden würde; bis jetzt labe ich aber fast nแ. Vejschiedeuheiten in dieser Bexiehung beobachtet, und die meistens überall ungleiche Färbung lässt bei blasseren Exemplaren oft an ganz abweichenden Stellen des Panzers leicht mit diesen Erliabenheiten zı verrechselnde hellere Scheiben und Kreise beobachten. Als sicher auf den älteren Exemplaren (minclestens auf einer Hälfte) vorhandene Auftreibungen, ausser den drei am Mittelpunkte des Rades, kanı ich daher nur 4 am Grunde jedes laappens und an Grunde jedes secundären Lappens angeben. - Audere kuglige Körper erscheinen oder siml der Färbung laalber nur periodisch sichtbar, zeigen verschiedene Grösse und sind ganz unregehmassig vertheilt Taf. II. Fig. 6. 7.; selır selten zeigt sich ein solches Körperchen auch im ungefärbten Saume der Scheibe, namentlich in dem stets helleren, oft ganz ungefärbten Ende des mittleren Lappens Taf. II. Fig. 6. in der unteren Hälfte und erscheint offenbar als das, was andere Beobachter fiir Amylum erliär't haben.

Von grossem plysiologischem Interesse musste es sein, bei einem Euastrum die Queertheilung durch alle Stadien zu verfolgen, lange jedoch war alle Mühe, welche ich anf Belauschung dieses Vorganges verwenden mochte, vergebens; ich fand nur ausgebildete Doppelexemplare und ungleiche Hälften ('T'af. II. Fig. 1. und 6.), als Resultate derselben, indess beides nach eifrigem Suchen doch so häufig, dass sich herausstellte, die Entwickelungsformen, wie sie in Taf. II. Fig. 4. und 5. dargestellt sind, könnten nur von kurzer Dauer sein. Ich suchte nun die Exemplare zu unterscheiden, bei welchen eine haldige Queertheilıng bevorzustehen schien, wählte die grössesten, die dunkelsten', diejenigen, deren Hälften möglichst gleich entwickelt schienen, seh. helle und mit grösseren Blasen erfüllte etc. aus, trug sie in einem 'Tropfen zusammen und hielt diesen unter genügendem Ersatz des verdunstenden Wassers melırere Tage unter dem Mikroscop — olune allen Erfolg in dieser Beziehung. Endlich löste ein Zufall das Rätlısel. Meine Beobachtungen waren, wie das iu der Regel der Fall sein möchte, Nachmittags und Abends angestellt, wo ich oft eine feststehende Loupe auf ein an der Wand des Glases haftendes Euastrum gestellt hatte, um an folgenden 'Tage zu bemerken, wie weit es sich entfernt habe; viele dieser Exemplare konnte ich gar nicht wieder finden, wenn ich Nachmittags darnach suchte und sah ilaher auclı am folgeuden Morgen nach, wo ich in demselben Glase, welches Abends vorher, trotz mühsamen Durchsuchens, keine Queertheilung auffinden liess. schon mit der Loupe zwei Exemplare, wie 'Taf. II. Fig. 5. entdeckte. Dieselben wurden in hinreichendem Wasser unter das Microscop gehracht, um sie Nachmittags mit Musse zeichnen zu können; aber wie sehr war ich erstaunt, bei meiner Rückkehr zwei ausgebildete Doppelexemplare zu finden, wie Taf. II. Fig. 1. Alle späteren Versuche bis in den Herbst ergaben dasselbe Resultat und berechtigen zu der wichtigen Folgerung; dass: jede $\mathbf{Q u e e r t h e i l u n g}$ in sehr kurzer Zeit - höchstwahrscheinlich von Sonnenaufgang bis zum Abend - soweit vollendet ist, dass die neuen Hälften mindestens die Form und Grösse der älteren ellangt haben, so weit es sich, wenn sie flach liegen, beurtheilen lässt, während die conischen Erhabenheiten, wie schon erwähnt wurde und aus Taf. II. Fig. 3. erhellt, anfangs fehlen: oft zeigten sich am folgenden Tage Spuren derselben. 
So interessant diese Entdeckung auch war, so schnitt sie doch leider mit einem Schlage jede Hoffnung ab, durch sorgfältiges Studium dieser Entwickelungsgeschichte zu weiteren physiologischen Aufschlüssen zu gelangen, denn selbst bei mehrstündiger aufmerksamer Verfolgung dieses Processes war die Veränderung unmerklich für das Auge und erst mit Hülfe des Mikrometers konnte jede Viertelstunde die Vergrösserung dargethan werden ohne im Imneren der neuen Hälfte bemerkbare Veränderungen nachzuweisen, die niclit aus meinen Abbildungen zu entnehmen sind. Erst nachlem dieser schleunige Verlauf der Queertheilung rou mir erkannt war, entdeckte ich bei E. margaritiferum und Pecten die Häntung, musste mir jedoch selbst sagen, dass in der Weise bei E. Rota der tiefen Einsclınitte halher diese Erscheinung kanm vorkommen könnte; eine solche Häutung zu beobachten gelang mir anch nicht; durch verschiedene Versuche bei möglichst stark abgehlendetem Lichte (mit Hülfe von Diaphragmen, die sich unter dem Ohjecttische nicht nu horizontal bewegen, sondern auch höher und niedriger stellen lasseı) vesmochte ich später an den älteren Hälften eine Schleimschichte deutlich zu machen, welche durch eine alhmählige Auflösung des äusseren Hant bedingt scheint, wie snlche bestimmter bei Closterium von mir nachgewiesen werden konnte und bei C. Trabecula Tafel III. Figur 19 abgebildet ist. Diese Schleinschicht fehlt den nicht in der Queertheilung begriffenen Exemplaren, wie sich durch mit Farbe getrülıtes Wasser nachweisem lässt; mu an jenem Punkte, wo die Doppelexemplare zuletzt sich trenuen, scheint erst später eine solche Auflösung zu erfolgeu, daher dieses Ende des mittleren Lappen gewölnlich durch einen solchen Schleim an der Wand des Glases oder an Wasserpilanzen eic. festklebt, so dass es nothwendig wirl, ein solches Euastrum mit der Nadel abzulösen, um es durch den in die Pipette dringenden Wasserstrom init fortreissen zu kömmen. Aus diesem Grunde findet man in Gefässen die längere Zeit rubig gestanden haben, die Melırahl derselben in aufgerichteter laage, wie ich sie in den Abhildungen beibehalten hatbe.

Andeutungen zı einer anderweitigen Vermehrung des E. Rota luahe ich bis jelzt nicht walıgenommen, namentlich nicht kleinere Exemplare beobachtet, welche zı grösseren heranwachsen könnten, weil stets die Beschaffenheit und Zahl der Randzähne auf eine vollkommene Aushildung hindentete. Nur die Möglichkeit einer Metamorphose ans einer anderen Species, welches luer E. Crux melitensis sein wiirde, bleibt weiterer Erwägung vorliehalten: da jedoch E. Rota zu allen Jahreszeiten in vollkommen ausgebildeten Individuen vorkommit, so wirl es höclsst walısclıeinlich, dass es kein einjähriges Product sein dürfte, wenn eine andere Vermelıungsweise existirt, was wieder, ansser der Analogie mit E. margaritiferum, für sich anführen lässt, dass die Queertheilung doch jmmer zu selten beobachtet ist, um eine hinreichende Vermelırung der Individnen zu Wege zu bringen. -

Die beiden Hälften eines $\mathbb{E}$. Rota stehen durch eine kreisıunde Oelfnung mit einander in Verbindung, durch welche lie erste $S_{p u r}$ der neuen Hälften bei der Queertheilung hervortritt, vor derselben muss also durch die Hant beiler diese Communication gehindert sein. Die kleinen tanzenden schwarzen Körperchen schienen mir oft aus einer Hälfte in die andere ïberzngehen, ob solches jedoch immer der Fall sei, liess sich nicht ermitteln, weil die meisten Exemplare zu dunkel gefïrbt sind und noch kein sicheres Merkmal aufgefunden, wodurch eine beginnente Queertheilung zu erkemnen ist. Der runde helle Fleck im Mittelpunkte der ganzen Sheihe vergrössest sich mitumter zu einem länglichen Orale gegen die Basis des mittleren Lappens, und hier sowie in den ungefärhten Siellen am Rande des letzteren, welche oft in der Mitte noch durch einen griunen Streifen in zwei Hälften getheilt sind, scheint die Bewrgung jener dunklen Kärperchen äusserst lebhaft. Es lag daher nahe an diesen Stellen nach etwa vorliandenen Oeffumgen zu suchen und in der 'That glanhte ich einst solche in dem 'T'af. II. Fig. 2. hei 600faches Vergrösserung im Längsdurehschnitt gezeichneten Exemplare bei a a aufgefunden zu lahen: dieselhen zeigten sich zwar mur in der mnteren lläfte, was jedoch Folge der Queertheilung sein konnte; eine Bewegung im Wasser, Anstreten des griuen Inlaltes an dieser Stelle bei Druck etc. und dieselben Oeffnumgen an leeren Hälften wurden dagegen fruchtlos aufgesucht. Bei der äusserst schwierigen Beobachtung eines solchen, auf der Kante stehenden Körpers bei so starker Ver- 
• 

grösserung ist mir daher eine Täusclıung wahrscheinlicher, die entweder durch die seitliche Ansicht einer Ausbuchtung der nahe dem Mittelpunkte auf den älteren Hälften vorkommenden Aufteeibungen. Taf. II. Fig. 1. oder durch zwei zufällig symmetrisch gelagerte grössere Kugeln, wie sie hei Euastrun verucosum 'Taf. II. Fig. 13. chenfalls a. a. bezeichnet sind, veranlasst gewesen sein mag. Eine andere Oeffnung als die mittlere, zur anderen Hälfte führende hat die leere, vollkommen durchsichtige und in jeder I sage sorgfiltig geprüfte Panzerhälfte mir nicht gezeigt. -

Die chemischen Bestandthcile der Steruscheihen zn enuitteln war bisher ans lem Grunde unmöglich, dass eine genïgende Quantitäi, nur aus denselhen bestehend, zu einer Analyse nicht erhalten werden kanı. Das mögliche aber unsäglich mübsame Unternehmen die erforderliche Menge einzelı zusammentragen zu wollen, wiirde doch ein Gemisch verschiedener Arten und die Individuen in allen Entwickelungszuständen liefern, was selbst bei sorgfältigster Analyse wenig dankbare Resultate geben könnte. - So wie die Beschaffenheit des Panzers nach der optischen Erscheinung vielen Gebilden in 'Thier- und Pflanzenreiche ähnlich ist, so auch in seinem chemischen Verhalten, so weit es zu prifen möglich war; im Wasser erhält sich der lecre Panzer wie es scheint sehr lange, bein Erhitzen desselben sowie in starken Lösıngen von Alcalien oder Säuren schrumpft er ein, bekommt Runzeln und Falten und eine leicht bräunliche 'Trübung wird nach längerer Einwirkung hemerkbar, womit eine langsame Auflösung zu heginnen scheint. Die Jodtinktur färbt ihn nicht.

Der Inlıalt zieht sich hei diesen Versuchen schnell vom Rande gegen die Mitte zusanmen, wircl braun oder entfàrbt sich, und zerfällt in unregelmässige zuletzt dunkelbraune Klümprchen. Auch Jodine färlut den ganzen Inlalt braun, welche Farbe an den Stellen, wo mehr Masse oder grössere Kugeln zusammengehäuft sind, äusserst lunkel erscheint; bei sehr intensiven Lichte und durch Zerdrücken solcher Exemplare überzengte ich mich stets, dass nicht die grösseren Kugelı des Inneren blan gefärbt waren, selbst nicht bei gleichzeitiger Anvendung von verdünnter Schwefelsäure, sondern dass in der Nähe derselben eine gleichunässige blane Färbung unregelmässiger Flecken entsteht. Bei der Behandlung eines Exemplars, wie 'Iaf. I. Fig. 15. mit einer lösung von Jodine in Kali hydriodinicum tritt sogleich die bräunliche Färlvung des ganzen Inhaltes unter Zusanmenzichung desselhen ein; viel Wasser zieht die Farbe wieder ans, ohue dass sich der Inhalt wieder ansdehnt, wird dagegen verdünnte Schvefelsäure zugesetzt, so wird der ganze Inlalt blaugriun, tritt wieder his dicht an den Rand nnd selbst der Panzer nimmt eine bäuliche Färbung an. Presst man ein so behandeltes Exemplar zwischen geschliffenen Glasplatten, so werden die ganz dunkel gewordenen mittleren 'Theile wieder durchsichtiger und es zeigen sich rein weisse hellere Scheiben mit einem dunkleren Umkreise; der bei intensivem 'Tageshichte deutlich blan erscheint, in ähnlicher Weise, wie in Taf. I. Fig. 15 durch die Schattirng angedentet ist. Bei E. Rota entsprechen diese weissen Scheiben vielleicht immer jenen conischen Erhabenheiten an Grunde der Lappen, welche oben erwälınt sind, und man könute annelımen, dass durch das Pressen der Inhalt derselhen zur. Seite gedriickt sei; allein ähnliche Versuche mit $\mathbf{W}$. Pecten geben ganz dasselbe Resultat und bei dieser. Species kommen gar keine Erhabenheiten in ähnlicher Vertheilung vor.

Dieses Verlualten giebt ein wichtiges Mittel an die Haud verscliedene Zustände der Euastren hinsichtlich der helleren und dunkleren Färbung derselben Art zu nutersuchen. Leider ist jedoch die Gattung durch das vereinzelte Vorkommen des Indiviluen zu solchen Versuchen wenig geeignet und das gleiche Verhalten der übrigen Desmidiaceen lässt bei anderen Gattungen sichere Resultate mit leichterer Mühe hoffen, daher bei einem späteren Rückblicke auf die ganze Abtheilung der Desmidiaceen darauf zuriickzukommen gerathen erscheint. Das Verhalten gegen andere Reagentien lieferte mir noch keine bemerkenswerthen Aufschlüsse, doch ist zu erwähnen, dass in concentrirter Auflösung von Chlorcalcium die Euastren sich vortrefflich als mikroscopische Präparate aufhewahren lassen.

Da schon in ersten Frühlinge vollkommen entwickelte Sternscheiben häufig vorkommen, so ist sicher anzunehmen, dass dieselben überwintern; vielleicht dürften die grïsseren Arten durchaus mehr- 
jährig sein, was sich ergeben wird, wenn die ganze Entwickelungsgeschichte einiger Arten heobachtet iverden kann, wozu bald ein günstiger Zufall fïlıren möge!

16) E. apiculatum. 1/10". - Ehrenberg unterschied diese sehr selten mit der vorigen von ihm gesehene Form, als besondere Art, welche ans Versehen auf uler 'Tafel des grösseren Infusorienwerkes E. aculeatum bezeichnet ist, — obgleich dieselbe in der Form ron E. Rota kaum abweicht, dagegen überall mit feinen Spitzen besetzt erschien. Das spätere Vorkommen solcher Spitzen auf den Randzälnnen ist bei älteren Exenılaren des E. Rota häufig und lässt sich durchaus nicht ermessen, wie weit sich eine solche spätere Zahmung und Znspitzmig der Zähnchen, oder vielleicht den 'Tüpfeln anderer Sternscheiben ähnlicher Erhabenheiten auf dem Panzer mag ausbilden können, so dass auf dieses Kennzeichen zur. Unterscheidung in der Form ïbrigens nicht wesentlich verschiedener Sternscheiben als besonderer Species wenig Werth zu legen sein möchte. Es wiirde vielleicht besser sein, diese Form als Varietät von E. Rota aufzuführen; allein die wenigen Exemplare, welche auch ich nur sah, zeigten bei allen Andeutungen völliger Ausbildung auf dem Panzer weder die conischen Errhabenheiten am Grunde der Lappen etc., noch auch die drei Hervorragungen neben der Mitte, wie aus dem Queerschnitte 'Iaf. I. Fig. 16 zu entnehmen ist. Auch ïber diese Frage muss daher die Entscheidung ansgesetzt werden, bis fernere Beobachtungen dazu berechtigen. -

Bei der Systematik dieser Organismen ist bisher allein die äussere Form, welche durch die Gestalt und Bildung des Panzers bedingt zu sein scheint, berïcksichtigt, während sich bei genauerer Untersuchung ergiebt, dass die Form sehr wechselnd ist, und mamentlich zu einer Unterscheidung in verschiedene Gattungen so lange nicht angewandt werden darf, bis eine Beobachtung der Entwickelungsgeschichte die Grenzen festgestellt hat, immerhalb welcher die Gestaltung eines Individuuns schwanken kanı. Die grösseren Formen sind häufiger und sorgfältiger beobachtet und zuerst unter dem Namen Euastrum in der Zoologie aufgeführt, in diese können andere, in der Voranssetzung, dass die Euastra Algen seien, gegebene Benennungen wie Oplarimm, Cosmarium, Eutomia, Holocystis etc., abgesehen davon, dass sie sämmtlich überflüssig sind, schon aus dem Grunde nicht übergehen, weil sie der Botanik angehören; der Streit, ob diese Organismen Pllanzen oder Thiere sind, betrift aber nicht einzelne Arten, sondern die ganze Gattung. -

Durch eine Zusammenstellung des physiologischen Details ergiebt sich, dass über die wichtigsten Fragen noch gar keine Auskmuft gewomen wurde, da weder die Ausbildung vom Eie (oder der Spore) noch die Art der Queertheilung bei allen angeführten Species haben beobachtet werden können. Statt der Gewissheit, welche beobachtete Thatsachen an die Hand gegeben haben wïrden, muss ich mich daher begniigen aus den gefundenen Erscheinungen folgende Vermuthungen zu rechifertigen:

Seit zwölf Jahren habe ich unausgesetzt den Desmidiaceen besondere Aufmerksamkeit geschenkt und selhst von Fundorten, wo zahlreiche Arten und Gattungen dieser Familie fast in jedem Cubikzoll Wasser vorkamen, und ich während der eisfreien Zeit wöchentlich frisch geschöpifte Quantitäten mit den im 'Zimmer aufbewahrten vergleichen kounte, salı ich nie jüngere Exemplare der verschiedenen Arten im Sinne der bisherigen Beobachter, mit der einzigen Ansnalme ron E. margaritiferum. Wemn Ehrenberg jüngere E. Rota auffülıt, so gehörten diese, wie beim Vergleich der Zeichnungen sich entschieden herausstellt, zu $\mathbf{E}$. Scutum, und was $\mathbf{C o r d a}$ und $\mathbf{R}$ alfs dafür angesehen haben, möchte ebenfalls dahin gehören, da die Zeichnung (Hassal. Plate XC. Fig. 1 b.) jene Species so darstellt, wie sie bei der schwächeren Vergrösserung erscheint, weun sie schief im Wasser hängt. Auf diesen Umstand wäre jedoch kaum Gewicht zu legen, wenn nicht linzukäme, dass von der Melızahl der Arten je zwei oder mehr im Längen- und Queerschnitt sich so ähulich sehen, dass allein stärkere 'Theilung des Randes, abgesehen von der Grösse, den ganzen Unterschied bedingt; zugleich erhellt aus der verfolgten 'Theilung, dass die neuen Hälften blasenförmig, olne alle Einsclnnitte und Zälne aus den älteren hervortreten und, zwar sehr schnell, aber doch nach und nach, sich abflachen und älnlich gestalten, wobei anfänglich flache Ausbuchtungen bald in tiefe Einsclunitte mit fast parallelen Rändem 
.

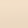


übergehen. Jede Hälfte eines Euastrum zerfällt auf den ersten Blick bei den meisten Species in einen nithieren und zwei seitliche Lappen; der mittlere erscheint ausgerandet, gezahnt, getïpfelt oder mit Spitzen besetzt, bleibt jedoch immer ungetheilt, während die seitlichen um so zahlreichere und tiefere Aushohtungen zeigen, je älter und entwickelter lie Hälfte ist. Vorausgesetzt nun; dass die vïllig entwickelten Wxemplare mehrjährig sind, so lässt sich vermuthen, die Theilung des Randes habe bei um ein ganzes Jahı älteren Exemplaren hedentende Fortsehritte gegen die um ein Jahr juingeren machen müssen; vergleicht man ferner E. Rota mit E. Crux melitensis, so leuchtet ein, lass eine Vergrösserung des ganzen Körpers um das Doppelte nebst einer Verdoppelung der Einschnitte an ıen seitlichen Lappen, sowohl an Zahl wie an 'Tiefe, vollständig zur Umwandlung der einen Species in die anlere genügen würde. Allerdings könnte ein zufälliges Zusammentreflen solehe eigenthïmliche Verhältuisse bedingen, sieht man aber von dem concreten Falle ab und hält sich nur an das IVesentliehe der Umwandelung, so verhalten sich wie E. Rota (und apiculatum) zu Crox melitensis:
E. Sentum : E. bifidum.
E. Pecten : E. didelta (und ansatum).
E. verrucosum : E. Botrytis.
E. margaritiferum : E. minutum etc.

und eine zufällige fïnffache Wiederholung eines so eigenthümlichen Verhälnisses bei derselben Gattung wird schwerlich angenommen werden können, da eine Vergleichnng anch die Längen- und Queerdurehschnitte ron ganz ähnlicher Form zeigt.

Weitere Verfolgung dieser Vermuthungen durch die Reihe der Desmiliaceen kann erst nach Vorführung derselhen einen passenten Platz finlen, es lässt sich jedoch schon hier erwägen, anf welche Weise die Umbildung z. B. eines E. Crux melitensis in $\mathbf{E}$. Rota vor sich gehen kömte? Die bekannten Vorgänge bei der Queertheilung legen zwei Möglichkeiten nahe: entweder entsteht in dem überwinterten E. Crux melitensis im Frühlinge ein rascheres $\mathbf{W}$ achs(hum und in Folge rlesselben ein Abwerfen der alten Laut, unter welcher die seitlichen Lappen sich häufiger und tiefer bei ihrer Vergrösserung einkerbcn; oder es erfolgt eine Queerlueilung, wobei die nenen Hälften die Forn ron E. Rota ammehnen. In letzterem Falle miisste man Exemplare finden kömnen, deren eine Hälfte zu Crux melitensis, die andere z. E. Rota gehörte, und dafiir spricht allerdings die Analogie mit anderen prismatischen Desmidiaceen, welche bisweilen 3- und 4seitige Hälften zeigen. Diese Untersuchungen machen es demnach wahrscheinlich, dass die Euastra aus unbekannten - vielleichı nur von den zahlreichen ähnlichen Bildungen bis jetzi nicht zu unterseheidenden — Vermehrmngsorganen (Eiern ouler Sporen) ihren Ursprung nehmen, bis zu einer gewissen Grösse anwachsen und sich dam durch Queertheilung vermehren; ferner nach Ueberwinterung am Grunde des Wassers in diejenigen einzelnen Formen übergehen, welche oben, weil dieser Vorgang noch nieht bestimmt erwiesen ist, als einzelne Arten aufgefiilırt werden mussten, deren Zahlı sich demnach später auf etwa die Hälfte reduciren könnte. -

Vorstehende Monographie der Gattung Euastrum wurde hiel eingesehaltet, um die Frage erörtern zu können, ob die Verwandtsehaft der Closterina zu den Desmidiaceen grïsser sei, wie zu den Vibrionen und folgt hier daher jetzt eine Darlegung der mir uber die Closterina bekannt gewordenen Ergebnisse der bisherigen uml der eigenen Untersuchungen.

\section{Fünfte Familic. Closterina. Spindelthicrchen.}

Viele Magen ohne Darm, unveränderliche Körperform ohne besondere Anhänge, eine hornartige Hülle des Körpers, welehe sich mit dem Kö̈per umvollkommen so theilt, dass stab-, faden- oder spindelförmige Polypenstücke entstehen, nnd bestimmte Bewegungsorgane in der Panzerïfnming (an der Mundöflnung?) bezeichnen nach Ehrenberg die Formen dieser Familie, welche die einzige Gattung:

31) Closterium (Nitzsch) umfasst. Tafel III.

1) Closterium Lunula. 1/s" Der halbe Mond. Wenige Körper sind so oft beobachtet und doch so verschieden gedeutet wie dieser! Eine bald sehr langsame, bald ungemein rasche 
Entwickelung aus verschiedenen Formen und durch verschiedene Vorgänge mag die Ursache davon sein. Für die Geschichte und Synonynie verweise ich vorläufig auf Ehrenbergs ausführliche Ërörterungen im grösseren Infusorienwerke und gehe sogleich zu den Ergebnissen meiner Untersuchungen über:

Die hänfigste Form dieser Species ist ein stielrunder aus zwei symmetrischen, konisch zugespitzten Hälften gebildeter, daher spindelförmiger, und halbmondfürmig gebogener Körper von 1/40"' bis 1/5" gross. Eine glasshelle änssere Hülle, ein innerer farbloser Körper, eine in beiden Hälften gleichmässig verbreitete grüne Färhnng, mit grösseren dunkleren ruhenden und kleinen schwärzlichen tanzenden Körnern durelısäet, scheinen ganz wie bei Enastrum gehildet. Die Verbindungsstelle beider Hälften und die Enden der gebogenen Spitzen zeigen sich ungefärbt und in Jetzteren ist eine kugelige Blase mit kleinen tanzenden zahlreichen Körnchen erfüllt. —

Closteriun Lumula zeichmet sich in der Gattung, so wie überhanpt unter allen verwandten Organismen, dadurch ans, dass es jederzeit in so verschiedene Grösse vorkommt. In Gefässen die reichlich damit erfülltes Wasser enthalten bildet sich allmällig ein grüner Ueberzug am Boden, an den Wänden und am Rande der Flüssigkeit, welcher der Hauptsache nach aus der Tafel III. Fig. 1, 2, 3 in verschiedenen Lagen abgebildeten Form besteht, die vom Grunde aus an einzelnen Stellen sich in oft zollhohe Pyramiden iibereinander thürınen und zu deı in Fig. 4, 5, 10 und 15 abgehildeten Formen heranzuwachsen scheinen. Wenigen mag jedoch diese weitere Entwickelnng hestimmt sein, denn sowohl im Bodensatze lirisch geschöpften, wie in Zimmer aufhewahıten Wassers findet sich eine grosse Zahl abgestorbener Fxemplare und entleerter Hülen vor, an welchen letzteren sich schon pine Gliederung zeigt, die an lebenden ron derselben Grösse nicht walızunehmen ist. - Schon diese Formen vermehren sich durch Queertheilung, wobei der grüne Inlıalt jeder Hälfte etwa 1/3 ilırer lsänge von der Verhindungsstelle sich einschnitrt Fig. 5, oder hellere Streifen den Zusammenhang der griuen Färbung ganz unterbrechen Fig. 10, und sich dann die mittlere Verbindungsstelle einkerbt, abschuuirt und die beiden Individuen sich tremnen Fig. 6, 7, deren anfangs ungleiche Hälften sich balı so gleich gestalten, dass ein Unterschied zwischen denselhen nicht melı zu erkennen ist. Sowohl die einfachere Forın, wie auch die viel geringere Grösse, machen ein Verfolgen dieses Vorganges viel schwieriger wie hei E. Rota, doch habe ich so viel ermittelt, dass anch die Queertheilnug bis zu den in Fig. 6 gezeichneten Abschnïren innerhalb 6-8 Stunden vorschreitet und die Abends in diesen Stadium verlassenen Exemplare zeigten sich am folgenden Morgen stets getrennt; auch versuchte ich die Fortschritte der Queertheilung daran zu messen, dass ich die Entfermung der beiden äusseren Spitzen zu verschiedenen Zeiten bestimmte, es fand sich jedoch keine Gleichförmigkeit zwischen verschiedenen Beobachtungen an Exemplaren aus demselben Gefässe, welches in der Nähe des Mikroscopes gestanden hatte. Die Gelegenheit zur Beohachitung dieser 'Theilung bietet sich selten dar' man kann melnere hundert Closterien vergehens durclimustern, ehe man selbst im warmen Sommer eine solche findet, und mir hat sie stets der Zufall in's Sehfeld gefülıt, wenn ich das Wasser von solchen Stellen des Gefässes nalım, wo dieselhen licht gedrängt sassen. Viel seltener aber ganz sichıer kommt auch bei diesen Formen schon eine Längstheilung vor Fig. 8; iiber den Verlauf derselben kan ich jedoch noch keine Auskunft geben, weil ich stets in derselben Infusion, nachdem ich die Zeichnung vollendet, nach anderen zur Vergleichung, und fast immer erfolglos, suchte. - Bis hieher reicht in der Entwickelung der Closterien ein Abschnitt, - ich würde sagen ein Jihl, wenn diese Organismen nicht von zufälligen Witterungsverhältnissen in ganz anderer Weise abhängig blieben, wie andere Wasserthiere und Pflanzen - und soweit es sich beurtheilen lässt, entsteht das Closterium am Grunde des Wassers, steigt bei Wärme und Sonnenschein allmählich bis an die Oberfläche und verschwindet bei Kälte, trüber Inft und Regen wieder, so dass sie im Spätherbste unter den grünen Anfluge auf dem Wasser immer seltener vorkommen. Man findet freilich an den Wurzelı von Lemna, in dem schleimigen Ueberzuge der Wasserpflanzen etc. und am Grunde noch zahlreiche Exemplare, aber doch nicht den zelınten Theil der frühesten Anfänge, und es scheint im Durchschnitl jeder Jahrgang, wenn ich den Ausdruck wählen 

darf, in demselben Wasser eine gleiche Entwickelung erreicht zu haben; von verschiedenen Fundorten ist dasselhe jedoch keineswegs der Fall. Da nuı kein Mittel bekannt ist, un darzuthun, waun im Laufe des Sommers die Entwickelung begonnen, da mehr oder minder häufige Queertheilung etc. von Einfluss daranf gewesen sein kann, so wirl Niemand mit Sicherheit anzugeben in Stande sein, bis zu welcher Gıösse C. Iunula in ersten Jahre wächst, vermutlen muss ich jedoch, dass in ller Regel die in Fig. 5, vielleicht in seltenen Fällen die in Fig. 10 gezeichnete Form als Produkt eines grösseren Abschnittes, der aber mehrjälırig sein könnte, anzuselıen ist. Gewiss bleibt, dass schon in Februar neben schmelzendem Eise dieses Closterium in Exemplaren von der Grösse der Fig. 10, 11,12 gefunden wird, die überwintert sein müssen, und es lässt sichnur nicht entscheiden, wie viele Winter sie schon erlebt haben; auch diese zeigen selten Queer-, noch seltener Längstheilung und dieselbe Verschietenheit der grïnen Färbung von einer helleren, gleichnässigen, sehr feinkörnigen, bis zu sehr dunkeler durch vielgestaltige grössere Körner bedingter, wie die Euastra. Jedes Closterium erscheint von dunkeleren Streifen der Läıge nach durchzogen, wehcher bei C. Lumula meisteus ein mittlerer, etwa $1 / 3$ der ganzen Breite eimnelmender ist, der jedoclı stets in der Mitte absetzt und eine Reihe grosser dunkeler meistens runder Körner trägt, deren Grösse und Zahl, wie aus den Abbildungen erliellt, mit dem Wachsthum sich vermelıt, deren gegenseitige Lage aber ebensowenig bestimmt ist, wie ilıre Anorduning auf der Achse des Closterium. Die durchsichtige Blase in der Spitze jedes Hornes erseheint bei den kleinsten Formen meistens rund, bei grösseren (die sich öfer getheilt haben?) findet sich eine ovale oder kegelförmige Blase, deren Contour der äusseren Haut parallel ist, bei den grössten dagegen ist sie wieder ganz kugelrund; die Zahl der in ihr tanzenden Körner ist sehr verschieden, vielleicht anch deren Grösse unter sich, was aber, da sie in jedem Momente wieder aus dem Focus verschwinden, schwer zu bestimmen ist.

Bei grösseren Exemplaren zeigt sich in seltenen Fällen die mittlere helle Queerbinde selur breit und lässt dann etwas üher der Mitte einen hassen runden Zellenkerı durchscheinen, in welchem ein grosser, kann zu unterscheidender, Kernkörper enthalten ist; of umgiebt diesen ein feines Netz verschiedenartiger Fäden, welches die sehr zarten Wandungen neu gebihleter Zelleu anzudeuten scheint, und deren Anordnung in jedem Fxemplare verschieden ist, Fig. 11. Mit dieser Veränderung sclreint ein ganz neues Leben füı das C. Lumula zu heginnen, wovon ich jedoch unr wenige Momente his jetzt erlauschen komte. Wie in Euastrum so zeigt sich auch in Closterium ein bestänliges Wandern sehı kleiner; schwarz erscheinender Körner durch die ganze Substanz, bei Closterium meistens der Contour parallel, welche den Körıchen in den Blasen der Spitzen ganz ähnlich zı sein scheinen; bald sind es einzelne, welche langsan sich bewegen, balı zahlreiche in rascherem Fortrïcken begriffene; nur eine kürzere Strecke legen sie in gleichförnigen Vorsehreiten, wie auf einem ruhigen Strome schwimmend zurück, bald wird ihr Gang beschlennigt oder sie hiegen wie um ein Hinderniss, weichen sich scheinbal aus, bleiben auch wohl kurze Zeit ruhen oder gehen selbst rüickwärts; so durcheilen sie unermüdlich das ganze Closteriun von einem Eude bis zum andern, wobei ihre Bahn sich offenbar nicht auf die grüne Färbung beschränkt, sonlern zwischen dieser und der äısseren Haut zı liegen scheint. Lange und aufmerksam habe ich dies träumerische Spiel beobachtet, ohne zı einem anderen Resultate gelangen zu künnen, als dass eine chemische Veräıderung die Ursache desselben seiı nüsse. Aber welches Resultat lieferte dieser rege chemische Process? Ich hofte je grösser die Exemplare, un so leichter würde ich Aufklärung finden, und nach mannigfach abgeänderten Versuchen erhielt ich die grössten Exemplare auf folgende IVeise: Aus einem nie versiegenden T'eiche, in welchem sänmtliche Wasserpflanzen mil einem bräunlichen Schleime überzogen waren an dem viele grüssere Closterien vorkamen, zog ich verschiedene Blätter und Aeste derselben dicht anı Grunde vorsichtig aus dem Wasser, brachte sie in ein grösseres aus demselben Teiche gefülltes Glas und suchte durch Schütteln desselben möglichst viel von dem Ueberzuge abzuspülen. Das trübe Wasser von den Pflanzentheilen abgegossen wurde dann in geeigneten Gläseın in die Sonne gestellt, worauf siclı an die Wände viele Luftblasen 
hingen, die auch den am Grunde sich lagernden Bodensatz dedeckten. Solche Luftbläschen hängen sich auch an die Closterien mod nach mehrtägiger Puhe findet man sie auf dem bräunlichen Bodensatze durch die Lupe an ihrer griunen Farbe kenntlich und kann sie mit der Pipette einzeln herausfangen. Auf diese Weise erhielt ich Exemplare bis fast $1 / 4$ " gross, wie die mittlere grösste Figur der dritteu 'Tafel (irrig 18 statt 13 bezeichnet) versimulieht — deren geradere Form bei Uebereinstimmung in jeder anderen Hinsicht schwerlich einen Artenuntersehied abgeben dürfte — in welehen die Bewegung der zahlreicheren Kömchen besonder's leblıaft und bei weitem besser zu heobachten war, weil die grüne Färbung sich in wellenförmigen Biegungen ganz ron der äusseren Iaut zurickgezogen hatte. Hier zeigte sich endlich die Ursache jener Bewegung: lie ganze innere Fläche des Panzers war mit sehwingenden Wimpern ausgekleidet, deren regelmässige Schwingungen, wie im Winde wogende Kornfelder, W Vellenlinien bildeten, welchen die zackigen Ränder der grïnen Färbung entsprachen. - Diese Beobachtung ist eine der schwierigsten Aufgaben für das Mikroscop; ahgesehen von del günstigeren Vertheilung der grïnen Färbung, der Grösse des Closteriun etc. ist es nicht die Stärke der Vergrösserung, sondern allein die Klarheit des Bildes, welche von der richtigen Beleuchtung abhängt, wodurch es möglich wird so feine Wimpern in einer so ungiustigen Lage zu sehen. Oft labe ich in dem röthlichen Saume, welcher dnrch diese feinen Wimpern bei durchfallendem Lichte erzengt wird, nach einęr deutlichen Auschanung lange vergebens gesucht und bei einer zufäligen Verstellung des Beleuchtungsspiegels oder der Bleudnng ward das Bild plötzlich so klar, dass auch Andere ohne Schwierigkeit die Bewegung der Wimpern wahrnehmen konnten. Auch bei kleineren Exemplaren, etwa wie Fig. 12, gelang es mir später, wenigstens an einzelnen Stellen, mich von dem Dasein dieser Wimpern auf das Entschiedenste zu über\%eugen, bei noch kleineren wird aber theils der Form des Körpers, theils der bis an den Rand sehr intensiven griinen Färbung wegen das Urtheil unsicher oder die Beobachtung unmöglich. - Da diese grössten Formen sowohl mit denen in Fig. 10, 11, 12, als auch mit denen in Fig. 1, 2, 3 abgehildeten zugleich im ersten Frühlinge beobachtet werden, so miissen sie wenigstens 3 jährig sein, was aber aus denselben fermer wird, oder welche Vorgänge, diese Entwickelungsform hedingen, dariber kann ich wenig mehr wie Vermuthungen liefern. Ich sah die griune Färbung sich weiter von den Spitzen gegen die Mitte zurückziehen und die grösseren ruhenden griunen Kugeln an Zahl und Umfang zunelımen ohne weiter diesen Vorgang verlolgen zu küunen, bis zuletzt der in Fig. 14 alogebildete Zustand eingetreten ist, wo der ganze Inhalt sich um grüne Kugeln, die mit gallertartiger Haut umgeben sind, zusammengezogen hat, und die Blasen in den Spitzen leer sind, Diese grünen Körper könnteı zu jungen Closterien also frühestens im 4ten Jahre auswachsen und die wirklichen Eirs oder Sporen derselhen sein, es kommt jedoch so häutig der Fall vor, dass entleerte Closterium-Panzer von Panzermonalen, Kugelthieren und anderen Infusorien erfült werlen, dass ein sicheres Urtheil erst möglich wirl, wemn dieses Answachsen wirklich beobachtet ist. _- Einen anderen Entwickelungszustand zeigt Fig. 12, wo die ganze Masse im Imnern sich aufgelösst hatte, und in derselhen sich offeubar nene Zellen bilden, dureh deren Ausdehnung die Mitte heller und die feinkörnige griine Substanz zur Seite gedrängt erscheint; die beiden Hälften haben jede durolı eine innere Haut gegen die Mitte und die Spitze ihren Inhalt isolir, in der Mitte liegen ansser derselben Zellenkerne an jeder Seite in deren grösserem ein Kernkïrper sichthar ist; die Blasen in den Sp̣it\%en enthalten nur noch einzelne wenige tanzende Kügelchen und haben sich zu konischen Behiiliern erweitert, deren Form dem inneren Raume des Panzers entspricht. Innerhalbjder grönen Masse halon sich grosse Zellen mit hellerem Inhalte und ein his zwei excentrischen Zellenkernen gebildet, welche sehr an die ersten Bildungen organischer Entwickelung eriunern und schwerlich etwas Kranklıftes sein möchten. -

Diese Vorgänge in eine geordnete Reihenfolge, die aber weder fïr alle Formen, noch ïberhaupt fuir die Entwickelung des Cl. Iunula maassgebend sein dürfte, gebracht, lieferten, wenn für einen längeren Zeitahschnitt, der sich nicht genauer begräızen lässt, ein Jahr angenommen wird, etwa folgenden Cyclus der Fisclieinungen: 

Angenommen die grünen Kugelı in Fig. 14 wachsen zı deı jungen Closterien Fig. 1, 2, 3 aus, so entwickeln sich diese im Laufe eines Sommers bald his zu den in Fig. 4 und 5 abgebildeten Formen und rermehren sich durch Qucer - und Läıgstheilung; im nächsten Frühjalıre erlangen einige dieser Zucht die Form von Fig. 10, fahren fort sich durch beilerlei Theilung zu vermehren und liefern im Herhste des zweiten oder Frühling des dritten Jahres Exemplare in der Grösse von Fig. 11 oder 12, welche im Laufe dieses Jahres zu den Formen Fig. 13 und 14 auswachsen und durch die oben geschilderte, in Fig. 12 gezeichnete Veränderung des Inhalts neue Zellen bilden, ans denen die grünen Kugeln in Fig. 14 - die Eier oder Sporen - entstehen. - Es kommen aber noch zwei andere Vermehrungsweisen des C. Lunula vor, welche die Uehersicht besonders deshalh nm so mehr erschweren, weil sie so äusserst selten in grösserer Menge gefunden werden. Bei der einen, deren Beobachtıng gan\% neu sein dürfte, wachsen zwei neue Hälften zwischen den älteren hervor wie bei Euastrum, wovon ich eine Abbildung in Fig. 9 gegeben habe, die jedoch um nicht zu grossen Raum einzunehmen wieder anf $1 / 3$ der Zeichnung rerkleinert ist. Die Individuen etwa von der Grösse von Fig. 10 naassen $1 / 6$ " Innd wird durch eine Vergleichung mit Fig. 6 der Unterschied von der Queertheilung gleich in die Augen fallen. - Bei der anderen legen sich zwei Closterien nebeneinander, verwachsen in der Mitte durch eine zapfenartige Verlängerung der änsseren Hant, und vereingen den beiderseitigen Inhalt zu einem dunkelgrünen Köıper; welcher zı einem neuen Closterium auswächst. Eine solche Vermelırungsart ist seit lange an den sogenannten Coujugaten (Zygnema, Spirogyra etc.) bekannt, wo die Zellen zweier Fäden verwachsen, der Inhalt durch die entstandene Verbindung aus einem Faden in den andern hinübertritt mod einen dunkelgriinen ovalen Körper bildet, welcher später zu Fäden derselben Alge auswächst; bei Closterium aher ist eine solche Vermehrungsart um so merkwiirdiger, da sie eigentlich eine Verminderungsart zı nennen wäre, indem zwei Indiviluen zu Grunde gehen, um ein neues zu bilden. Wäre der besondere $\mathbf{Z}$ weck derselben klar, etwa eime Ueberwintermug der Species möglich zt machen oder Aelmliches, so fiele jeder Grund zur Verwunterung weg; aber man beobachtet sie gerade im Frülijahre, wenn die Kälte abnimnt und Alles aus dem Winterschlafe zu neuer Thätigkeit erwacht: - es hleiht also noch etwas Unklares in diesem Vorgange, und nur vermuthen lässt sich, dass die Individuen, welche daduch entstehen, vielleicht allein die in Fig. 14 vorkommenden Eier oder Spren bilden kïnnen. Mir ist der Vorgang bei C. Lumula äusserst selten, bei C. rostratum sehr häufig vorgekommen, ohne dass ich mehr darïber ermitteln konute, wie Ehrenherg und Moren bereits angegeben haben, und bedarf es noch weiterer Beobachtungen.

Die Spitzen von Cl. Immula sind, soweit ich mit allen Hülfsmitteln und sorgfältigster Aulinerksamkeit habe ermittelı kömnen, ganz geschlossen und auch Elırenberg salı hier keine Oeffnungen; ebensowenig kounte ich hervorragende Papillen entdecken. -

Closterium Lumula hat der vielgestaltigen Formen im Verlaufe seiner Entwickelung so manche aufzuweisen, dass bei einer ähnlichen Verschiedenheit verwandter Arten für einzelne $\mathbf{Z}$ wischenformen es gar keine Möglichkeit melı giebt, mit Sicherheit zu bestimmen, welcher Species sie angehören, sobald man, weil sie noch klein sind, allein auf die Form angewiesen bleibt. Ehrenberg unterschied in der Mitte aufgetriebene Formen mit einfacher Reilse grösserer dunkler Körper in der Mittellinie als Cl. moniliferum, es sind das aber nur Entwickelungsformen, die unter denselben günstigen Einfliissen hei rascherem Wachsthume entstanden sind. Je länger man zu verschiedenen Jahreszeiten und aus verschiedenen Gegenden Closterien untersucht, je mehr iberzengt man sich von der weiten Ausdehmung der Grenzen, innerhalb welcher die Form der einzelnen Arten schwanken kann, mol labe ich z. B. eine Reihe von Uebergängen gezeichnet, durch welche alle Zwischenstufen von Fig. 5 bis Fig. 15 gegeben werden und kann letztere daher nicht von $\mathrm{Cl}$. Lumula trennen. Das einzige Mittel um in's Klare zu kommen bleibt auch hier das wöchentliche Nachsehen der Veränderungen, welche an demselben und an verschiedenen Fundorten sich während eines Jahres beobachten lassen. 
2) C. Dianae. 1/7“. Bogen-Spindelthierchen. Taf. IIr. Fig. 16. - Den besten Beweis fïr das oben Gesagte liefert diese Species, welche in der Form C. Lunula so sehr ähnlich ist, aber durch andere Kennzeichen sich bestimmt unterscheidet. Die Form ist stets schlanker, die Spitzen kürzer ahgestımpft, die Blasen in len Spitzen kleiner, mit einem oder doch sehr wenigen schwärzlichen Kömchen darin, dessen Bewegung nur langsam ist; dabei die Färbung und Anordnung des Inhaltes, wie aus der Abbildung zu ersehen, ganz alweichend. Zudem ist C. Dianae nur in Torfwasser beobochtet und fehlt an vielen Fundorten, wo C. Lunula trefflich gedeiht, durchaus.

3) C. Trabecula. 1/4". Balkenförmiges Spindelthierchen. Fig. 17 -21. U Um so bestimmter zeigt sich diese Art durch die Form verschieden, welche gerade cylindrisch, oben und unten scharf alıgestutzt oder leicht zugermndet, nur in der Mitte etwas eingezogen und zu beiden Seiten dieser Kinschnir.ung etwas hauchig aufgetrieben ist. Zuweilen sieht man bei schiefer Lage im Wasser an dem Ende $3-4$ kleine warzenförmige Hervorragungen, wie am unteren Ende von Fig. 18, die alser nicht constant sind und ganz den 'Tüpfeln gleichen, welche den Panzer von Euastrum verucosum, margaritiferum etc. bedecken. Die Grösse dieser Art hat es nöthig gemacht von dem Grumlsatze alle Figuren bei gleicher Vergrösserung zu zeichnen abzugehen, um nicht den Raum der 'Tafel ohne Nutzen opfern zu müssen, und komten anch nicht die gröissten der beobachteten Exemplare zu den Abbildungen gewählt werden; nur die Fig. 18 nnd 20 sind daher bei 400facher Vergrössernng gezeichnet, Fig. 17 und 19 alser nach in demselben Verhältnisse ausgefuihrten Zeichnnngen auf die Hälfte, Fig. 21 auf $1 / 3$ verkleinert.

C. 'I'rabecula kommi nur in zwei Grössen vor', deren eine um die Hälfte schmaler' und mur ein Drittel kürzer ist wie die andere (Fig. 18, wenn deren beile Hälften symmetrisch, wie die untere, gebildet wären, und F"ig. 20); nie habe ich ein jüngeres Exemplar gesehen, und liese kleinsten entstehen nicht durch Queertheilung der grösseren Furmen: Längstheilung ist nicht beobachtet worden. Woher entstehen sie? Nach dem was bei Euastrum vorgetragen, sollte man nach Kürpern suchen, die sich in zweiten oder dritten Jahre in diese Form verwandelı könnten; anch die sind aber his jetzt nicht aufzufinden. - Die dunkelgrïne Färbung lässt von dem Inlaalte nur unregelmässige grüıe Streifen und Häufchen erkennen; bisweilen unterscheidet man am Ende eine hellere Blase mit tanzenden Körnchen, meistens aber ziehen sich letztere in einem breiten geschlängelten Streifen durch die ganze Länge des Körpers und verdrängen die grüne Färbung; ja die grösseren selı dunkeln drïsenartigen Kugeln lösen sich of bei intensivem Lichte ganz in solche tanzenden Körnchen auf. - Um die mittlere Verhindungsstelle liegt ein durchsichtiger Ring, an welchem ich oft klcine Fetren einer glashellen Hant hängen sah, was mich auf die Vermuthung brachte, dass auch diese Organismen sich häuteten,. und die Beobachtung der Queertheilıng hestätigte hald diese Vermuthung. 'Trotz aller Mülıe ist es mir nicht gelungen, cin anderes Stadium der Queertheilung zu finden, wie zwei vollkommen ansgebildete und aneinanderhängende Individnen, und bin daher ganz ungewiss über die Zeit, welche dazu erforderlich ist; da ich jedoch in der Queertheilung begriflene Exemplare in verhältuissmäissig grosser Anzalıl während längerer Zeit ans Gläsern im Zimmer entnelmmen konnte, die ich selır oft sorgfältig auf ihren ganzen Inhalt prifte, inden ich denselben durcheinander schüttelte und zahlreiche Proben hei schwächerer Vergrösserung durchunsterte, so hahe ich Ursache zu glauben, dass diese Verwandlnng eines einfachen in ein Doppelexemplar sehr rasch vor sich gehen müsse. Auch die Unterscheidıng rou Exemplaren, die sich zur Quecrtheilung vorbereiten, ist mir nichıt gelungen; doch müsste nach spüterer Krfahrung sich in einer begimenden Anflösung der änsseren Haut viellcicht cin Mittel dazu finden. Die Doppelexemplare zeigen an den beiden älteren Hälften diese Zerselzung des alozuwerfenden Panzertheiles, was besonders dentlich wird, wenn man das licht sehr lämpft oder Farbe zum Wasser mischt, die neuen Hälften sind aber anfangs glatt und ihre IIïlle wasserluell, Fig. 19; später jedoch löst sich auch von letzteren rine farblose Hülle ab, die aber festerer Natur ist und an dem Ringe, welcher die Nath umgicbt, oft unregelnässig abreisst, wobei die früher erwähnten Fetzen zurückbleiben; aus dieser Hant 
zieht sich damn jederseits die neue Hälfte, wie der Finger aus dem Hanelschuh zuriick, Fig. 17. Mittlerweile sind auch die alten Hälften ihrer Haut entledigt und jedes neue Individum hat somit eime ganz neue Oberfliche. Bei diesem wahrscheinlich rasch rerlanfenden Processe muss wohl nicht inmer Alles genau in einandergreifen kömnen, denn man findet viele Missgebnrten, bei denen die nene Hälfte nicht die gehörige Länge crreichte und daher keulenförmig aufgetrieben wurde Fig. 18, oder es entsteht eine mehr oder minder starke Biegung nach einer Seite, die sich in Fig. 21, (die 3mal grösser sein müsste) hereits als Erbfehler bei einer späteren 'l'heilung wiederholt lat, so llass heide Hälften dieselbe Monstrosität zeigen. -

Diese Beobachtungen bestätigten mich um so mehr in der Vermuthung, dass anelı bei C. Luula die Queertheilung von einer Hïutung begleitet sein müsse, und ich fanl aneh ähnliche Nissbilungen, wo das eine Horn in schiefer Richtung und ganz verkür\%t dem anderen angesetøt war: ein förmliches Abstreifen von äusserer Haut beobachtete ich jedoeh nicht; lagegen lagen grosse Exemplare, etwa wie Fig. 10 noch nach vollendeter Theilung nahe beisamnen unl folgten gemeinschaftlich dem Zuge der durch eine Nadel in Wasser erzeugten Strömung. Es musste also noch etwas sie rerhinden und hei Zusatz ron Farbe bemerkte ich einen sich auflösenden Schleim, dessen Contouren mir nur entgangen waren, weil sie schon um das dreifache des Queeviuchmessers jederseits ron den Closterien entfernt waren, und ich sie in deren unmittelbarer Nähe gesucht hatte.

Dass auch bei C. 'Trabecula die Bewegung der tanzenden Kügelchen durch schwingende Rimpern hewirkt werle, ist mil wahrscheinlich geworden, obgleich es sich nieht lirekt beobachten lüsst. Ungefärbte Stellen kommen hier nur in de: Mittellinie ror, wo die schwingenden Wimpern ron der TYurzel ans in der möglichsten Verhürzung gesehen witrden und hei der erforderlichen 600fachen Vergrösserung in jedem Angenblicke aus dem Focus rerschwinlen müssen; hier fehlt es aber nie an den nimmer ruhenden, tanzenden Kügelchen, bei welchen llerselbe Fall eintritt und es lässt sich nicht entscheiden, ob das verschwinlende ein solches Kügelchen oder eine Vimper ist.

4) C. Digitus 1/9". Fingerfürmiges Spindelthierchen. - Fig. 22 his 27. Die Form dieser Art erhellt zur Genüge aus den Abbildungen, so wie das gleichzeitige Vorkommen grösserer und hlenerer Exemplare; in jedem Ende liegt eine grosse Blase, welche jedoch nur ein dunkles Körperchen entlält, dessen Bewegung sehr langsam sein muss, zuweilen fehlt letzteres ganz Fig. 26. In dieser Figur, welche durch eine leichte Zuspitzung Jes oberen Endes etwas von der gewöhnliehen Form ahweicht, liegt auch etwas oberhalh ler Mitte én dentlicher Zellenkern. Die Farbe ist oft hlass gelbliclı-grün mit Junkleren parallelen Längsstreifen, die sich allmählig verbreitern; körniger und lunkler werden Fig. 23, his zuletzt wie in der (links danehen stehenden) Fig. 22 das ganze Innere mit Ausnahme der mittleren Queebinde mit einer grohkörnigen dunkelgriunen Bĩasse erfüllt ist, worin nur noch schwache Andentungen ler frülesen Iängsstreifen durchscheinen. Andere Exemplare werten an der Spitze wieder heller, die grïne Fïhung zieht sich gegen die Bitte zurïck und hildet jene wellenförnig gezackten Bänder, wie in Fig. 13 bei C. Lumula ahgehildet sinł, neben welchen die schwingenden Wimpern bei dieser Art sich of leiehter beobachten lassen, weil die Spitzen des Panzers heller sind und günstigere Form haben. Flurenberg vermuthete in dieser Anordnung des Inlialtes ein jüngeres Entwickelungsstadiun, ich muss aher nach der Analogie mit C. Lunula und C. acerosum gerade das Gegentheil amehmen. Die Vermehrung geschielıt häufig Jurch Queertheilung: wohei sich in der Mitte jeder Hälfte eine helle Queerbinde zeigt, Fig. 23 (wie hei C. Lumula in Fig. 10) und später findet man Exemplare, die etwas kleinel sind mit ungleichen Hä]ften; auch hier geht dieser Process glaube ich raseh vor sich, dem Doppelexemplare wie bei C. H'rabecula aufzufinulen gelang mir nicht, dagegen findet eine Häntung durch allmählige Aufösung der äusseren Hülle statt, wie bei C. Lunula, immerhalb welcher die Theilung sich wiederholen kann, so dass bis 8 Exemplare in einer weitabstehenden gallertartigen Blase vorkommen, wie in Fig. 27 hei sehwächerel (80facher) Vergrösserung abgebildet ist, während eines dieser Exemplare in Fig. 23 bei $400 f a c h e{ }^{\circ}$ 
Vergrösserung gezeichnet, schon die Vorbereitung einer neuen Queertheilung wahrnelımen lässt. Längstheilung und Copulation sind nicht beobachtet. -

6) C. acerosum. 1/6" Nadelfürmiges Spindelthierclen. - Fig. 28. Die Form dieser Species weicht duch die eine geradere Seite, die eigenthümliche Zuspitzung und das Verlı̈ltniss der Breite zur Länge von C. Lunula und Dianae wesentlich ab und diese Form herrscht bei allen Exemplaren von der verschiedensten Grösse vor. C. acerosum findet sich in allen Grössen, wie C. Lunula und ist ebenso verschieden in der Breite; bei den grösseren sind aber die hellen Blasen in den Spitzen immer kleincr, liegen weiter von der Spitze entfernt und enthalten weniger tanzende Körperchen. Die Reilıe grösserer dunkler Kugelı in der Mittellinie salı ich immer in gleichen $\mathbf{A b -}$ ständen regelmässig vertheilt, nur nehen der Mitte liegen die beiden ersten näher beisammen und ist die zweite oft kleiner; Junkele Längsstreifen ziehen — wahrscheinliclı acht — von beiden Enden ohne Unterbreclıung gegen die Mitte, welche eine breitere in der Mitte ansgeschweifte helle Queerbinde zeigt, die von kolbig zugerundeten Spitzen der dunkelen Längsstreifen ïherragt wird, zwischen welchen oft ein Zellenkerı mit Kernkörper siclıtbar ist. Die innere Hant ist wie bei C. Iounula mit schwingenden Wimpern beklejdet und tanzende Körnchen erfüllen den ganzen Körper; anch sah ich Andentungen zur Bildung der wellenförmigen Zacken an der grïnen Färbung gegen lie Spitzen hin. Queertheilung und viergliedrige Al)theilung ıles Panzers sind beobachtet, so wie auch parallele Queerstreifen auf ler lıellen Queerbinde der Mitte, welche mit der Queertheilung in Beziehung zu stehen scheinen.

Eine besondere Färbnug des Panzers bei C. acerosum und anderen scheint anf einen Eisengehalt desselben schliessen zu lassen. Seit lange sind an einigen Closterien rothe $S_{p}$ itzen beobachtet, theils in Folge mangelhafter Untersuchung durch nicht achromatische Linsen, theils nach ciner wirklich vorhandenen Fiarbung, und eine eigene Species C. ruficeps dafür eingelührt; es hat sich jedoch herausgestellt, Ilass iliese Erscheinung nicht nur bei manchen bekannten Arten von Closterjum, sondern auch bei Desmidiaceen zu verschiedenen Gattungen gehörig vorkommt: Namentlich erstreckt sich bei sehr grossen älteren Exemplaren von Micrasterias Ehr. die Färbung auf alle Theile des Panzers. In manchen Gräben oder in Gefässen mit Grabenwasser tritt oft eine voriibergehende Zersetzıng ein, die mit Entwickelung von Schwefelwasserstoffgas verbunden ist, worlurclı siclı der ganze Bodensatz, soweit er eisenlıaltig ist schwarz färlot. Die Closterien werden von dieser Zersetzung durchaus nicht afficirt und ich besitze noch jetzt lebende Closterien in Gefässen, deren Inhalt schın einige Male jene Zersetzung erlitten hat; die Panzer abgestorlener Closterien werden jedoch ebenfalls schwarz gefärbt, und zwar um so intensiver, je ätcr sie sind. Bei C. acerosum trifft es sich bisweilen, dass ein nach melırfacher Queertheilung abgestorbenes Exemplar diese Färbung erleidet, wo denn die ältere Hälfte viel dunkler gefärlst wird wie die jüngere und von letrterer wieder der an die Mitte grenzende 'Theil, etwas schwärzer wird wie die Spitze, wie ein solcher Fall von Ehrenberg abgehildet ist.

Aus einer grösseren Reilıe von Formen, deren Entwickelıng noch unbeendet oder verkümmert sein konnte, deren Vertheilung an eine bestimmte Species daher immcr schwierig blieb, fïge ich lier die drei folgenden ein, welche durch ilıre Form und Grösse den Rang bestimnter Arten in der Nähe der vorigen zu verdienen schıeinen; ich sab dieselben jedoch so selten, dass mir nicht meh" darüber bekannt geworden ist, als was die Abbildungen zeigen, nämlich die Form und dass es Closterien sind:

6) C. Libellula. 1/" - Die Wasserwaage. Fig. 29. - Ganz so geformit wic zwei verschmolzene C. acerosum, oder ein solches in der Längstheilung begriffen, aussehen wiirden; die grösseren Blasen in den Spitzen, die unregehnässige Vertheilung der grösseren dunkelen Kugelı und die ganz gerade Richtung unterscheiden es jedoch zur Genüge; auclı weicht das Verhältniss der dunkleren Längsstreifen zuı grünen Färbung wesentlich von dem bei C. Digitus al), wo anch die Zıspitzung der Enden eine andere Form zeigt. Laeider kamen mir aus einem entfernten 'Torfmoore mu' 

wenige Exemplare in gleicher Grösse und Aushihlung vor, und bot sich mir zu weiterem Studium dieser gewiss lehrreichen Art keine Gelegenlıeit dar.

7) C. Ulna. 1/s"'. D Die Elle. Fig. 30. - Sowohl duch die Färbung, als auch durch die Anordnung der dunklen, grösseren Kuggelı ausgezeichnet. Die schon erwähnte Queerstreifung anf der mittleren Verbindungsstelle findet sich bei lieser A.t, die ich auch nur so selten ellangen konnte, zuweilen auf der Mitte jeder Hälfte, wo 6 und mehr solche Ringe, wie deren einer bei C. 'Trabecula die Verbindungsstelle muschliesst, gleich Falten in der insseren Schicht des Panzers dicht aneinauder liegen. Da einige Exemplare in der Mitte eine begimende Abschüirung wahrnehmen liessen und leere Panzer in 4 gleiche 'Theile zerfallen waren, so steht dieser Vorgang wohl mit der Queertheilung und Häutung im Zusammenhang.

8) C. Ensis. 1/7". - Die Klinge. Fig. 31. - Die wenigen Dxemplare, welche ich freilich nur wïhrend eines Friihlingsmonats — finden konnte, zeigten alle dieselbe Biegung und gleiche Dicke der ganzen Länge nach; die immere Fïrbung und Anordnumg aller 'V'heile würde freilich sehr an C. Libellula erimern, und Fig. 20 und 21 von C. 'Trahecula bei einer Veroleichung wohl dera Uebergang von C. Libellula in diese Form als möglich denken lassen: aber Fig. 21 von C. Trabecula ist eine äusserst seltene Missbildung unl von C. Ensis salı ich mu venige Exemplare mu alle in gleicher Biegung.

9) C. setaceum. 1/6"'. - Bolstenfürmiges Spindelthierchen. Fig. 32. - Die Ahbildumgen, welche Ehrenberg von dieser nod der folgenden Art gegeben hat, würde nan nach Obigem für Altersverschiedenheiten ansehen kïmen, wofür anch der Umstand spräche, dass Fhlenberg die Copmlation beobachtete und nach meiner Lofahung lie letztere bei C. rostratum sich am häufigsten zeigt: ich habe daher die beiden Arten in zwei grossen Exemplaren neben einander gesteli, $1 m$ z beweisen, dass es ein wirklich verschiedenes ganz gerades $\mathbb{C}$. selaceun giebt. Während es übrigens von kleineren etwa $1 / 20$ " messenlen Formen oder verwandten Arten in manchen Infusionen wimmelt, zählen so grosse zn len Seltenheiten.

10) C. rostratnm. 1/4". - Geschuabeltes Spindelthierchen. Fig. 33 - 36 . (Die untere ller beiden Abbildungen zwischen Fig. 32 und 33 muss mit 34 bezeichnet sein). Die bauchige Erweitermg der Mitte mul die gebogenen Spitzen sind hei dieser Art constant, die Blasen am Ende ler grünen Fälbung meistens oval oler konisch, die dnnkleren Kugehn liegen oft zerstrent und sind von ungleicher Grösse. Oberhalb der Mitte, wo in der Figur nu eine Ansliölıng in der grünen Färbung angedeutet ist, liegt, wie ich später sah, ein dentlicher Zellenkern mit Kernkörper. — Ton allen Arten reigte mir diese am häufigsten die Copulation und zwar im ersten Friblinge sowohl in vereinzelten Exemplaren als auch in einem grimen Ueherzuge am Rande eines Grabens haulenweis; wie im letzteren Falle die Individuen sich fimleı, um durch eine zapfenartige Verbindung des anzers zn verwachsen, wäre noch zu erklären, da sie die hüchsten Punkte des Wassers erreichen, also den Band des Ufers etc., und hier rom Winde durcheinander geweht in die manniglaltigste Beriilıung kommen unüssen; im ersteren Falle jedoch, wo man nicht immer zu einem dieser seltener 1/4", in ler Regel 1/6" messenden Kürper olme längeres vergebliches Siuchen den zweiten finden kann, ist wohl anzunelımen, lass eine vorhergehende Wheilung die Amäherung vermittelt lıabe. Es inüssen jedoch auch Zufälligkeiten diese Verbindung stören künnen, demn ich beohachtete Exemplare mit jener zapferıartigen Verlängerung ohne Verbindung mit einem anderen; die von Monen abgebildete Copulation eines sich zur Queertheilung vorbereitenden Exemplars an jeder Hälfte mit einem anderen kam mir nicht ror: - Die anfangs schmale Verhindung, Fig. 34, zeigt die beiden Exemplare oft an einer Seite mil den Spitzen genähert, bei späterer Verbreiterung derselben divergiren letztere, Fig. 35, und der grüne Inhalt zieht sich gegen die Mitte zusammen, wo später ein umegelmàssig eckiger grüner Körper entsteht, welclıer die ganze Verbiudungsstelle ausfiillt, Fig. 36 , und sich mit einer eigenen Haut umgieht. Die aus diesem Körper erwachsenden Closterien konnte ich bei dieser Species nicht auffinden 
and daher nicht entscheiden, ob sie durch ihre Grösse sich gleich von den übrigen unterscheiden. Der griine Inhalt dieser und der ïbrigen Arten verhält sich gegen Reagentien wie der von Euastrum. -

Die hier aufgeführten Arten von Closterium und ihre Untersuchung genügt ohne Zweifel für den nächsten Zweek, die Gleichartigkeit der Organisation mit Euastrum nachzuweisen; bei den gestreiften, von Ehrenberg unter den Gattungsnamen 'Toxotium vorläufig als Unterabtheilung aufgefülnten, gilt in Allgemeinen dasselbe, indem nur die Streifung des Panzers, die anch Altersverschietlenheit sein könnte, und die Oeffnumgen an den Spitzen, deren Ehrenbergg erwähnt, als Unterschiede hervorzuheben sind. An der Stelle, wo diese Oefinungen sich finden sollen, beobachtete ich allerdings bisweilen eine umschriebene Stelle, welehe das Licht auf eine andere Weise bricht, wie die übrige Substanz les Panzers, konnte dieselbe jelloelı weder constant, noch immer in beiden Spitzen finten: bei einem Versuche liese Erscheinung zu denten muss ich auf andere Beobachtungen bei den Desmidiaceen zurückkommen, nachdem letztere im Zusammenhange vorgefïhrt sind; die angefülırten 'Thatsachen gestatten jedoch auch fär dlie Closterien die Ammahme einer nicht unwesentlicheı Veränderung in der äusseren Form durch verschiedlene Vermehrungsarten und Entwickelungsweise, deren Erörterung sich durch die Desmidiaceen ebenfalls klarer herausstellen wird, laher auch eine Critik del bisher aufgestellten Species und ihrer Synonyme his lahin verschoben werlen muss, wo auf folgender Zusanmenstellung der bisher gewonnenen Resultate weiter gehaut werden kann:

Die Closterien sind so augenseheinlich verwandte Arten derselben Gattung, lass es nicht gefährich erscheint, die Mehrzahl der beobachteten Erscheinungen für alle Species als gleichlıedeutend anzunehmen. Die bisherige Beobachtung ergab für diese 'Thiere oder Planzen eine einjährige oder fortwährende Dauer als Norm und möchte in Beziehung aul durch 'Theilung entstandene zum Theil Geltung behalten: für die Vermelnrung aus Keimen (Eiern oder Sporen) his zu nener Keimbildung in einem daulurch erzeugten Indiviluum muss aber cin mehrjähriger Zeitraum angenommen werden, wälı'en! dessen verschiedenartige Gestaltungen derselben Art vorkommen kömen. Die Aufklärung dieser Verhältuisse bahnt geradezu den Weg zur Lösung der vielfachen Fragen uiber die Individualität und Arten dieser Organisnen, über ilne thierische oder pllanzliche Natur und durch IRückwirkung auf alle mikroscopische Pflanzen und 'Thiere, deren ausschliesslicher Aulenthalt das Wasser ist, wird die Möglichkeit nahe gelegt, llass manche physiologisch noch unklare Species frülıere Entwickelungsstufen grösserer sein kömuten. Es wirl daher wichtiger für die Forbihlung ler Missenschaft sein, wemn conseyuent lurch das ganze Jahr, etwa zwei Mal monatlich, hekannte Gattungen von demselben Fundorte mit der nöthigen Anfmerksamkeit ınd in ausreichendem Maasse beobachtet werden, als wenn ephemere Lrscheinungen nach flüchtiger Musterung zur Bereicherung des systematischen Index dienen. Schon das Ansehn des Wassers, noch mehr die mikroscopische Untersuchung, spricht dafür, lass viele Organismen zu Zheiten von ler Oberfliche ganz verschieden, und doch so schmell wieler erscheinen können, dass eine Neubilung noch nicht vor sich gehen konnte, daher nothwendig dieselben Species, vielleicht in anderem Entwickelungszustande am Grunde des Wassers vorkommen muissen. Śchon oben wurde daratf hingedeutet, wie bei manchen Infusorien das Verlältniss des grün gefärbten Körpers zur Gallerthülle in verschiedenen Entwickelungszustäuden ganz abweichend gefunden werde und las Ueherwiegen des einen oder anderen 'lheiles auf das specifische Gewicht von Einlluss sein könnte, und in der That fundet man im Frühlinge die meisten grünen Kugeln mit knapp anliegender Gallerthülle, etwa wie in 'Taf. III. Fig. 14. am Grunde des IVassers, während ähnliche mit weit ahstehendem Panzer an die Oberlläche kommen. Vielleicht verändern sich dieselben schon während des langsamen Aufsteigens. Sehr zu wünschen bleibt es daher, dass eine Beachtung des gleichzeitigen Vorkommens ähnlicher Körperchen an demselben Fundorte ebenfalls consequent durchgehührt werde. Das angegebene Verfahren den braunen Ueherzug der Wasserpllanzen abzuspülen und in einem flachwandigen Gefïsse melırere 'Tage in lie Morgensome zu stellen, liefert das nöthige Material zu sulchen Beolıachtungen; aus diesen Gläsern ( 3 Zull hoch, 1 1/2 Zoll breit, 1 Zoll weil), die in der Hölıe meines Auges am 

Fenster stehen und zum 'Theil duch einen schwarzen Schirm gegen die gerade durchallenden Lichtstrahlen geschuitz.t sind, kann ich vermittelst einer festgestellten Loupe und in eine feine Spitze ausgezogener Glasrölure jelen Körper his etwa 1/25" Grösse innerlalb weniger Minuten unter eine 600fache Vergrösserung bringen. Demuch mïssen die grösseren, meh" wie 1/10" messenden Körper zu den feineren Untersuchungen rorgezogen werden, weil Alles hei ihnen bestimmter und klarer zur Anschauung kommt, und der Beohachter dadurch lesnt, woraul bei den kleincren zu achten sein möchte.

Anf diesem Wege siml bei den Euastren und Closterien die oben angefïhrten 'I'hatsachen ermittelt, namentlich die mehrjährige Dauer, die Art der Queertheilung, die Häutung bei derselhen, die rasche Ausbildung der nenen Hälften in 12 Stunden; bei den Closterien die Auskleidung der imneren Fläche des Panzers durch eine dicht mit schwingenden Wimpern besetzte Selicht, das Vorhandensein eines Zellkernes mit Kernkürper und die Bildung nener Zellen im Innern, welche zn beobachten bei den Fuastren die Form und gesättigte Färbung bis jetzt nicht gestattete. Ferno die eigenthümliche Erscheinung, dass einzelne Arten in jeder Grösse vorkommen (Euastrum margaritiferun: Closterium Lunula, Digitus, acerosun ete.) während andere nie in einem jüngeren $\boldsymbol{Z}$ ustande gefunden sind (E. Rota, Pecten - Cl. 'lrabecula, rostratum (?) ete.); hestätigt fernere Untersuchung len Uebergang ron E. Crux melitensis in Rota, so wirl für $\mathbf{C l}$. Trabecula folglich noch der entsprechende Jugendzustand anfzufunden sein: letzteres beobachte ich seit Jahren von einem gelegenen Fundorte, dessen Oherfläclıe und Bodensatz auf das sorgfältigste bei Untersuchmug der Euastra zu allen Jahreszeiten, besonders aber im Frühlinge und Spätherbste und läufig von mir durchgemustert sind, um die crsten Aufänge des $\mathbf{E}$. margaritiferum zu entlecken, und in welchen selten ein nie gesehener Körper vorkommt, während die beiden Grössen von Cl. Trabecula ziemlich häufig sind - nud doch habe ich auch nicht die geringste Vermuthung, in welchem der vorkommenten Organismen ler Jugenlzustand von Cl. 'Trahecula zu finden sein möehte! Bevor solche Rätlsel nicht gelöst sind, wird üher die thierische Natur der Desinidiaceen kein entscheidender Beweis gclicfert werden: und doch ist es für die Panzernunaden und Kugelthere ron grosser Wichtigkeit, ob sie durch die Desmidiaceen, wenn letztere Planzen sind, den Algen uäher gestell, uder in Fall ihre thierische Natu sich bestätigt, den Bacillarien und Astasieen verwandter werlen. - Fiir die Mehrzalı der Desuidiaceen gilt durch stillschweigemle Uebertragmg des für einzelne grüssere ermittelten Banes, das fü die Familie im Ganzen gewonnene physiologische Detail; die rasche Bewegung der foinen schwarzen tanzenden Kiigalchen ist eigenthiimlich für diese Familie und vielleicht inmer durch schwingende Wimpern an der inneren Fläche des Panzers vermittelt. Bei Closterium Digitus 'lafel III. Fig. 22 ist die Spitze, wo diese Bewegung znerst deutlich wird, etwa $1 / 100^{\prime \prime}$ breit, die Wimpern sind nicht einzeln sichtbar; dagegen die hewegte Schicht in einer Breite ron etwa $1 / 1200 "$ zu unterscheilen, welches die 耳änge Jer Wimpern sein würde, deren Breite ebensogut 10 wie 20 mal in der Länge liegen könnte, oder 12,000 bis 24,000 Wimpern auf den Raum einer Pariser Linie geben wiirle. Bei den grüsseren Formen von C. Lumula, wenn die Sppitze schon heller geworden und eine langsamere Bewegung del Wimpern eingetreten ist, lassen sieh freilich in seltenen für die Beobachtung sehr günstigen Fällen einzelne Wimpern unterscheiden; es gieht aber so kleine Desmidiaceen, dass an cine Constatirung des Vorhommens der Wimpen bei ihnen — obgleich die kleinen schwarzen Kügelchen in lebhaftester Bewegung sind - mit unseren jetzigen optischen Hülismitteln gar nicht zu denken ist. -.. Der Raum auf welchem dieser Frage ihr Recht werden soll ist folglich fïr wissenschaftlich sichere Ermittelung laum zugänglich, und doch ist die. Frage selbst vielleicht von eingreifender Wichtigkeit!

Denn die Beobachtung ist neu und sehr sehwierig; es bedarf nicht allein der sorgsamsten Aufmerksamkeit des Beobachters, sondern auch eines guten Instrumentes, wweckmässiger Beleuchtumg und des geeigneten Objectes um die Erscheinung klar und unzweifefhaft hervortreten zu lassen. Dieselbe kann daher noeh bei Pflanzen sowohl wie bei Thieren beobachtet werden und wïrde dann in systemam tiseher Hinsicht die Frage unverändert lassen. Da nun rorstehende Untersuchungen zeigen, dass bei 
diesen Organismen noclı gar nicht zu bestimmen ist, welche Formen zusammen unter den Begriff einer. Species fallen, so ist das rätlıselhafte dieser Frage um so erklärlicher und nur zwei IVege versprechen zu einer Lösung derselben Mittel an die Hand zu geben: erstens genaue Priifung der ähnlichsten Organismen auf dieselben Erscheinungen und zweitens conseguente Beobachtung desselben Art, von demselhen Fundorte, zu allen Jahreszeiten, in der Voraussetzung, dass sich die verschiedenen Entwickelungsstufen oder Keime bei himeichend sorgfältiger Nachsuchung stets daselbst müssen nacliweisen lassen.

Eine solche Untersuchnng wiude aul alle bisher besprochene Organismen rïckwirkend sein, die mit den Desnidiaceen gleichzeitig rorkommen unı nachweisen, welche $\mathbf{V}$ eränlerungen mit dem Wechsel der Jahreszeiten bei ihnen eintreten; dadurch bïunten zunächst bestimmte Arlen ausgesondert rerden, die einen gewissen Cyhlus der Lebenserscheinungen - Entstehen, Wachsen, Vermelımg und Absterben - nach Verlauf unl Bedingungen beobachten lassen und zu sicherer Anwendung des Schlusses durch Analogie berechtigen: Denn auf letzteren beibt lie Physiologie bei diesen Familien zmächst ausschlicsslich angewiesen. Existenz, Grösse, Form, Farbe, Gruppirung unı Fundort sind Alles, was von den eigentlichen Monaden und Vibrionen ermittelt werden kann; Rüissel, Augenjunkt, dunklere Drise unl contractile Blase, welche bei Monadinen, Panzermonaden und Kugelthieren oft hestimmt nachzuweisen sind, kömen ihre pliysiologische Dentung nur von den grösseren Polygastricis entlelmen, mnd von den Vermehrungs-Arten gilt fuir das Wesen derselben offenbar die Vergleichnng mit ähnlichen Vorgängen in anderen Familien als Massstab. So lange nicht wenigstens in geniigenden Bcispielen gezeigt ist, wie sich jede Gattung und Alt scharf begrenzen, bleibt jede Vergleichung unsicher, mnd wie bei den Enastren und Closterien wirl sirh anch bei den folgenden Familien in dieser Hinsicht leider noch manche Schwierigkeit zeigen.

Anfgaben, welche die Kräfte des Cinzchnen ohne Nutzen fiir die VVissenschaft erschöpfen würden, künen in jetziges Zeit, wo die Zahl der besseren Fnstrumente und geübten Beohachter alljährlich anselmlich wächst, ım su eher ihrer Lösung entgegengefiihrt verden, je ınehr ihr Einfluss anf die Forthildnng unserer Kenntnisse gewürdigt und je richtiger der Plan zu ihres Lüsung vorgezeichnet ist. Mïchte es mir gelnngen sein für einen Schritt vorwärts den Weg zn diesem rimkelsten Gebiete mit der dichtesten Bevölkerung gebahnt zu hahen! 
. 


\section{ErkIärung der Abhillungen.}

Die drei beigefügten 'Tafeln, durch Uebereinanderdrucken verschiedener Farben und verschiedener Arten der Lithographie erhalten, sind erste Versuche die natürliche Färhung der Objecte ohne Illumination durch den Pinsel wiederzugeben, so dass alle Abdriicke in jeder Hinsicht gleich sind; die gelungeneren Figuren der zweiten Tafel mögen zeigen, was nach so wenigen Versuchen von dieser Methode künftig erwartet werden kam. Die Zeichumgen zu allen Figuren sind durch den Sömmeringischen Spiegel hei 400 facher Vergrösserung gemacht, einige derselben auf der zweiten und dritten Tafel jedoch um Raum zu sparen wieder verkleinert. Zur Beobachtung diente ein griisstes Mikroscop von Schiek in Berlin (seit 1838) mit Reflexionsprisna, woran die stärkeren Linsensysteme von Oberhäuser, Chevalier, Nobert und Anderen angebracht werden komnten, um für jedes Object die günstigsten Bedingungen zu erlangen. Die Beleuchtung geschah durch Tages - oder Lampenlicht und nur zur Belehrung ist bei den dunkelsten Objecten mitunter auch volles oder durch farbige Gläser und Papier gedämpftes Somnenlicht versucht. Alle abgehildeten Objecte sind in der Ungegend Bremens gefunden. Die angegehene Grösse bezieht sich auf die grüssten der heobachteten Exemplare, welche meistens, jedoch nicht immer, abgebildet sind: die Queer- und Längsschnitte wurden immer von demselben Exemplare, neben oder über welchen sie gezeichnet, sind, durch Einstellung des Focus auf die breiteste Contour erhalten. 


\section{Ta f e I I.}

Bietet eine übersichtliche Zusanmenstelltung aller Arten der Gattung Euastrum (Ehrenberg) in drei Ansichten - mit Ausnahme von E. Botrytis, welches auf 'Taf. Ir. Fig. 18 nachgetragen ist bei gleicher Vergrösserung:

Fig. 1. E. minutum. $s p$. $九$. $1 / 120^{\prime \prime}$. - Zeigt in der Milte jeder Hälfte einen dunkleren Körper, welcher in del Seitenlage nicht liervorragt, oft aher aucb nicht zn unterscheiden ist.

Fig. 2. E. ornalum. Ralfs. $1 / 60 "$. - In der Mille bauchig aufgetrieben; ältere Exemplare zeigen zahlreiche lanzende Körnehen und Tïpfelung des l'anzel's.

Fig. 3. E. crenatum. Ralfs. $1 / 65 "$. - Zeigl in der Regel einen dunkleren Ḱörper in der Milte jeder Hälfte, während die entsprechenden Stellen im Langen- und Queerschnitt anfrallend gerade erscheinen. Die Queertheilung sieht man häufig.

Fig. 4. E. spinosum. Ralfs 1/50". - Zeigt oft eine sehr elegant geschweifte Form wie in dem gezeichneten Exemplar die untere, ältere Hälfte. Ein kreisförmiger dunklerer Schatten in der Hlitte könnte, wie aus den Durchsehnitlen zu ersehen ist, von der entsprechenden Auftreibung und dadurch bedingten Verdickung ler Seheibe herrühren. Die Queertheilung ist Taf. Il. Fig. 14, 15 abgebildet, so wie allch eine elwas abweicherde Form mil ausgezogenen Spitzen Fig. 16, welche den Speciesnamen veranlasst hat.

Fig. 5. E. ovale. Ralfs. 1/30". - Diese Am zeigt den Typus der Euastren, ron welchem alle anderen Formen leicht ahzuleiten sind; stets sehienen mir jedoch sowohl der Panzer wie dessen Inhalt ein unreifes Anselın zu haben, was siclı schwer in Worten begriinden lässt.

Fig. 6. E. margaritiferum Turpin $\mathrm{t} / \mathbf{2}^{\prime \prime \prime}$. - Ein sehr grosses Exemplar uil einer glashellen bei der Querthejlnng: sicb abhäutenden äusseran Schichte des Panzers, welcher ïberall getüpfelt erscheint, daher die Kerbung des Randes. Die durchsichtigere Mitte zeigt jenes lehhafte Spiel der tanzenden Körperchen oft in so hohem Grade, dass wer die sehwingenden Wimpern in Cl. Lunula gesehen hat auch hier an ihrem Dasein kaum zweifeln bann. - Queertheilung ist auf Taf. 11 . Fig. ti und abweichende Formen daselbst Fig. 19 - 21 abgebildet.

(E. Brotrytis Ehreubq. Taf. II. Fig. 18, wäl'e hier eluzuschalten.)

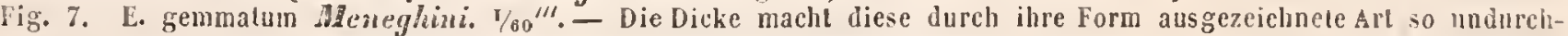
sichtig, dass im Inneru nichts zu erkeunen ist. Quertheilung wurde beobachtet.

Fig. 3. E. ansatum Ehrenberg. V/15". - Diese Art zeigle sich häufig von ähnlichem Ausehn wie E. ovale und die Umrisse sind bald ganzrandig, bald Ieichl ausgebnchtel wie in der Zeichnung; bei sorgfältiger Vergleichung mil Fig. 9 findel sich jedoch in Queerschnitle E. ansalum in der Milte flacher und im Längsschnilte an beiden Enden spitzer, woranf jedoch bevorstehende Queerlheilung bei der folgenden Art ron Einfluss gewesen sein könnte.

Fig. 9. E. dilelta. Turpin. 1/2r". - Die Verschiedenbeit beider Halften deutel lier viel bestimmter auf eine vorhergegangene Quertheilung hin, besonders in Längsdurchschnill, wo aber durch Zufall die altere Hälfte nach oben gerichtet isl, die in der Hanjtfigur nach inten sicht. Der Inhalt des Panzel's ist ziemlich gleichmäsig grün gefärbt und sehr undurelssichlig. Die Form erhellt noch deullicher aus der leeren Hälfte Taf. 1l. Fig. 24.

Fig. 10. E. Pecten. Ehreuberg. 1/1"'. - Anch hier zeigt aufmerksame Vergleichnng bei der unteren Hälfte die Ausbuchtungen etwas tiefer, die Räder der tieferen Einschnitte mehr parallel wie in der oberen. Dic Fajbung ist lier nicht so lebhaft und die Schalten in derselben minder bestimmt, wie bei dieser Alt in der Regel gefumlen wird; frülser glaubte ich dem Alter des grossen Exemplares solche Färbiug zuschreiben zu dirfen, fand sie aber später auch bei kleineren und vermuthe, dass solclıe Euastren zufällig vorher trocken gevorlen sind und späler wieder ins Wasser aelanglen. Zur Vergleichung diene Taf. II. Fig. 8 und 9.

Fig. 1t. E. verucosun. Eleveubry. 1/3s". - Die ganze Oberfliche des Panzers ist getipfell, wie hei E. mar tiferun und Taf. II. Fig. 23 deutlicher zu sehen ist. Bei dieser Art findel sich der grösste Contrast in der Färbung verschicdeuel Exemplare, inden bei den blasseren nur eine hellgriine Schicht dicht unter Jem Panzer zu liegen scheint, daher trotz der Diche diescr Sternscheiben die lelshafte Bewegung der tanzenden liörperchen gut beobachtet werden kann; andere sind ganz undurchsichlig. Qnertheilmng und leere Hälfte sind Taf. II. Fig. 12, 13 und 23 ahgebildet.

Fig. 12. E. bifidum. sp. 21. 1/40" - Diese Species erüfnel eine nene Reihe ron Euastren, welehe sich durcls tiefere Einschnitle und spilze faudzähue ron den bisher erwahten, deren Ausbuchtungen stets abgerundet sind, unterscheiden. Die leere llälfe findel sich Taf. II. Fig. 22.

Fig. 13. E. Crux melitensis. Ehrenberg. 1/18". - Die olere ailtere Hälfte unterselseidet sich in den seitlichen Lappen hinteichend von der jiiıgeren unteren durch spitzere liandzähne und liefere Einschnitte, was auf vorlıergegangene Queertheilung zu deuten scheint. Die zierliche Forn der Umrisse bewahrt sich anch in den beiden Durchsehnitten und soltte auf eine vollkommene Entwickelung sehliessen lassen, die durch andere Uebergäuge doch unwahrscheinlich wird.

Fin. 14. E. Scutum. $s p$. $n$. 1/32". - Hier ist die untere llälfte die ällere, was bei dieser Art am leichteslen durch die Eckzabne des mittleren Lapjens angedeutet wird, welche sich zuletzl ausbilden. Die grüne Färbung tritt in zaplenartigen Vorspribngen gegen die milllere Verbindung in den ungefärbten Theil hinein, wie bei den folgenden Arten und vielen Closterien. in der Regel sind die beiden llälften nur an der Berührungsstelle verbunden, zuweilen zeigl sich jedoch wie hier eine grösserc Strecke zwischen den parallelen Pändern beider Hälften durch cine farblose Ilaut verwachsen, wclche sich vermuthlich bei der Häulung hier algesetzl hat und zwischen den nahe zuzammenliegenden Halften sich nicht herauslösen konnte. - Qucertheilung und lecre llälfte finden sicl Taf. 11. Fig. 10. 11. 26.

Fig. 15. E. Rola. Ehrenberg. 1/8"'. - Eines der grössten und schönsten Exemplare, das mir iiberhaupl vorgeliommen ist, mit sehr geich entwickelten Halften; die obere, etwas grössere zeigt jedoch melu hantzhhne nul licfere Einbuchtungen des milleren Lappens und ist laher die ältere. Die helleren Kreise am Grunde der Lappchen sind so dargestellt, wie sie bei ctwas zu hoch gestellten Linsen durch optische Täuschung erscheinen und die sic umgebende Sehattirung deutel die Stellen an, welche bei Anwendung von Jorl und Sehwefelsäure hlau werdell. Das Nahere folgl bei Fig. I- 7 del zweiten Tafel.

Fig. 16. E. apiculatun. Ellı'enbery. 1/10". - Die Spitzen auf den Randzihnen, welche Elırenterg iber Jen ganzen Panzer verbreitet sal, wnl einc etwas ahweichende Form und Theilung des Randes bedingen den Uulerschicd von E. Rola; anch liessen sich auf deo Qucerschulte die drei miltleren Auftreibungen nicht nabiweisen. Die griine liarbung bat sich hier weiter vom liaude znzüekgezogen und lïsst in dew farblosen Körpel zahlreiche Kijgelchen wahrnehmen, was auf beginnelldes Absterben alentel und auch bei den anderen Arten vorkomml. 




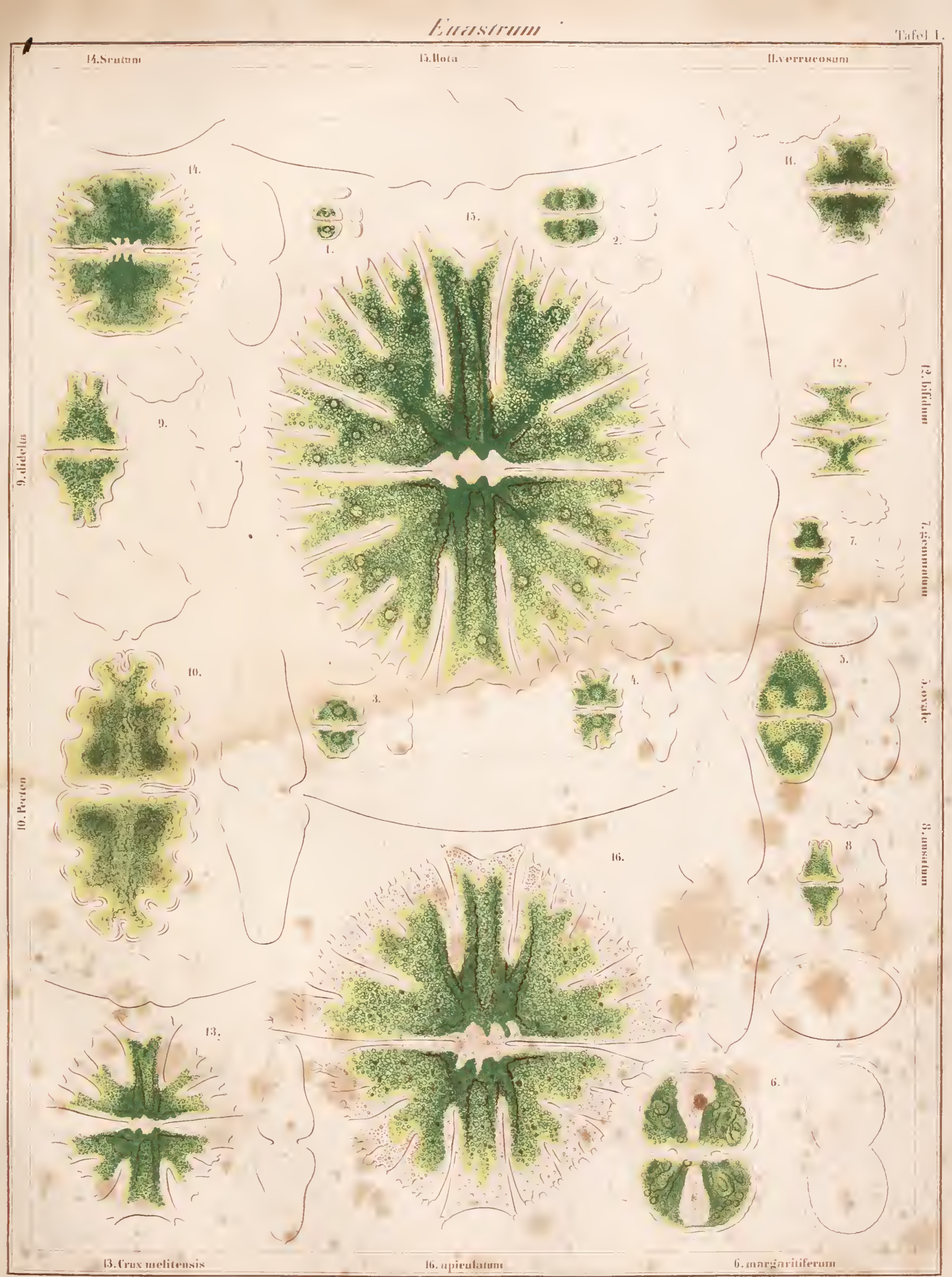






\section{Ta e I I}

Bietet eine Darstellung des bei der Gathung Euastrum heohachteten plysiologischen Details und ist in ler Ausfülntung unter den rorliegenten als die gelungenste zu bexeichen; mamentlich lassen die Figuren 6, 7, 9, 12 weniger zu wiunschen übrig. Auch hier sind alle Abbildungen hei 400 ancher Vergrössermug durch den Sömmeringischen Spiegel bis in's kleinste Detail gezeichnet, so dass selbst kleinere Kreise von 1/2" Durchmesser in der Zeichmug, wenn auch nicht genau in entsprechender Grösse, doch anf ler richtigen Stelle angedeutet sind; mur die Figuren 5, 10 mal 11 wm-

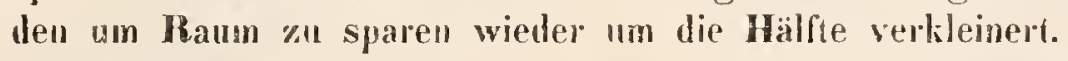




\section{Taf e III.}

Fig. 1 - 7. Euastrum Rota.

Fig. 1. Doppelexemplar nach vollendeter Quecrtheilung. Die ohere alfere Halfte ist hleiner wit die nen crzengte jüngere, auf jeder der älteren Hälften sind 10 dunklere Kreise regelmässig verlheilt, welche den conischen Hervorragungen auf der Fläche der Sternscheibe entsprechen und den jiingeren fehlen. Zu beiden Sciten der mittleren Verbindungsstelle tragen ansserdem die alleren Halften sehr dunkle cigenthünlich geformte Auftrejbungen, unter welchen sieh dic Masse fuir ne'ı zı erzeugende Hälften anzusammeln seheint und die den beiden seillichen duftreibungen des Qneerschnitts von Fig. 1.j Taf. I. entsprechen.

Fig. 2. Ein grösseres vollkomuren allsgebildetes Exemplar in der Seitenlage bei 600facher Vergiösseruug llessen verschiedene Durehschnitte, so weil es der Lichtrerlust gestatlete, bei verschieden eingestellteu Focus ibereinander gezeichuei sind. Bei diesem Verfahren ist also zum Beispiel der grösste Umriss zuerst gezeichnet, Mubei die iburigen Contouren, weil sie nicht im Foeus waren, gat nicht gesehen witden; dann ethielt ich durch vorsiehtiges Senken des Objecllisches rermillelst der Nikrometerschraube lie zweiten Unrisse, wälrend die ertsen rersclwanden, und so weiler: da jedoch die Randainde in dieser Lage gerade uber llem dunkelsten Theile in der Hille standen, so honnten sie naliorlich nicht erkannt werden. In der unteren Haifte uahe der Mille bei a. a. finden sich zwei hellere scharf utschrichene Stellen, entweder durch die Verhibung in der åluliche Auftreibungen, wie in Fig. 1 auf den älteren liälften liegen, crscheinen ledingl, on̉er kugeln in falblosen Inhalte des lanzers wie in Fig. 6 im milleren Lappen der unteren Hälfte und Fir 13 bei a, a.

Fig. 3. Eine solche Seiteulage ron der in Fig. 4 ahgebildeten halhvoltendeten Qucertheilung, um sowobl dea Uuterselied der beiden dilteren Hilften, als auch die noch ganz glalten Fläehen der neuerzengten zu zeigen. Die grosse Sulwierigkeil cinen solchen köpper genau in dieser lage zu halten tinderte mich die Zeichung so gunau auszuliilıen wie die rorige.

Fig. 4. Dasselbe Exemplar fach aulliegend in habvollendeter Queertheilung um 11 Uhr Vormillags gezcichnet.

Fig. 5. Das friheste Stadinm der Qneertheilung, welehes ieh aufgefunden halse, um 7 Ulı Morgens gezeiclnet. Beide erreichten noch an demselben Tage die Ausbildung ron Fig. 1. - Fig. 5 ist lun die Hälfle wieder verkleinert, also etwa 200fach vergrössert. Bei der Aufhewahung in Chlorcalejum schrumplen dic nethen Habten sehr zusammen, wähend die alteren ibre Form rollkommen behielten.

Fig. 6. Ein Excmplar, welehes sich in einem Stadiun der Queerllicilung, das elwas weiter vorgeruckt war wie in Fig. 4, bereits abgelöst lıtte, und daher noch ungleiche Hälften zeigt, zwischen welciten jeloch schou die vitte farblos geworden ist. In beiden Hïlfeu bewegten sich die kleinen schwärzlichen kingeln sehr lebliaft,

Fig. 7. Ein vollkommen entwickeltes lixemplar von sehr blasser Färbung (vermullulich naeh hurz rorice gegangener Quectheilung) Woriu die Anorhung der inneren kugeln und Körmer ganz genan nacligezeichnel ist; die hleinsten in der Zeichmung elua $1 / \mathbf{s}^{\prime \prime \prime}$ messenden körnehen beweglen sielı lebhaft, die grosseren lingeln, elwa f"' in der Zeielinung gross, ruhen stels: auch das Anschen beider Arten ist in der Natur viel ungleicher wie es auf der Tafel werden musste.

Fig. 8 und 9. Euastrum Pecten, dassehe Exemplar in rerschiedener Lage mit grematester Darstelium der Anordnung des Inhaltes. Auch hier waren dic bleinsteu Körnchen iu lehhaftester Beweguig und ausserdem flimuerte über Fig. 9 in ihrer ganzen Ausdehnung ein Schimmer, der unretkennbar vou schwingenden sehr teinen und dicht gestelflen Wimpern herrühte, welche dic Undurchsiehtiglieit und die Schnelligkeit der Bewegmng nur nielıt einzelı unterseheiden liess.

Fig. 10 und 11. Eustram Seulum anf die Haifle verkleinest (200fach). Fig. 10 mit ganz, Fig. Il mil halbrollendeter Quectlleilung. Aus einer Vergleichung der Fig. 11 mil Fig. 4 und g ergiebt sich anf las Bestimmteste, Jass E. Seulum nieht der juingere Zusland von von E. Rola sein kans.

Fig. 12 und 13. Enastrum verrucosum, 400faeh vergrössert in vollendeter und eben begonnener Queerlheilumg. In Fig. 13 bei a. a. zwei grössere Kugeln, welche las Licht eigenthimlich brechen; leider hommen dieselloen in ungefärblen Theileu so selten vor, lass jeh weder durch Jodine noch durch polarisirtes Licht eine Prifung derselbeu versuclen konule.

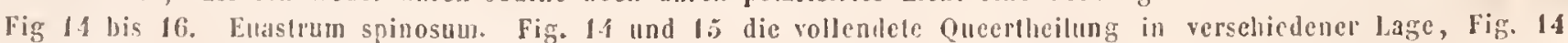

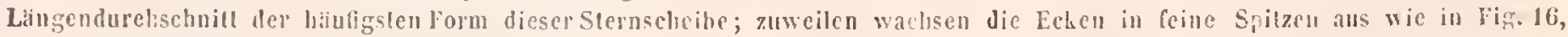
was zu ler Benennnng Veranlassungr gegehen hat.

Fig. 17. Enastrum margariliferum, Doppelexemplar in vollemleter Quecrtheilung 400fach vergrösserl, aiso ein viel hleineres Exemplar wic Fig. 6 'Taf. 1., woran jch friher nie eine sich ahlösende Haul bemerhte; nenere Beobachlungen lassen jedoch vermutlen, dass nur die Durehsichligkeil derselien sie bisher iiberselien liess.

Fig. 18. Enastrum Botrytis, bei Anferligung der Tafel von mip noch fur eine Varietal ron E. matgaritiferum gehallen, späler aber liesonders durch zwei kleiuc Herroragungen in der Nähe der Mille, welehe in Lingsschnilte sichlbar werden, als hesondere Art bestatigt. Im Uehrigen sind Queer- nnd Längenschnill so wie die Queertheilung ganz ähnlich, wie bei E. verrucosum, womit es immer zugleich beoliachtet nurle.

Fig. 10 bis 21. Einige der abweichendsten Formen ron L. margaritiferum, wie solche einzeln und mil deullichen Uebergangen dazwischen gefunden werden. Fig. 20 and 21 sind vermulhlich ein oder melurere Jahre alter wic Fig. 19.

Fig. 22 bis 26 . Leere l'anzerhälften verschiedener Sternscheihen. 


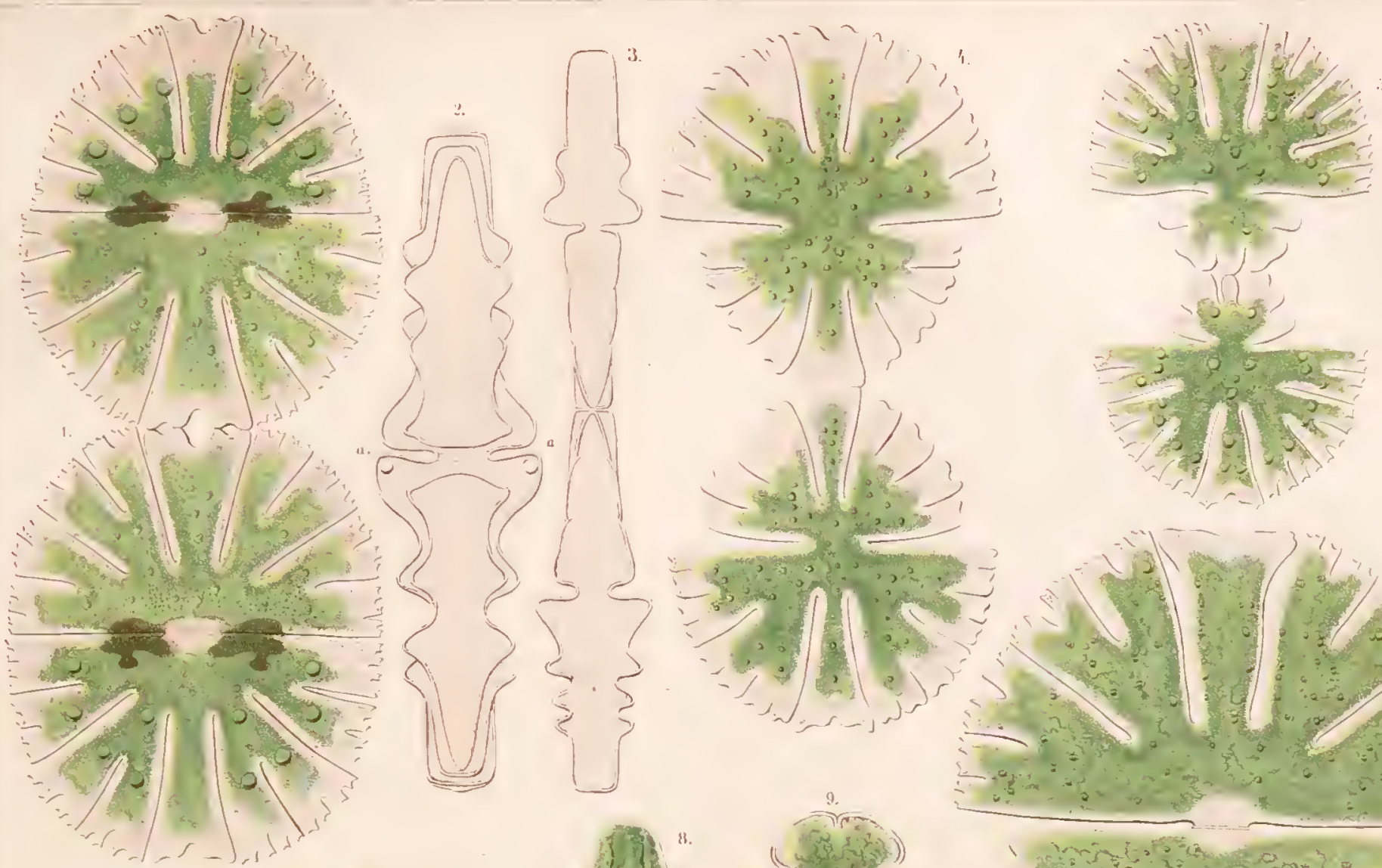

2)

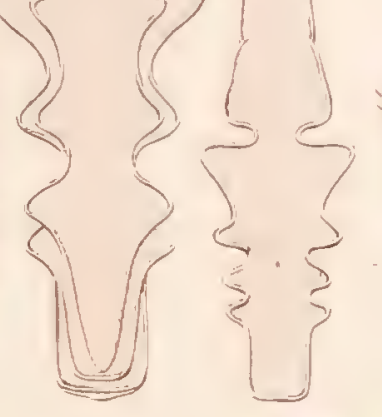

$-\operatorname{lom}_{0}$
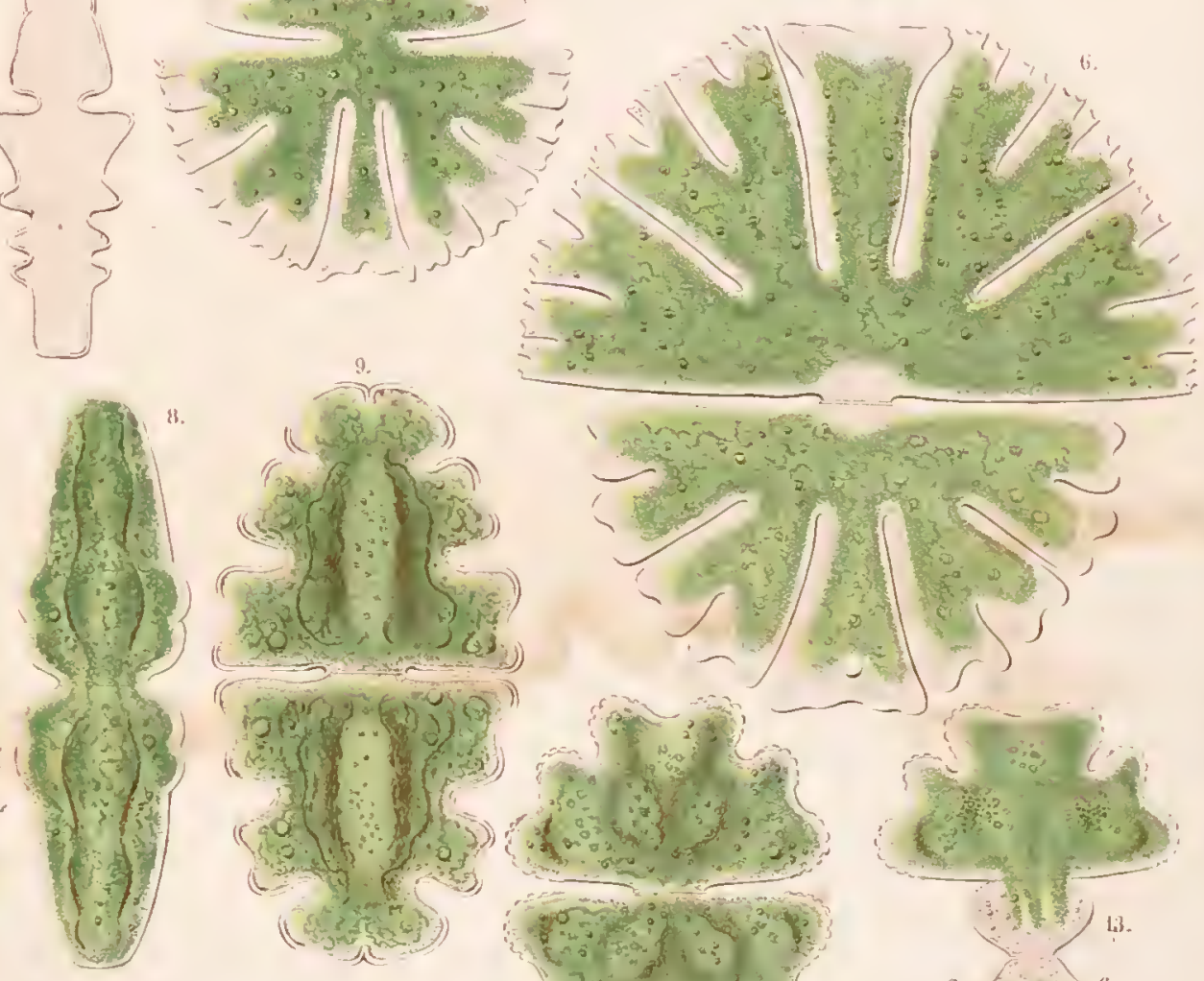

(क)

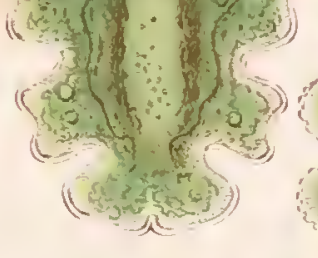

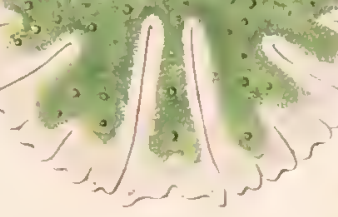

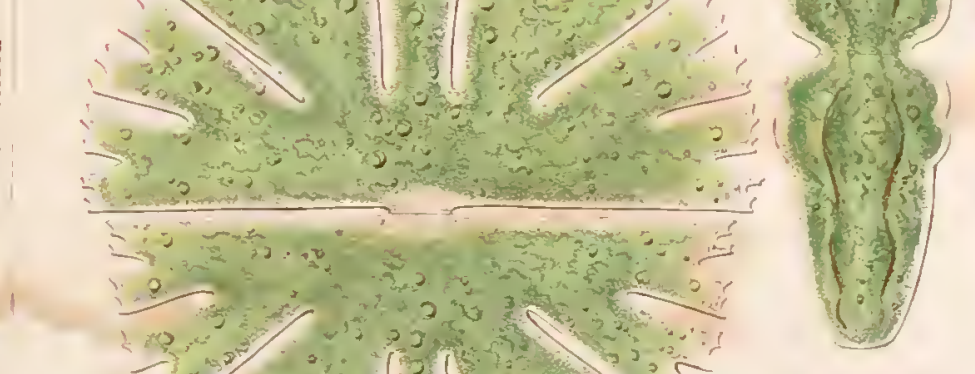

$-4 \%$ का का का
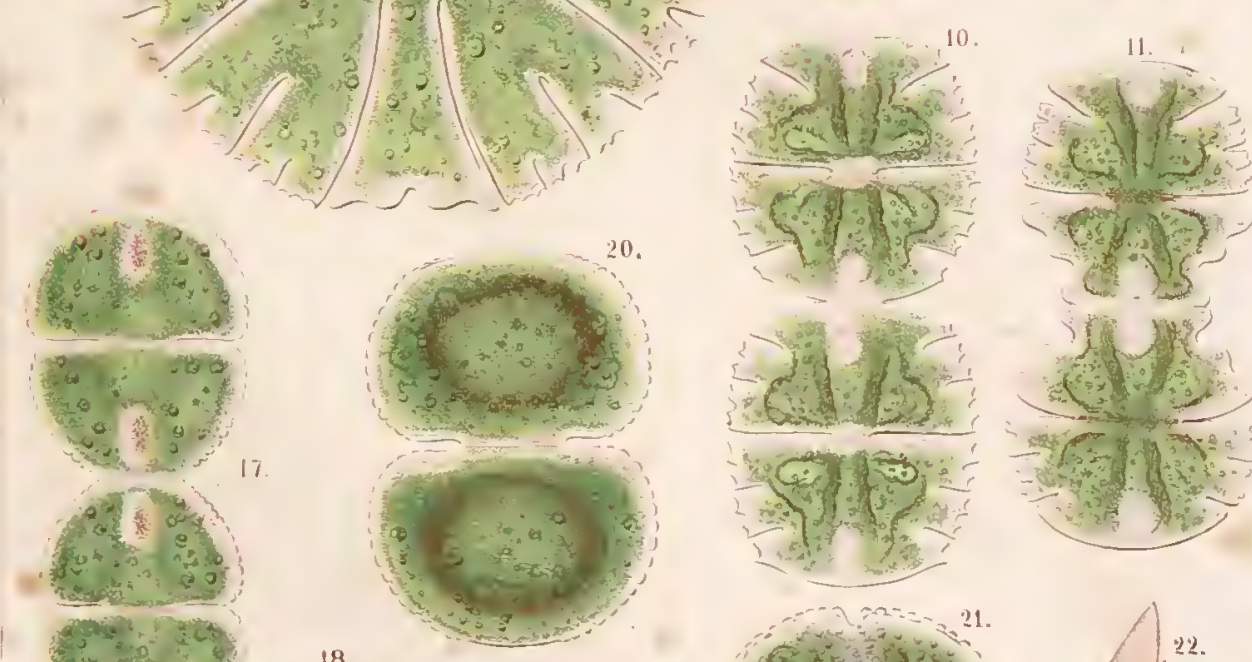

IIS

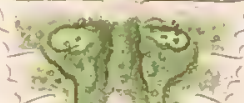

a $(2)$

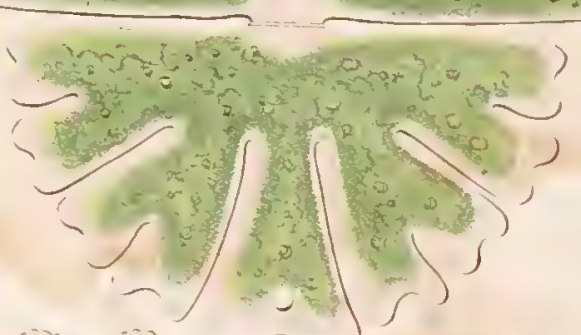

$\frac{(20)^{c}}{(20)}$
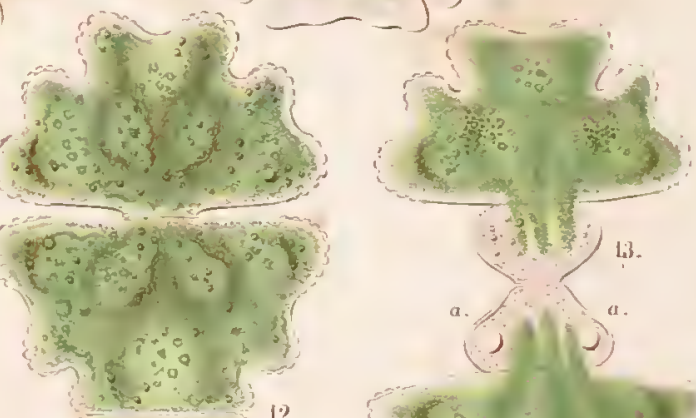

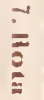
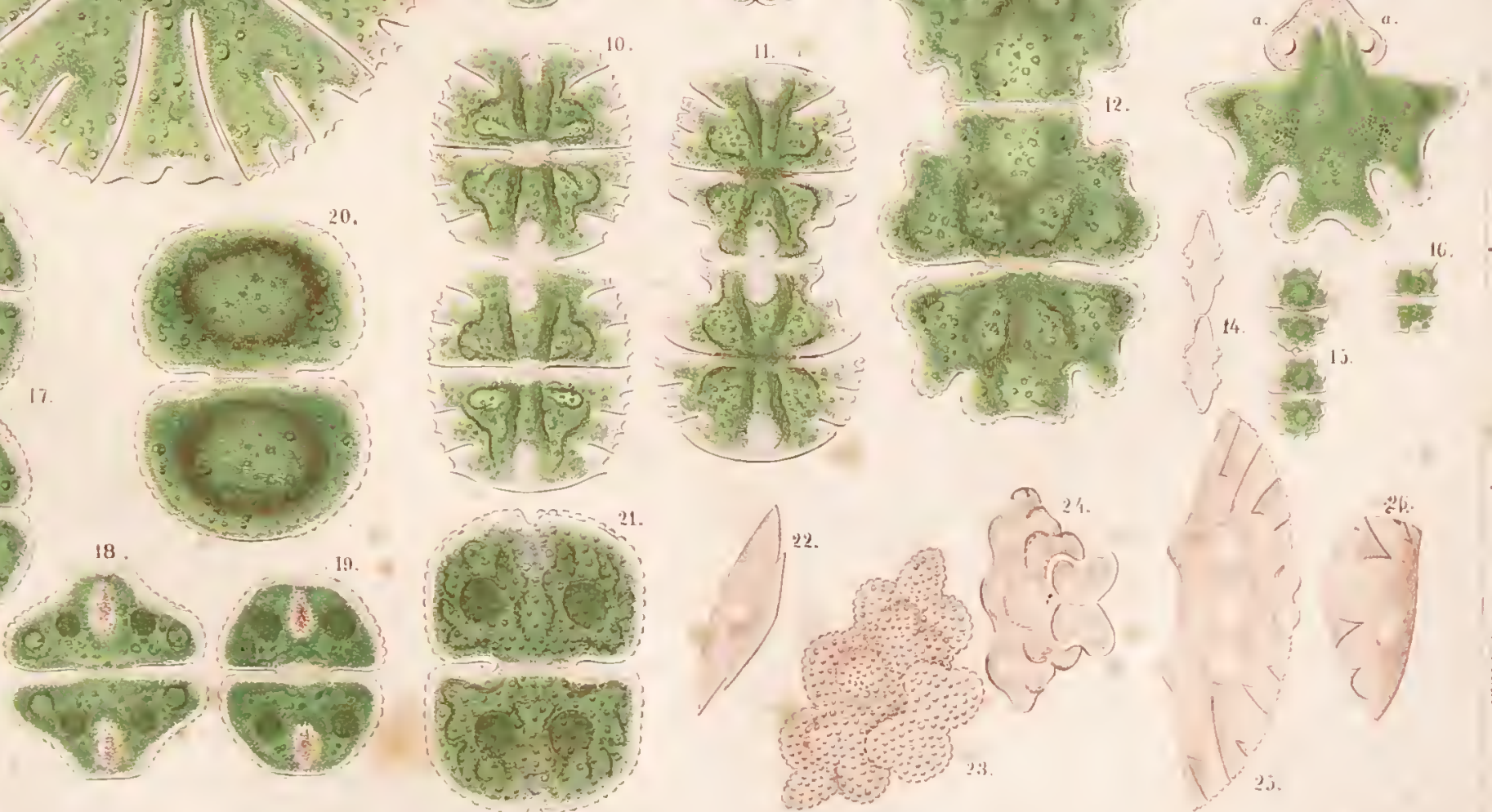

言 


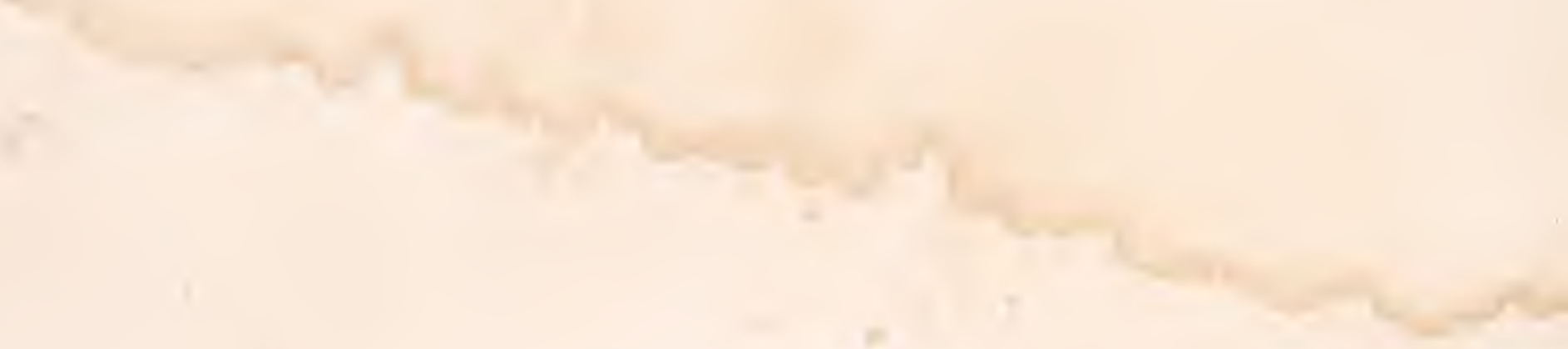



Bei der nicht \%u überwindenden Schwierigkeit, dass eine sichere Begrenzrng vej Npecies für die Gatung Closterium noch nicht durchufuiluren ist, sind anf der Hritten Tafel vorlaufig diese Schwierigkeiten und das physiologiwche Letail an den griassten und hänfigeren Arten versimnlicht. Während einer kurzen Abwesenhei des Verfassers sind einige Figuren dieser Wafel aninder gut ausgefuhrt und in der Bezeichnung Fehler moherichtigt gebliphes, dercr nachstehente Verbesserung zu heachten gebeten wird; die Figuren 9, 21, 27 unl $34-36$ sind bei schwächerer Vergrösserung gezeichmet, alle anderen 400 fach vergrëssert. Da alle Closterien stielrum sind, su ist ihre Gestalt in jeder Lage zu erkennen und Queer- oder Längsdurchschnitte ganz wherflissig. -

\section{T: a}

Berichtigung: Die grösste mittlere Figur zu C. Lumbla gehörig ist nicht Fig. 18, sondern Fig. 13; die unter Itig. 11 in der linken unteren Feke der 'Tafel gezeichnete Abbildung von C. Digitus ist Fig. 22; lie nnter Fig. 35 zwischen Fig. 32 und 33 in verkleinertem Massstabe angedeutete Copnlation von C. rostratum ist Fig. 34 .

Fig. 1 - 1j. Closterinem Lumulu. (Nitssch.)

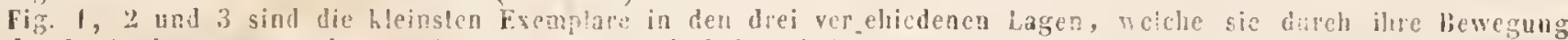

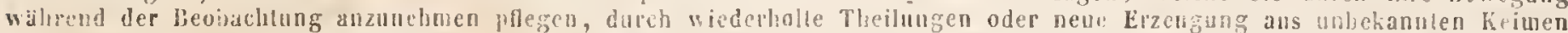
finden sich diese Formen wiluend cines lingeren Zeitrames (Jalures) an demselbrn fundorte in derselben Grösse vor; mil ilnen vicle leere Panzer, welele in ricr steiche Theile zerfailen.

Fig. 4. Ein grösseres Exemplar, wie sie unler den vorigen, jedoch un greich sellener rophommen.

Fig 5. Ein noch grösscres mit Yorbereimng zur Quecrheilung, welche sich durch iejchlo Eintierlung des grünen Inlaltes, elwa $1 / 3$ der Länge jedms Hormes von der Wilte enlfernt, andeutel.

Fi: 6. Ein Exemplar in der Quecrlheilums hegrifen.

Fig. 7. Ein grösseres kurz naeb erfolgter Treumng äurch Ouerthcilung; in diesem Zustande isl die Färbung slets heller, wie vol der Theilung.

Fig 8. Ein Exemplar in Langstheilung begriffen, wie mir nur äusserst sellen zu beobachlen vergönnt nar.

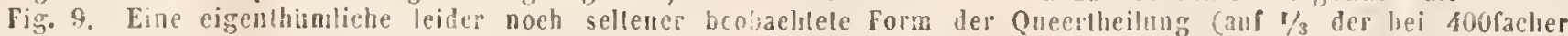

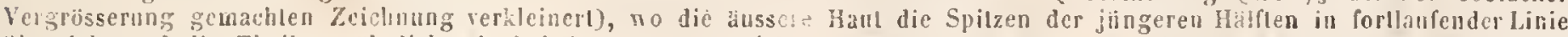
iiberzicht und dic Theilung ahnlich wie bei Euaslrnm vor sfeh gegangen sein muss. Bei diesen Theilungen findel zugleich

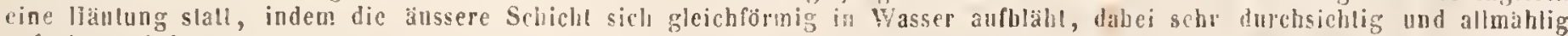
alifgelöst nird.

Fig. 10. Ein grösseres (mehrjähriges?) Exemplar, welehes zur Queerllicilung durth Alsscheidung des lulalts in 1 liammern vorbereilel ist. - Solehe Zustinde, wie sic Fig. 5 und 10 darstellen, kommen ungleich luafiger vor, wie die in Fig. 6 und $S$ gezeichnele wirhliclse Theilung, woraus sicls schliessen lisst, dass für lelzlere ein sehr kutzer $Z$ cillaum genügen muss.

Fig. 11. Exemplare in dieser Grösse und form sind am leichteslen zu finden und daher am häufigsten abgebildel; gewöhlich ist ihre Färbung und die Anordnung des lnhalls älnlich wie in Fig. 28 hei C. acerosum angedculet is!. Hier hal sich die milltere durchsiehlige Queerbinde anfiallend verbreitert und lasst elnas über der Mille ciuen blassen Zellenkern mit

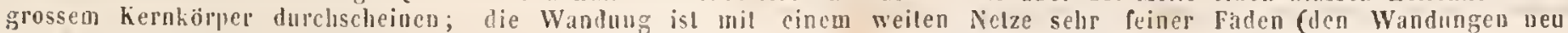
gebildeter Zellen?) bekleidel. In den beiden Hörnern isl dic milltere Parlhic der griinen Färbung auffallend dunkler und

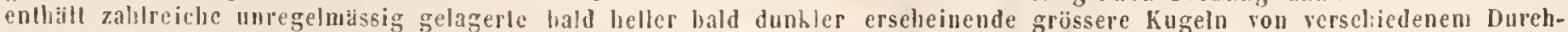
messer; in den beiden Spilzeu sind runde Blasen mil tanzenden Kïgelchen, welche lelzlere auch in dem helleren Saume zu beiden Seiten der Hörner is dem grïnen Theile uulerschieden werden. 
Fig. 12. Ein etwas kleineres aber in der Entwickelung, wie es scheint, weiter vorgeriicktes Exemplar. In der farblosen Milte licgl rechts ein Zellenkern mit Kernköpper, links ein bleinerer dunklever Kern; der Inhalt jedes Hornes hal sich mit einer besonderen Haut $\| m g e h e n$, ist viel heller und feinkörniger geworden und zeigl in der Millellinie hellere Zellen von verschiedener Grösse mit 1 - 2 dunklon Kernen, die blassgrün erscheinen, soweil sie die zur Seite gedrängle gefärbte Substanz des Inhaltes ungiebl, wahrend an jedem knde und gegen die llitte jederscits loch ein kleiner Raum ungefärbe lileibt. Die Blasen in den Spitzen haben sich sehr ansgedehnt nnd die Form tles Panzers angenommen; die Zahl der lanzenden Kügelehen in denselhen ist selır rermindert.

Fig. 13. Die millere grösste Figur dieser TaPel (irrig 18 liezeichnet) stell dicjenige Entwiekelungsslufe des C. Lunula vor, welche im Schlamm der Gewässer versteckl selten der beobachtung angänglich wirul und jedeufalls mehr- (4) jahrig sein muss. Die Auordnung des Inlualts diirfle aus den vorigen figuren sich zum grossen Theile von selbst erklaren und nur die wellenförmige Ausrandung der grunen Firbung gegen die seitliche Contour ist als Wirkung der schwingenden Wimpern hervorzuleben. Letatere sind so fein, Jass es misslich heilut eiue naturgetreue Darstellung davon zu geben, daher dieselben dureh cine selı frine, ron der inneren Grinze des Panzers gegen die Längachse gerichtele, Schraffirung, g.u deren Erkennen bei manchen Abdricken die Lupe dienlich seiu wird, angedeutel sind. Die bekannte Erseheinung, dass gewisse Wimperuparthieu uach denselben Rylhums schwingen, entspricht hier jedesmal eincr der wellenfiomigen Auszaekungen der griinen Farbung. In tem gezcichncten Exemplare lag wahrscheinlich oberbalb der Milte ein uicht erkannter Zellenkern, wie die leichte Einbuchtung der griinen Färbung an der entsurechenden Slelle altentel.

Fig. 14. Ein etwas hleincres Excmplar von derselben Form wie Fig. 13, worin sich dic grijne lairbung verloten, der farblose Käjper dagegen 1 m kuglige liblungen (Eier oder Sporen?) nusammengezogen hat, dic auts den in Fig. I2 sich bildenden nenen Zellen entslanden sein kömmen. Der Umstand dass im ersten Friblinge melırach ilieser Zustand beobaclute worden und zu auderen Jahreszeiten mil nichl vorgehommen ist, möchle eine solche Deutung rechlfertigen; zur genauen Prïfung eines tinzelnen dieser Körper auf dic Beslandlloile des thicrisehen Eies bot sieh nuir leider keine ansreicliende Gelegenheit dar.

Fig. 15. Zwischen den slatker gebogenen Formen wie Fig. 1 und 5 bis z.u deu geraderen wie Fig. 13 finden sich mannigfache Uebergänge, die offenbar nicht z॥ Cl. acerosum gehölen. Fig. 15 zeigl etwa die ällsserste Grenze der läugeren und geraderen Fn:men, die noch zu Cl. Lunula gerechnet werlen bïnnten, wemu nicht iiberbaupt noch cine ahnliche Form als besondere Specics abgetrenut werden muss. -

Fig. 16. Cl. Divnae. Ehrenberg. 1/7". - Die schlankere form, die hleineren Blasen in den Spilzen mil e inem centrisch gelagerten kiigelchen und dic eigenthiimliche Zurunulung der Spitacn unterseheiden dirse Form ron den älınlichen bestimmt; oft sind dic Spritzen röhlich. -

Fig. 17 - 21. Cl. Tiabeculu. Ehrenbery. 1/4". -

Fig. 17. Doppelexemplar mit Ilautuig der jüngeren Itälften.

Fig. 18. Ein Exemplar lel kleineren Form, welehes vor beendeler Theilnng siel abgelöst hat. Dic jungere obere, anfangs kllglige Halfte beginnt erst sich zu dehnen und zeigt in der Spilze eine Blase mil lanzcnden körperchen. Die Spilze der ätleren unteren Ilallic erscheint getiofelt.

Fig. 19. Doppelexemplar mil lläutung der älteren Hälfen dureh allmällige Aufösıug der schleimigen Hiille.

Fig. 20. Eines ler grässeren Exemplare mit genauer Darstellung der Form und der Anorduung des lulaalts.

lig. 21. Eine Missgeburt deren beide Halften schief gebogen sind.

lig. 22 - 27. Cl. Digilus. Nhrenberg.. 1/9". -

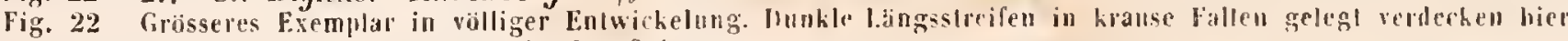
den ganzen interen lian unul selbsl die Blasen in den Spitzen.

Figr. 23, Fin Exemplar bald uach der Theilung, aus fig. 27, il 4 kammoru alggetheili. bie dunkelen Lingsstreifen sind noch klar und schlich, dic grossen blasen in den Spizen fille'u un e in centrales Körperelien, unit selu langsamer liewegung.

Fig. 2f. Die jünste und hleinste Form dieser Species, welehe ich gefumden, ebenfalls 400fach vergrässell. Diese

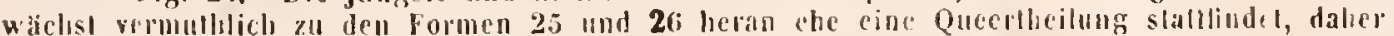

Fig. 25 eine andere Anordunng des Inhaltes wahruelanen lisst

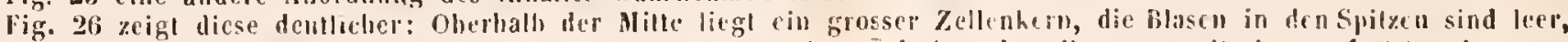

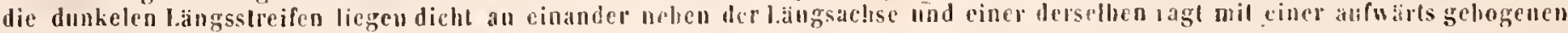
Spilze ïher dic unithere helle Ouecrhinde vor.

Fig. 27. Eine durch Aufösung dé änseren Haut entstandene Blase, welehe 8 durch Queertheilung entstandenc Fremplare umschliesst hei sofacher Vergrösserung. Eins derselben ist in Vig. 23 liei 400 ar.her Vergrösserung ałbgebildet.

Fig. 28 .

C.l. acelosim.

Schrank.

(1/\%"ink. -

Fig. 29.

C. libellula

sp. n.

Cl. Ulna.

s) 7 .

$1 / x^{\prime \prime \prime}$.

I:i 31

Cl. Finsis.

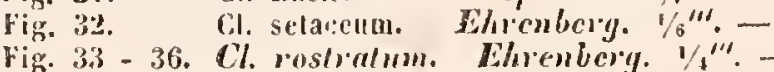

Fig. 33. Ein selir grosses lixemplar, dessen l'anzer in zwei gehogene Spizen verlangeri isl, wälrenl die lier ovalen

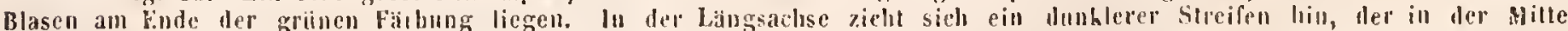

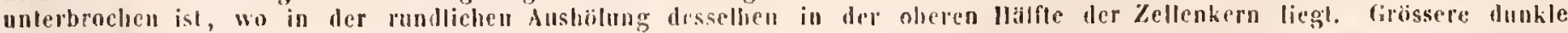
griine kilgclu sind muregelmitssigr rerthcilt.

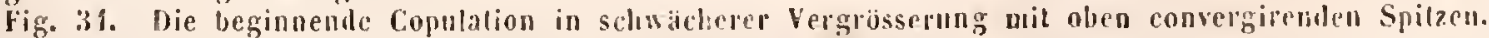

Fig. 33. Wieselle weiter vorgeriucht mit beiderseils divergirenden Spilzen.

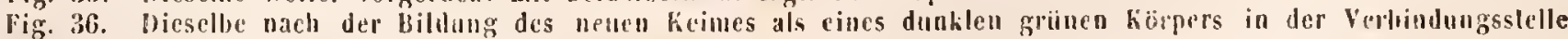
beider closterien, welcher sich mit einer eigenen Hant nugeien hal. 



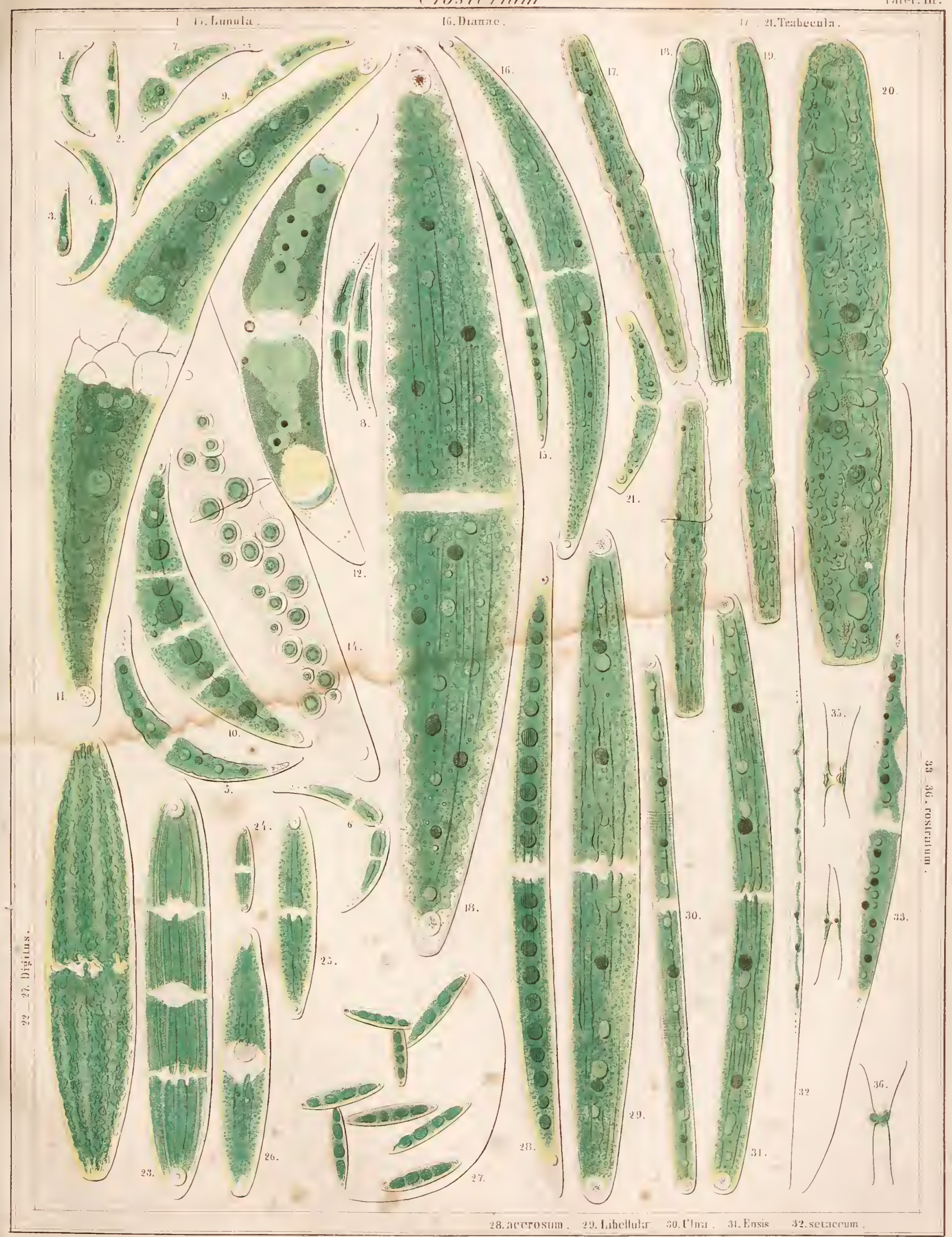




\section{,}






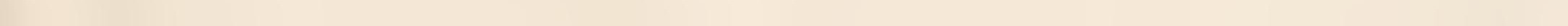




. 


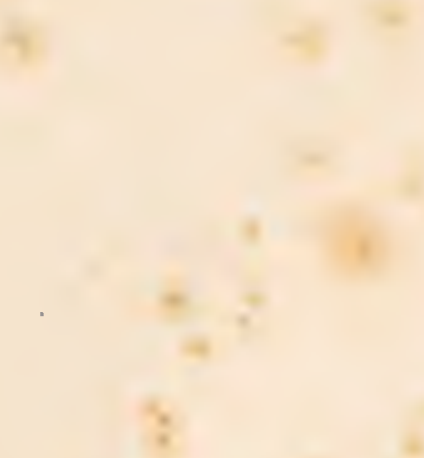

\section{$+$}
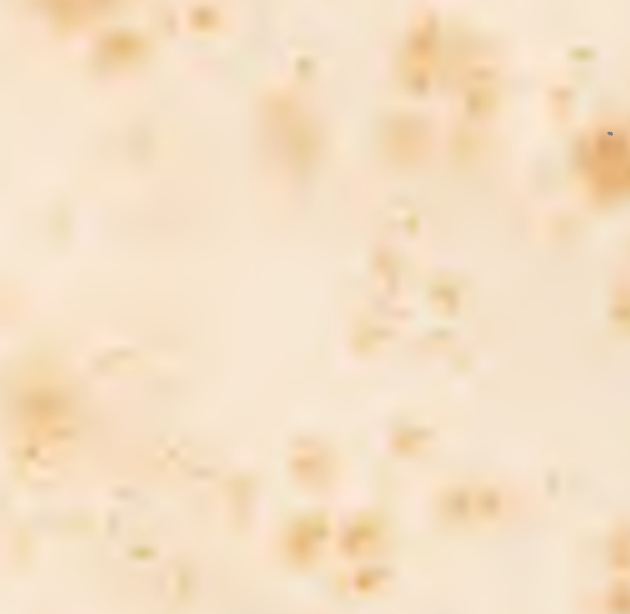

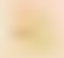

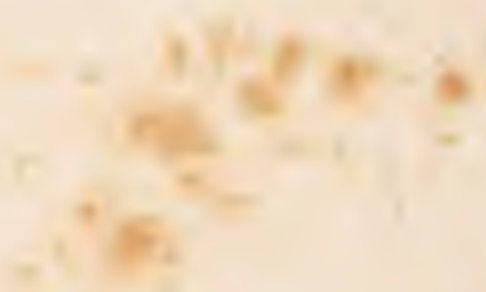



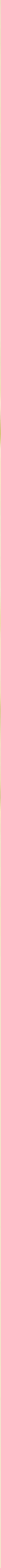

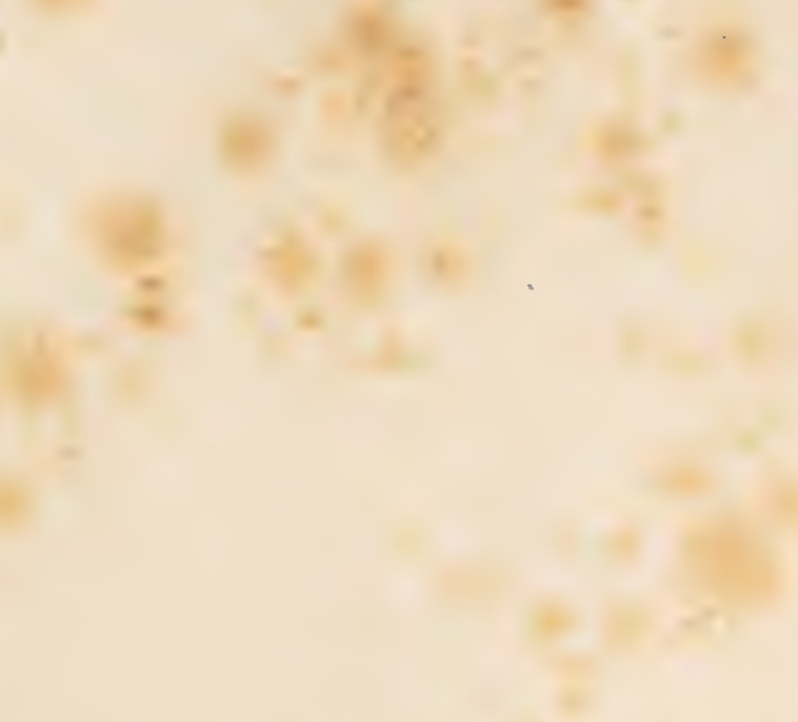

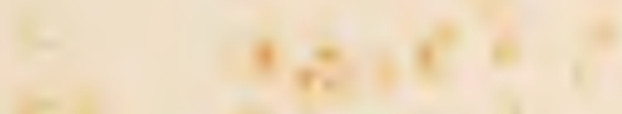
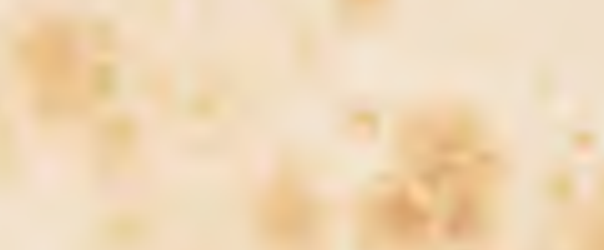

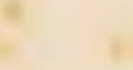

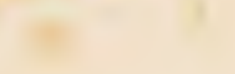

$w^{\prime}$

1

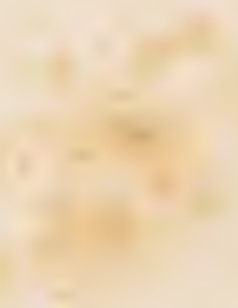




